GEOLOGICAL SURVEY CIRCULAR 172

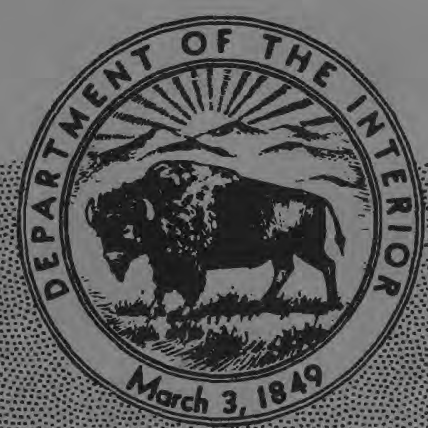

\title{
RECORDS OF WELLS DRILLED FOR OIL AND GAS IN MONTANA
}

By J. D. Vine and C. E. Erdmann 
UNITED STATES DEPARTMENT OF THE INTERIOR FRED A. SEATON, Secretary

GE OLOGICAL SURVEY

Thomas B. Nolan, Director

GEOLOGICAL SURVEY CIRCULAR 172

\section{RECORDS OF WELLS DRILLED FOR \\ OIL AND GAS IN MONTANA}

By J. D. Vine and C. E. Endmann

REPRINTED 1959

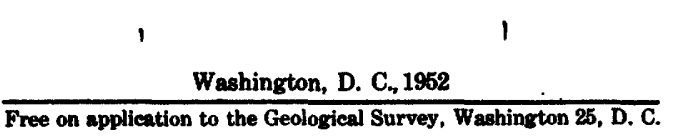




\section{RECORDS OF WELLS DRILLED FOR OIL AND GAS IN MONTANA}

The locations of test wells drilled for oil and gas were shown on a structure contour map of the Montana Plains which was published in $19321 /$ with revisions in 1935 and 1946. Data on significant tests for oil and gas in Montana were published in tabular form in $19442 \%$. A map that is now in preparation 3/ shows the locations of productive areas and dry holes, and for most wells the map shows the total depth and the geologic formations at the top and bottom of the well. Additional data about the dry holes that have been drilled in Montana have been assembled in this circular.

The list of wells has been compiled from information in the files of the Geological Survey. It is believed to include all unsuccessful "wildcat" test wells and most of the unsuccessful field extension wells. In addition, the list includes one or more representative wells, deep tests or the discovery well for each producing, abandoned, or shut-in oil or gas field in the State. The list of nearly 1,800 wells includes wells irrespective of their depth or significance as tests for oil or gas. Wells drilled after June 1, 1951, are not included in the list.

Data are tabulated under location, county, field or geologic structure, operator and lease, elevation, geologic formation (at the surface and the lowest formation tested), production or shows of oil or gas, total depth, and status and date.

The locations of the wells are arranged in the list by township, range, and section.

The names entered under "Field or Geologic Structure" are those of the productive area or the geologic structure on or near which the wells have been drilled.

Many of the names of operators and lease names have been abbreviated for economy of space in the tabulation; the names therefore are not necessarily completely stated, but they are believed to be adequate for identification.

The elevations listed in the tabulation are the available figures which have been obtained from various sources and determined by various methods. Although they cannot be considered accurate, they are believed to be close approximations of the true elevations.

1/ Dobbin, C. E., and Erdmann, C. E., 1932, 1935, and 1946, Structure contour map of the Montana Plains: U. S. Geol. Survey.

2/ Erdmann, C. E., and Davis, N., April 20, 1944, Tests for ofl and gas in Montana: U. S. Geol. Survey (mimeographed statement).

3/ Vine, J. D., and Erdmann, C. E., Map of Montana showing oil and gas fields and test wells for oil and gas: U. S. Geol. Survey OM 130 (in press).
Geologic information including the formation at the surface of the well site and the lowest formation reached by the drill were obtained from existing records, where possible; but new interpretations were made for some wells on the basis of geologic maps and other publications on the respective areas. The formations are indicated in the tabulation by letter symbols which are identified in the generalized stratigraphic section. Because the geologic information has been obtained from diverse sources, all the nomenclature may not accord with the usage currently accepted by the Geological Survey. Depths to the tops of the lowest formations reached by the drill are not available for many. of the wells; differences in figures obtained from different sources for some wells introduce uncertainty as to the accuracy of the figures selected for those wells. A few wells reported to have been drilled through thrust faults are marked by an asterisk (*). following the letter symbol for the lowest formation; the lowest formation indicated for such wells is the oldest formation tested and is not necessarily at the bottom of the well.

Production or shows of oil or gas were identified by the symbols GS for gas shows, OS for oil shows, GOS for shows of both gas and oil; and similarly, gas production, oil production, and the production of both gas and oil are shown by the symbols $G P, O P$, and GOP, respectively. A number following the symbol for a show or production indicates the depth to the top of the zone in which the gas or oil was found. The letter symbol following the number or following the hyphen indicates the geologic formation in which the gas or oil occurs, and the symbols are the same as those used on the generalized stratigraphic section for Montana.

Total depths of the wells, as obtained from different sources, generally differ by a few feet. The figure selected for some wells may therefore be a few feet different from the figure recorded elsewhere. The figures in the tabulation are the greatest depth reached by the drill regardless of plugging back to test higher formations.

The status and date of each well is indicated. The letters A, C, and D preceding the date indicate abandoned, completed, or drilling, respectively, in the specified year. Most if not all wells that were producing but were abandoned later are shown as a completed well rather than an abandoned well. The date of abandonment is generally the date drilling ceased; for a few wells the date indicates the time of final abandonment after a period of suspended operations.

The following diagrammatic representation of the succession of geologic formations in Montana provides identification of the letter symbols used in the tabulation to indicate geologic formations. 
EXPLANATION OF LETTER SYMBOLS

USED IN WELL LIST TO IDENTIFY FORMATIONS

Surficial deposits other thon Tertiary loke beds (T/b)

are not identified on the mop.

Tertiary and Cretaceous intrusive igneous rocks ( $T K_{i}$ )
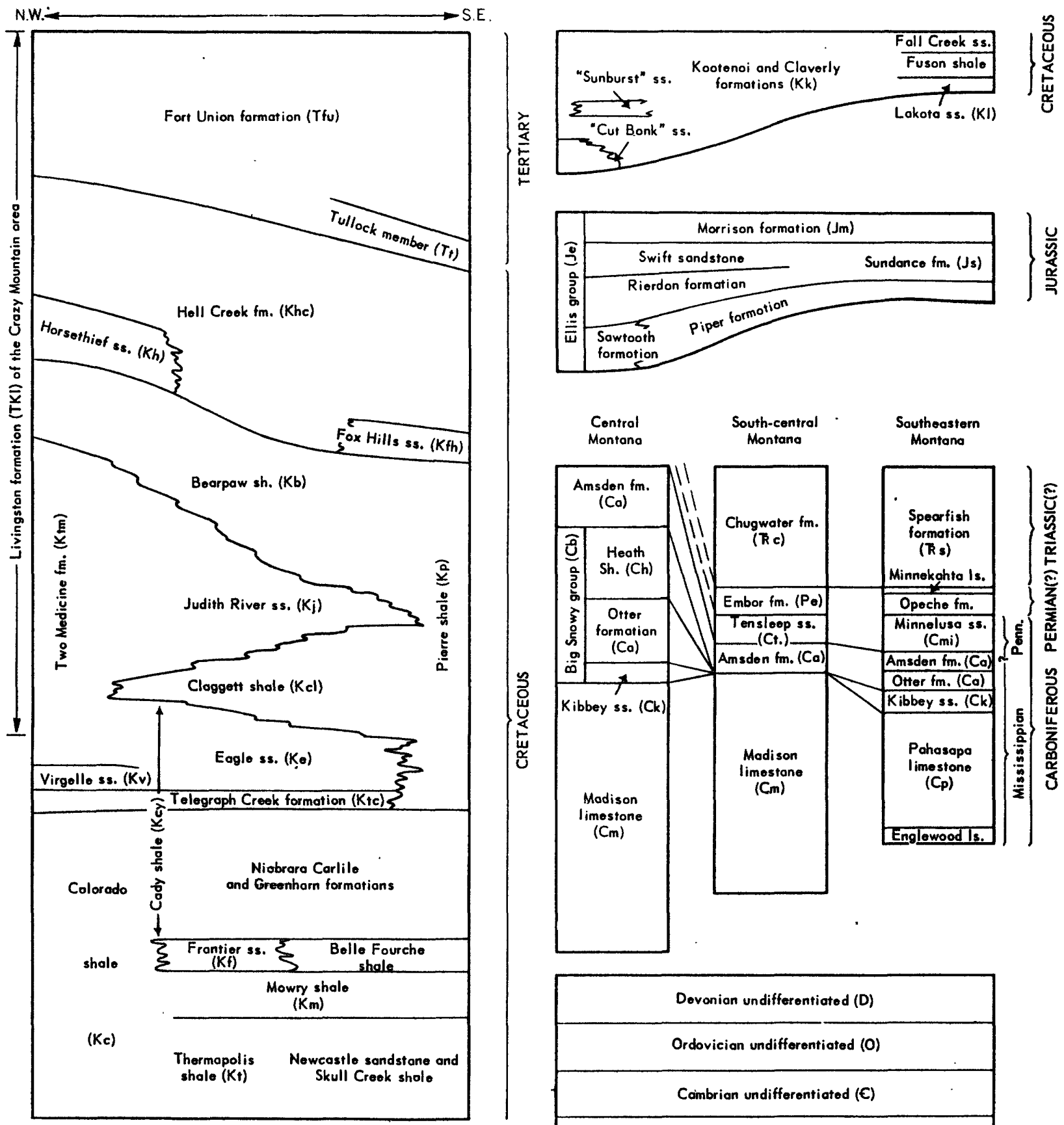

(Continued at right)

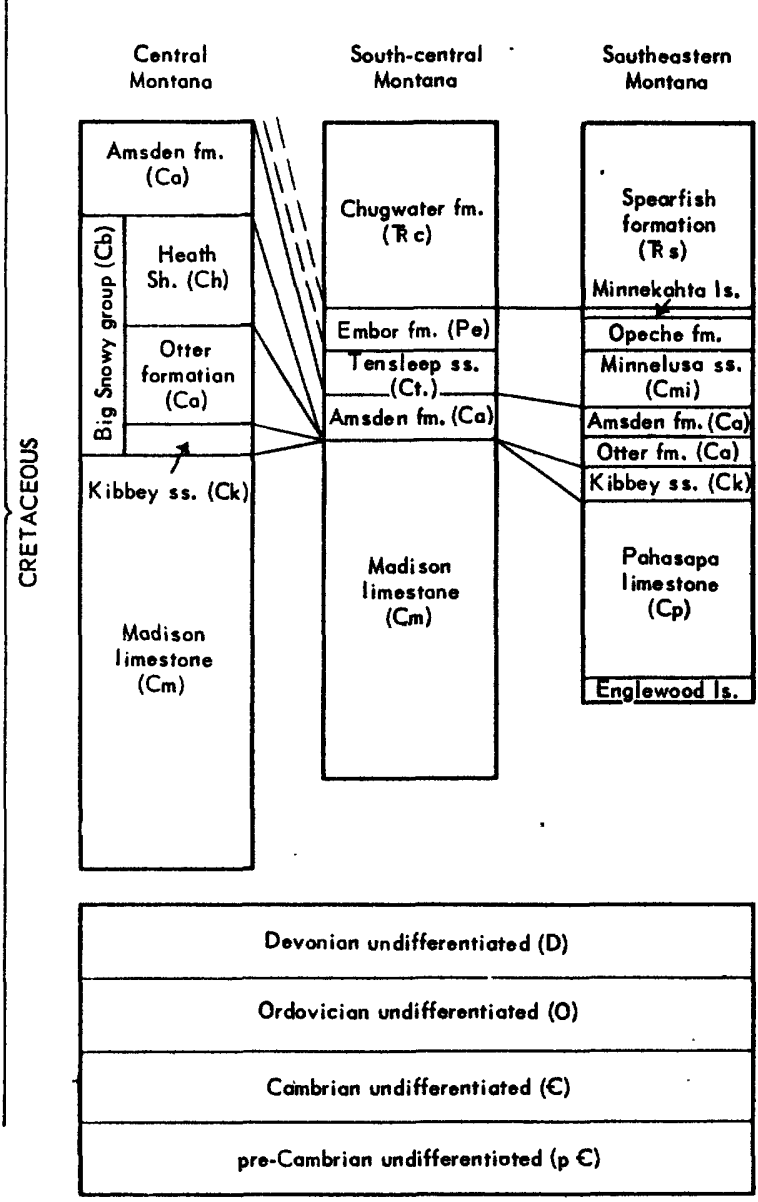

The fields productive of oil or gas in Montana and the geoluyic formations from which production is obtained are shown in the following table. 


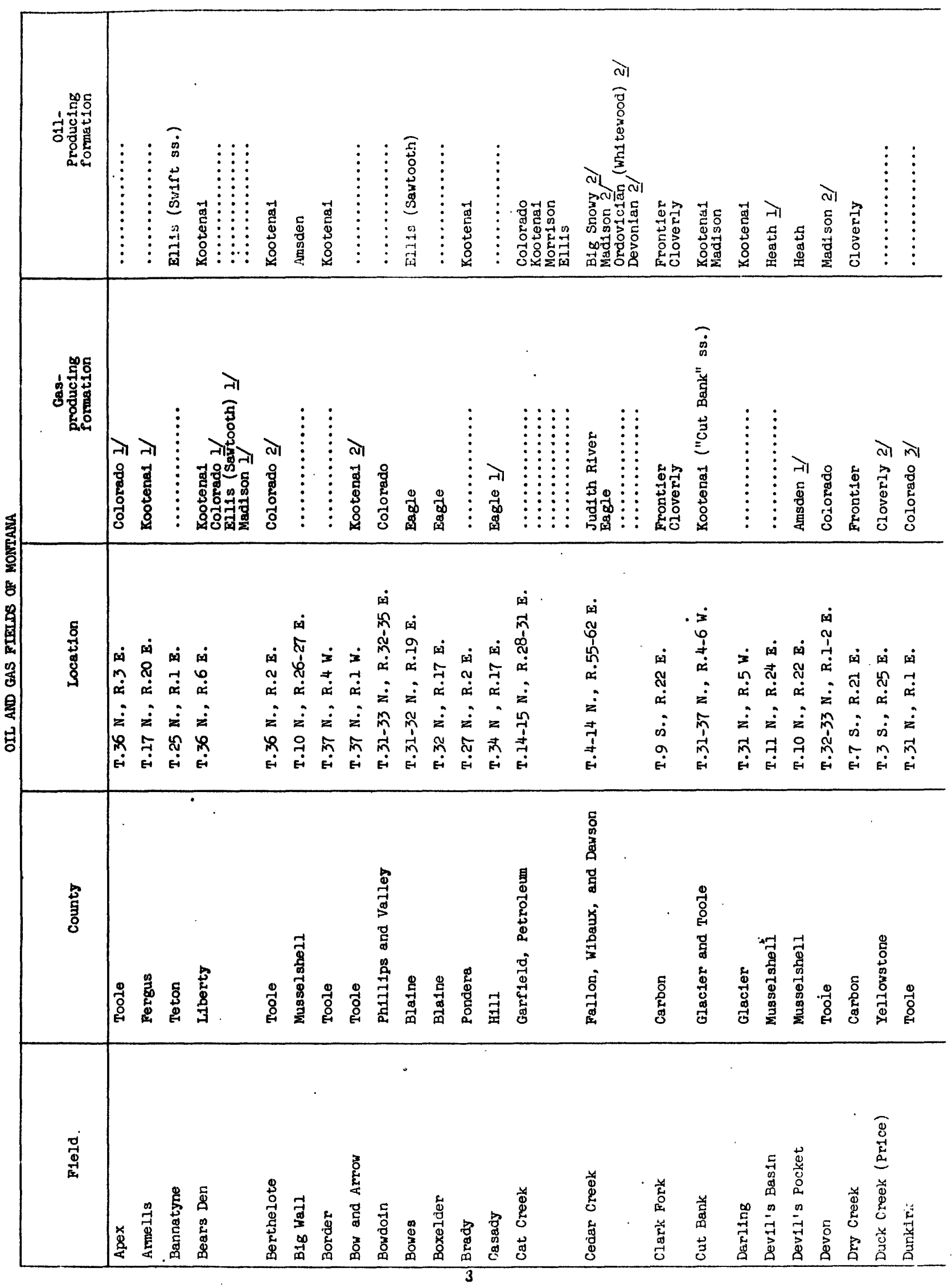




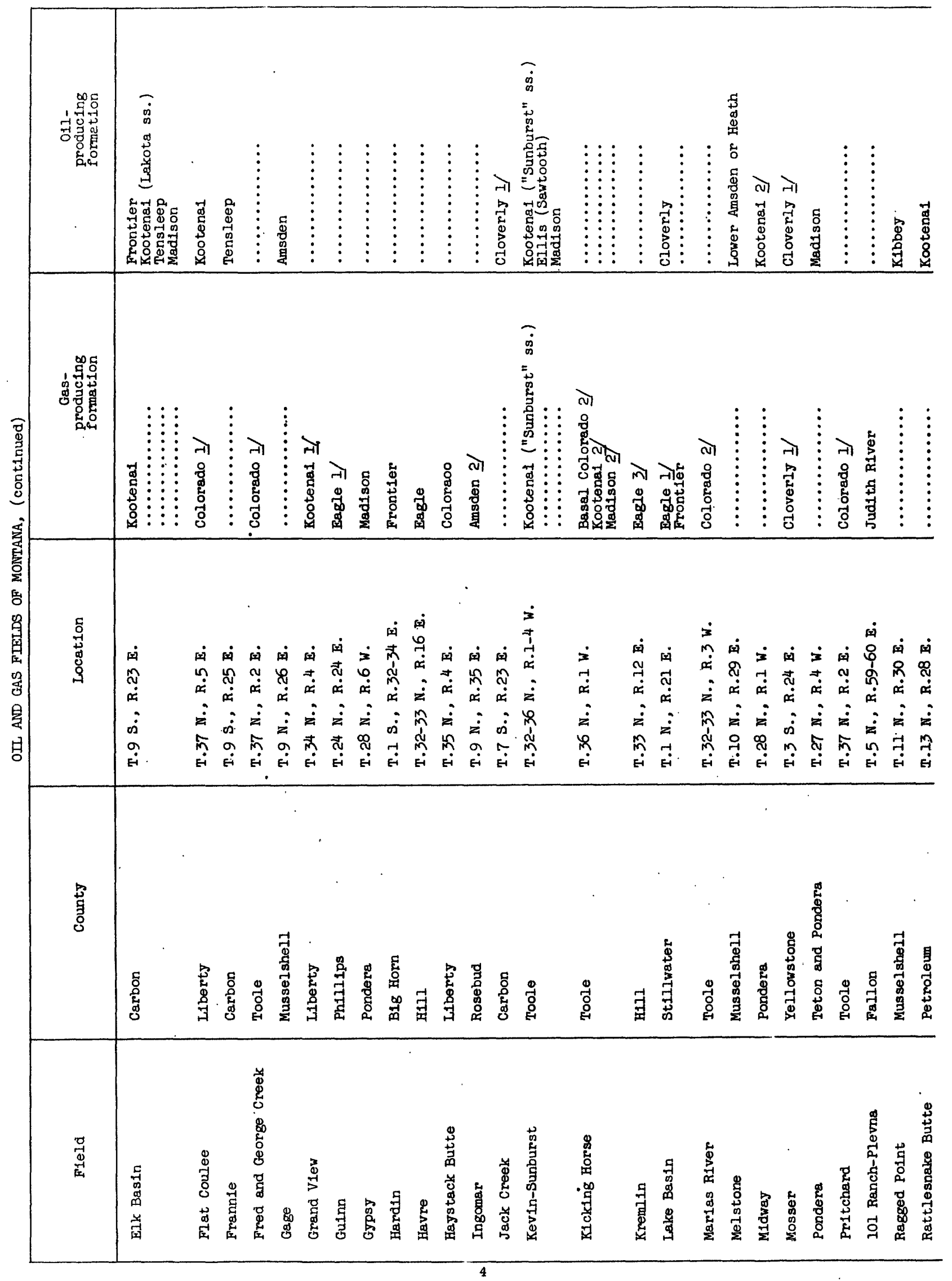



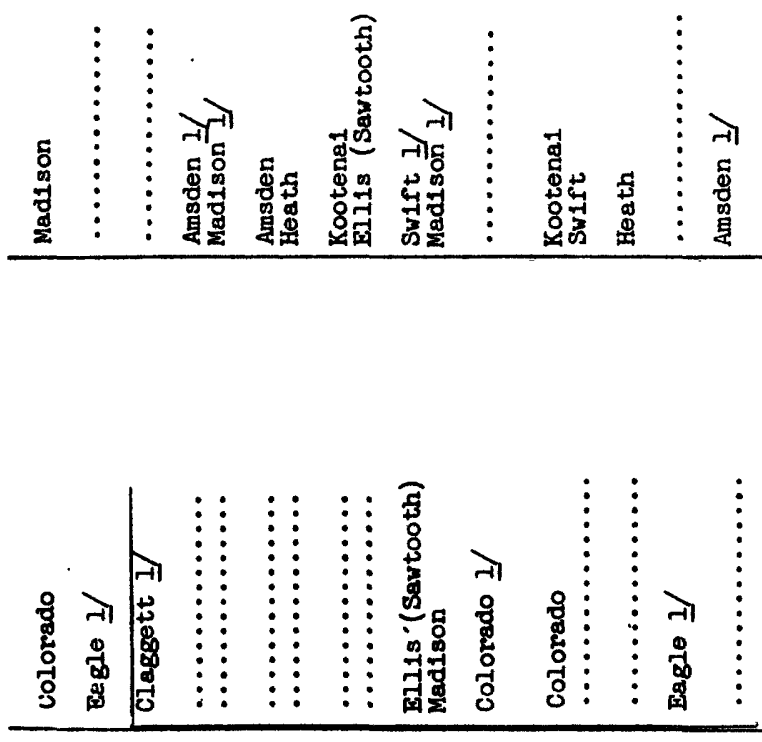

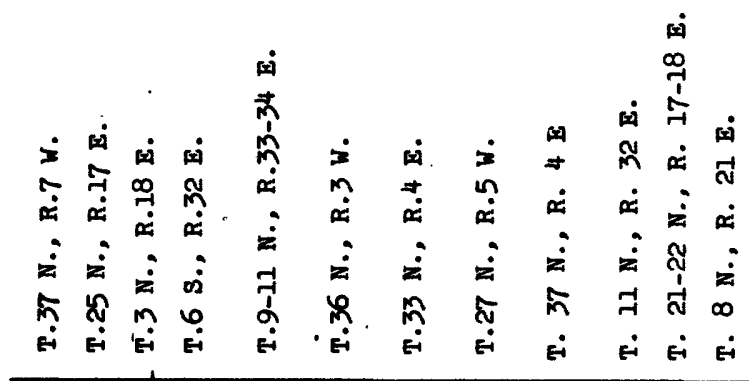

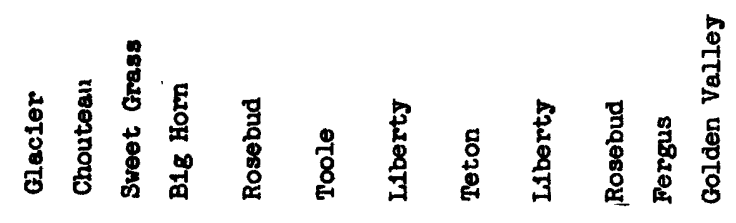

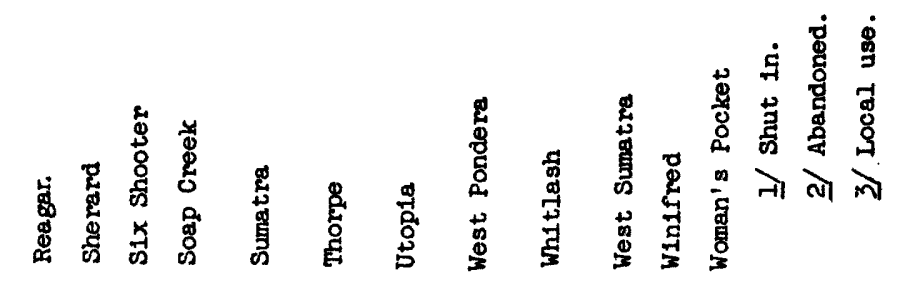




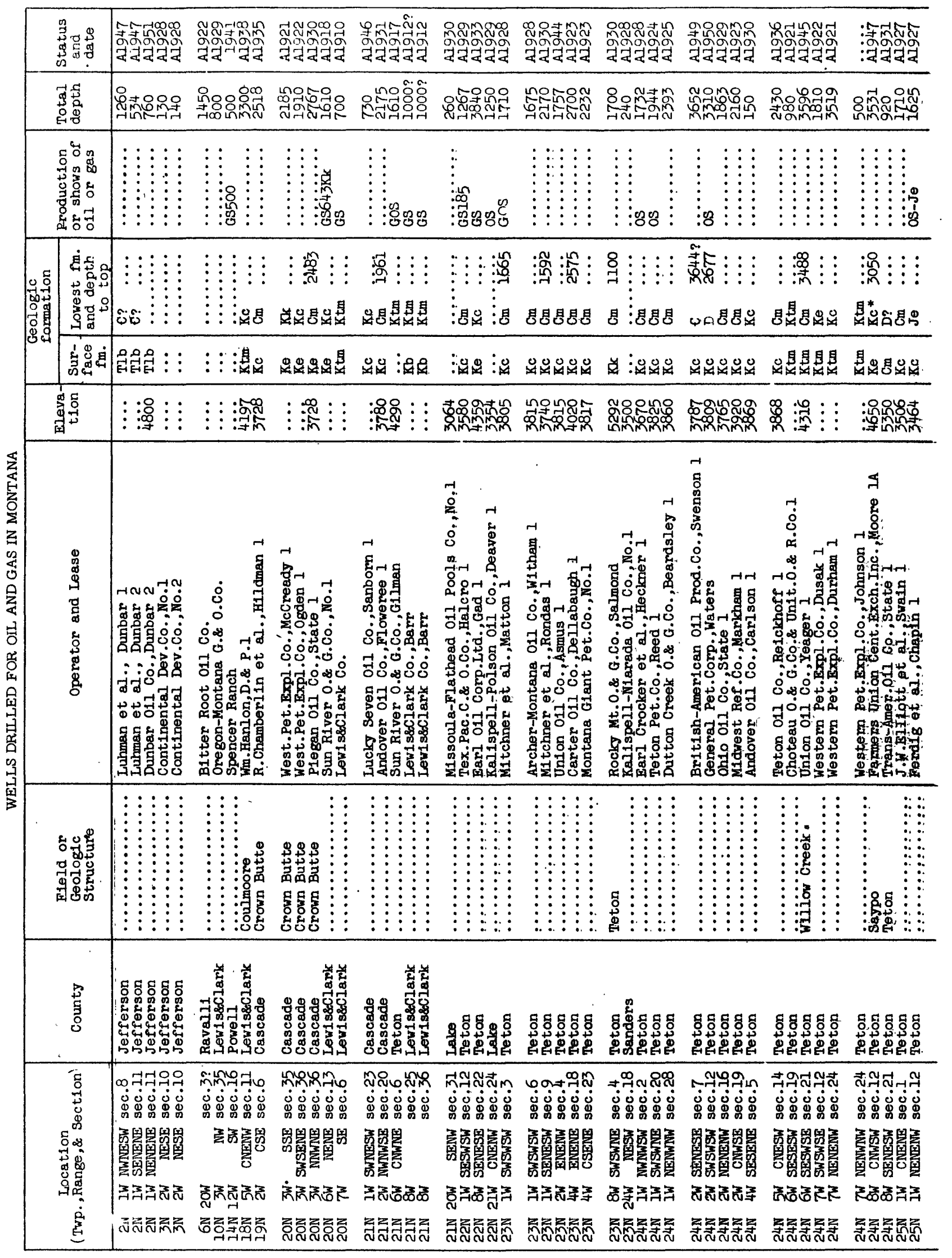




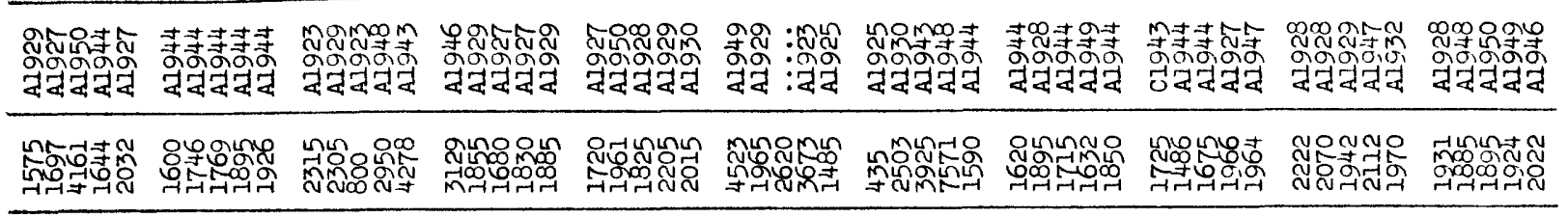

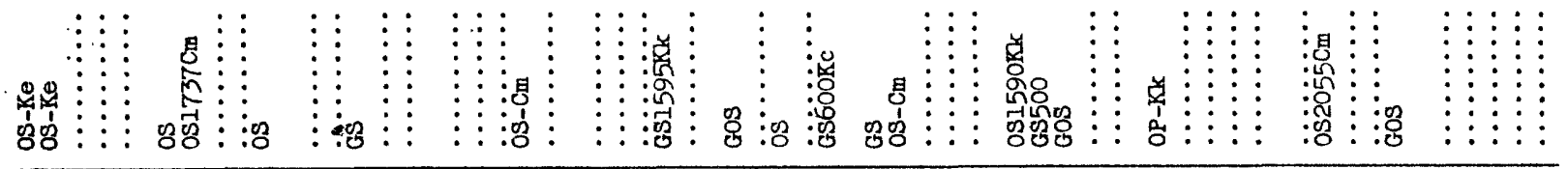

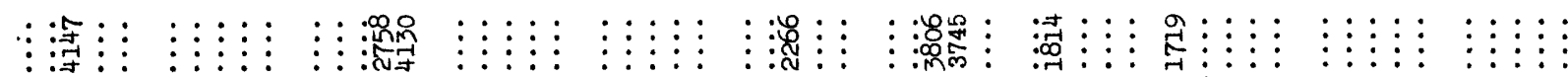

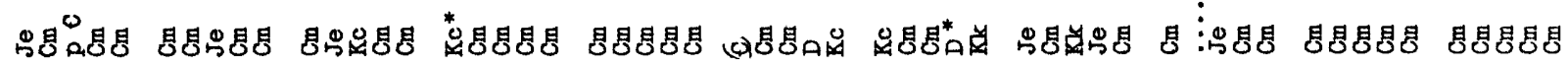

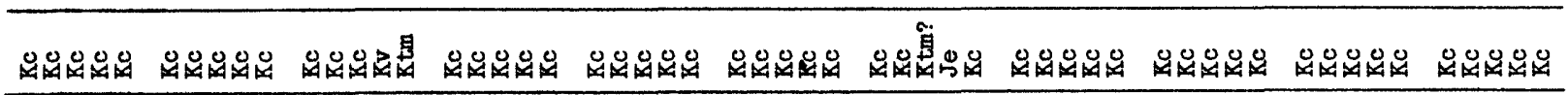

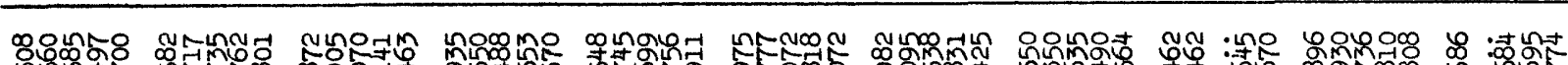

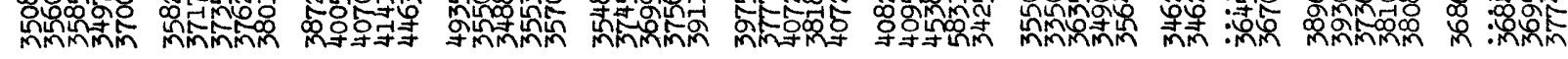

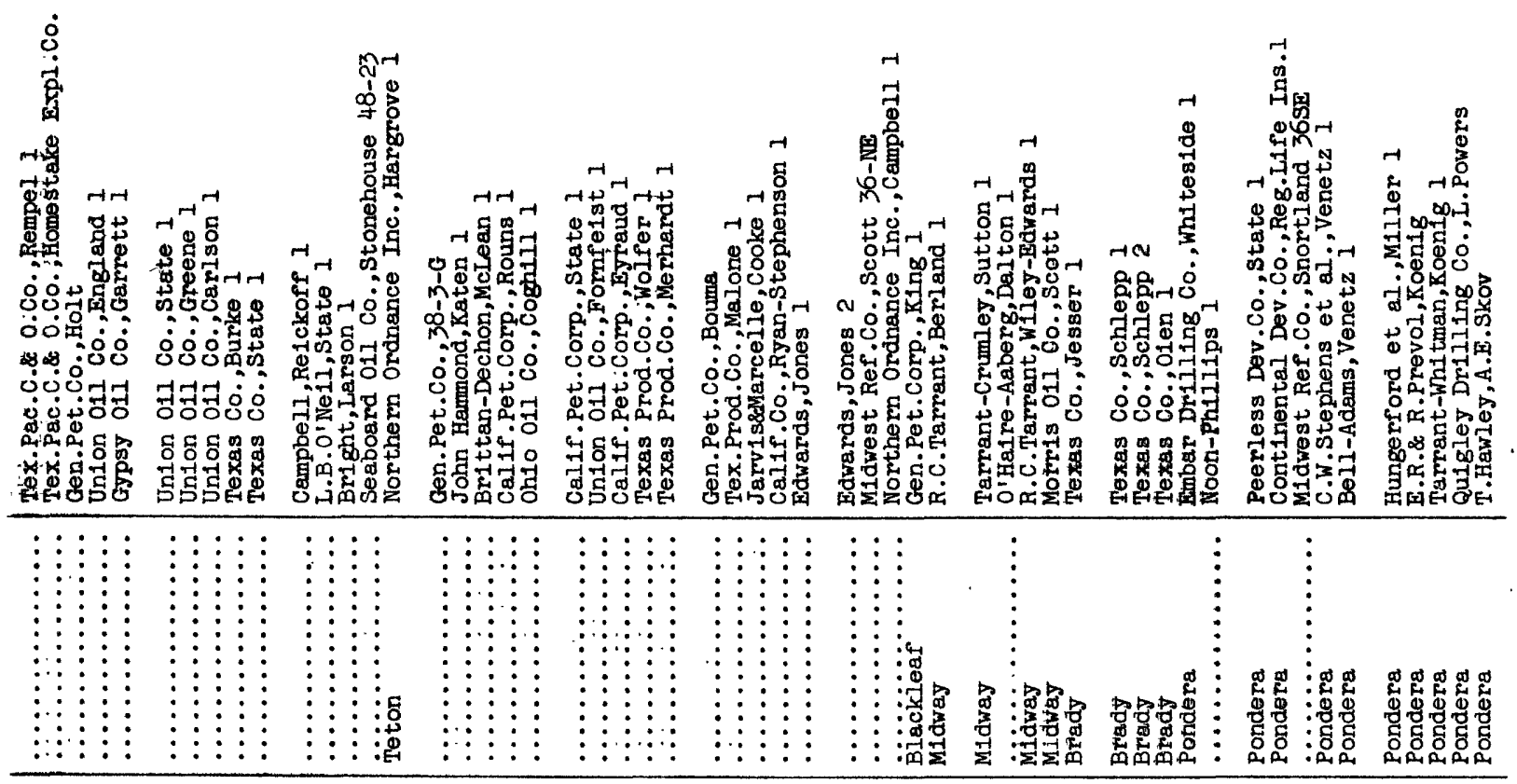

\begin{tabular}{|c|c|c|c|c|c|c|c|c|c|c|}
\hline 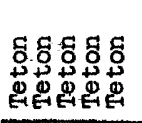 & 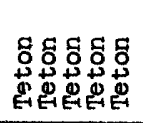 & 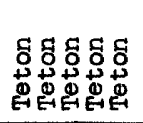 & 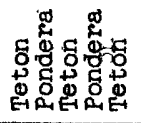 & 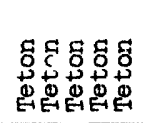 & 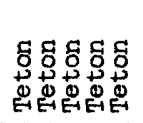 & 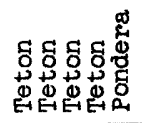 & 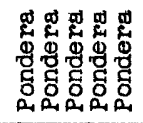 & 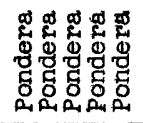 & 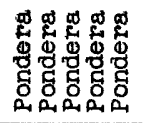 & 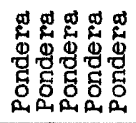 \\
\hline 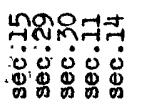 & 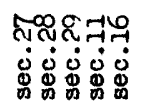 & 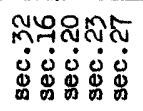 & 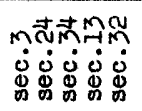 & 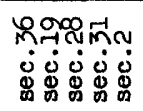 & 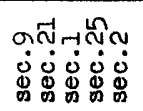 & 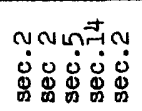 & 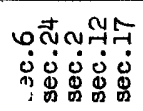 & 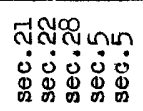 & 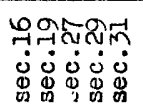 & 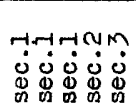 \\
\hline 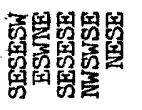 & 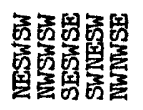 & 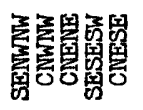 & 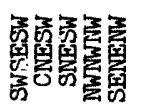 & 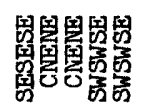 & 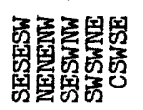 & 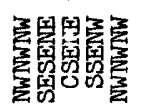 & 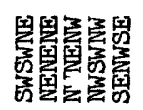 & 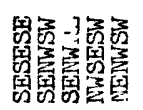 & 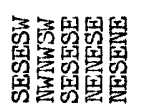 & 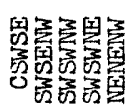 \\
\hline 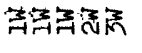 & 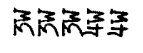 & 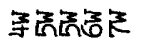 & 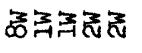 & 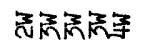 & 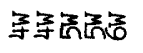 & 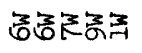 & 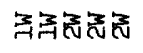 & 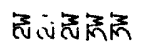 & 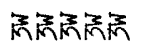 & 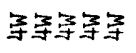 \\
\hline 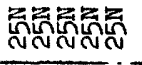 & 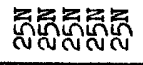 & 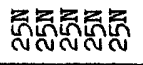 & స్టై & 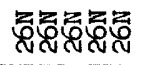 & 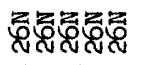 & 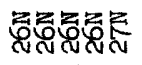 & 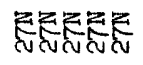 & 츤ํํำ & 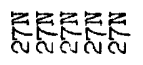 & 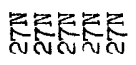 \\
\hline
\end{tabular}




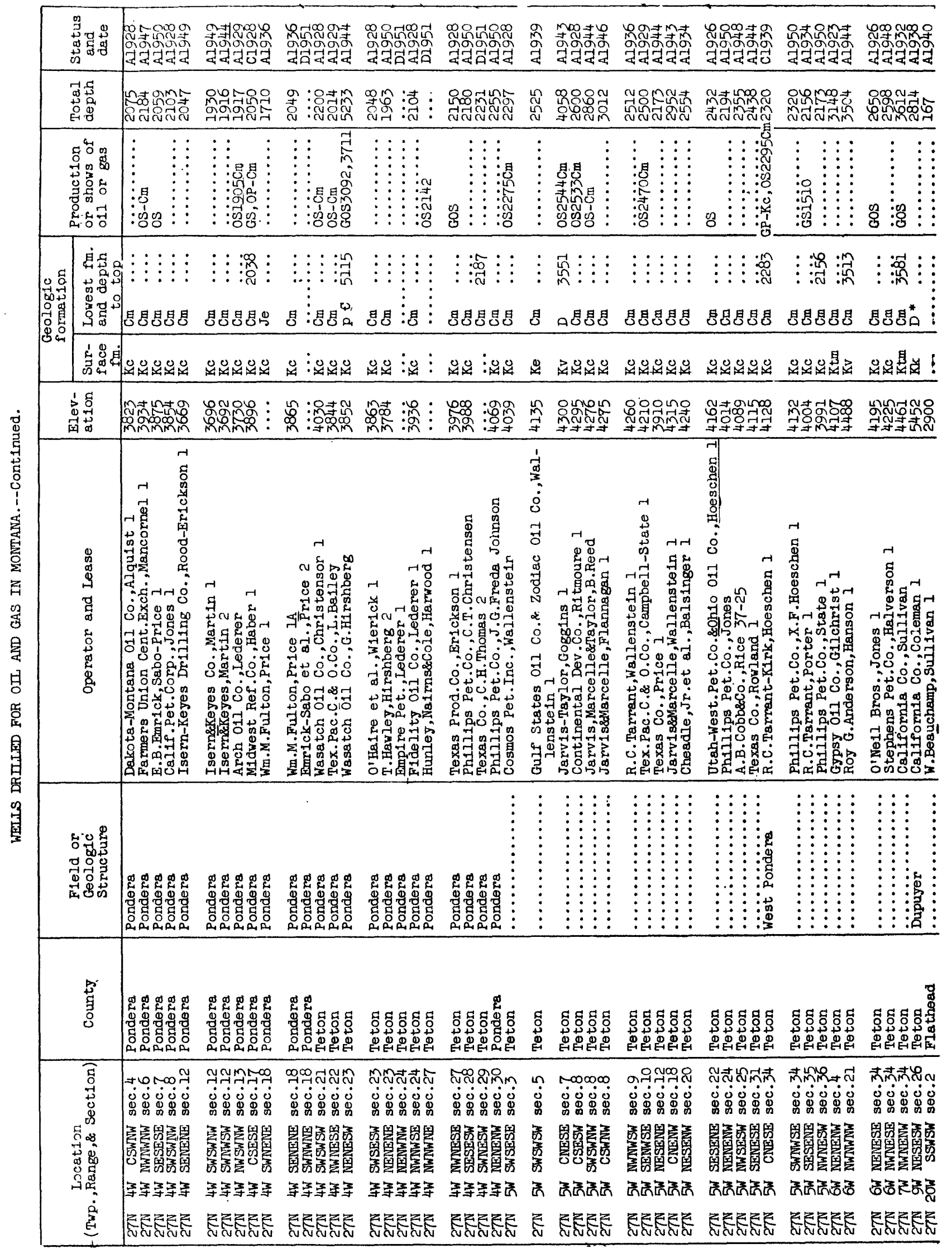




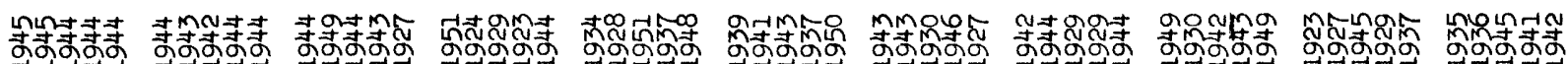

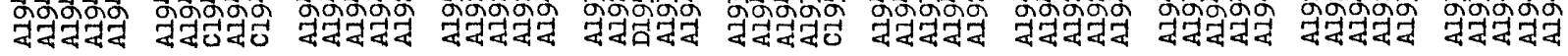

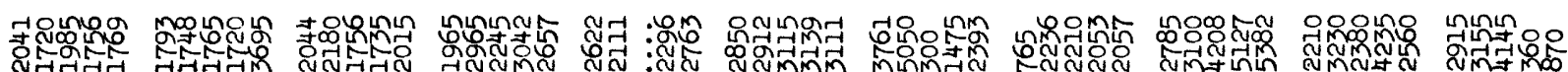

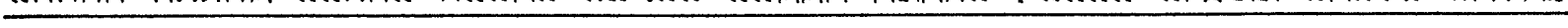

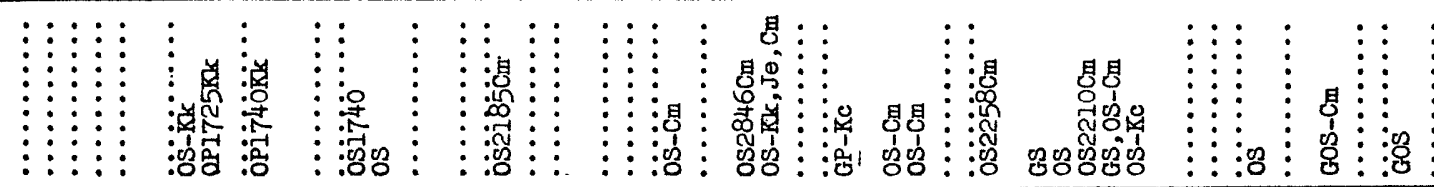

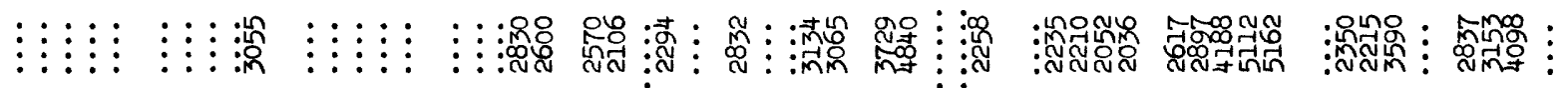

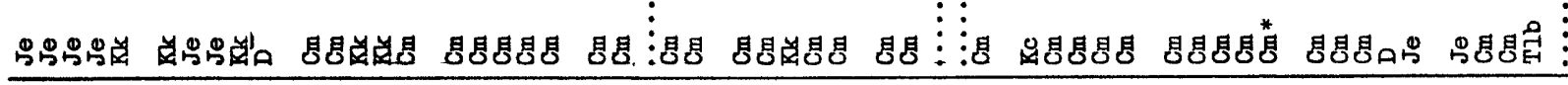

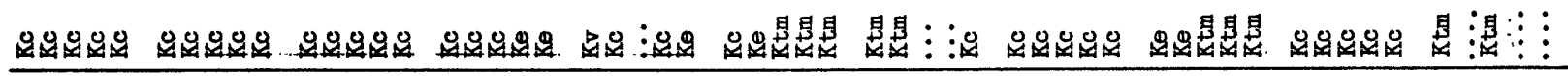

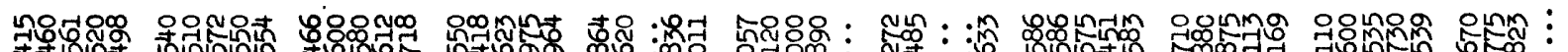

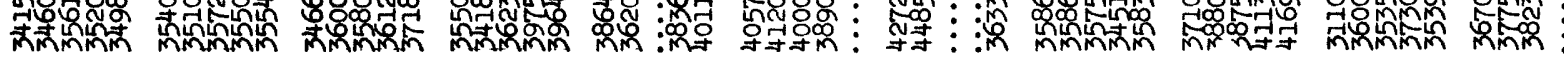

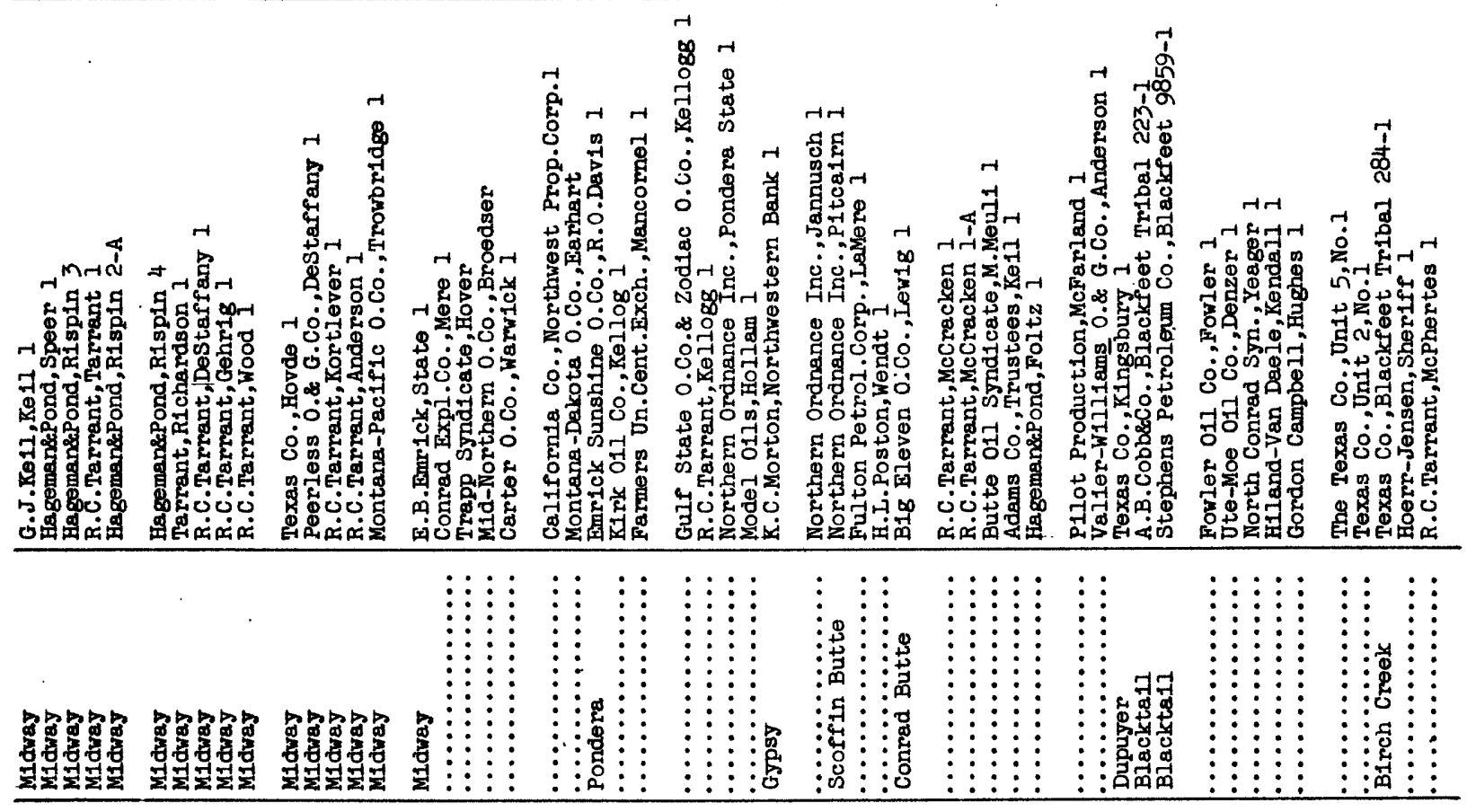

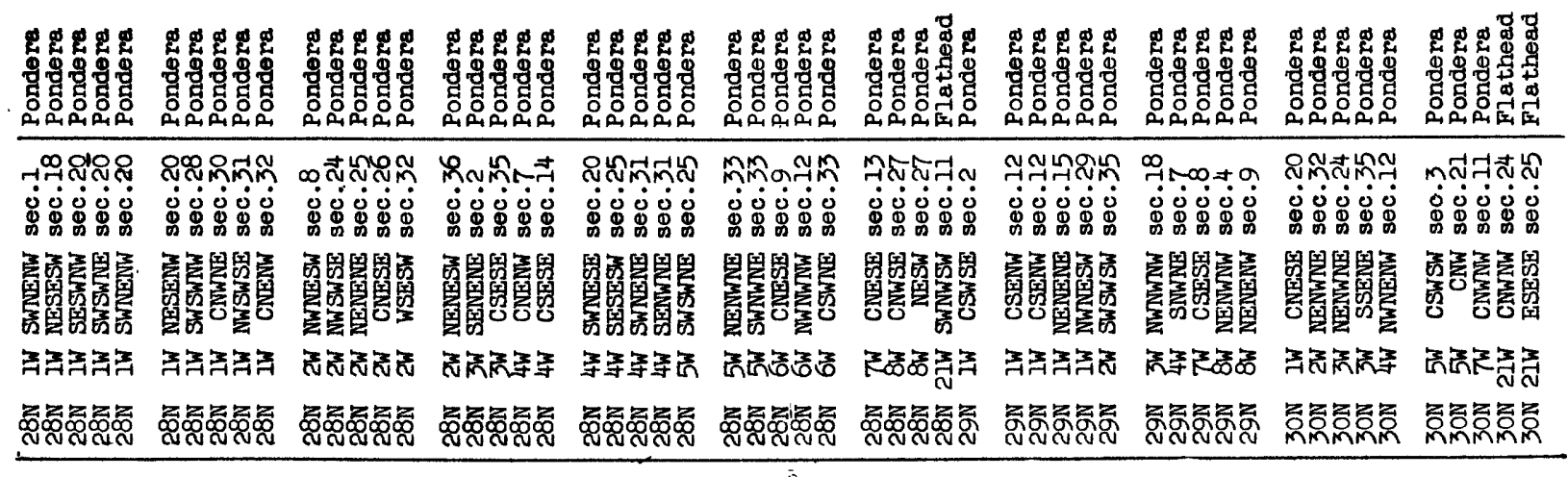




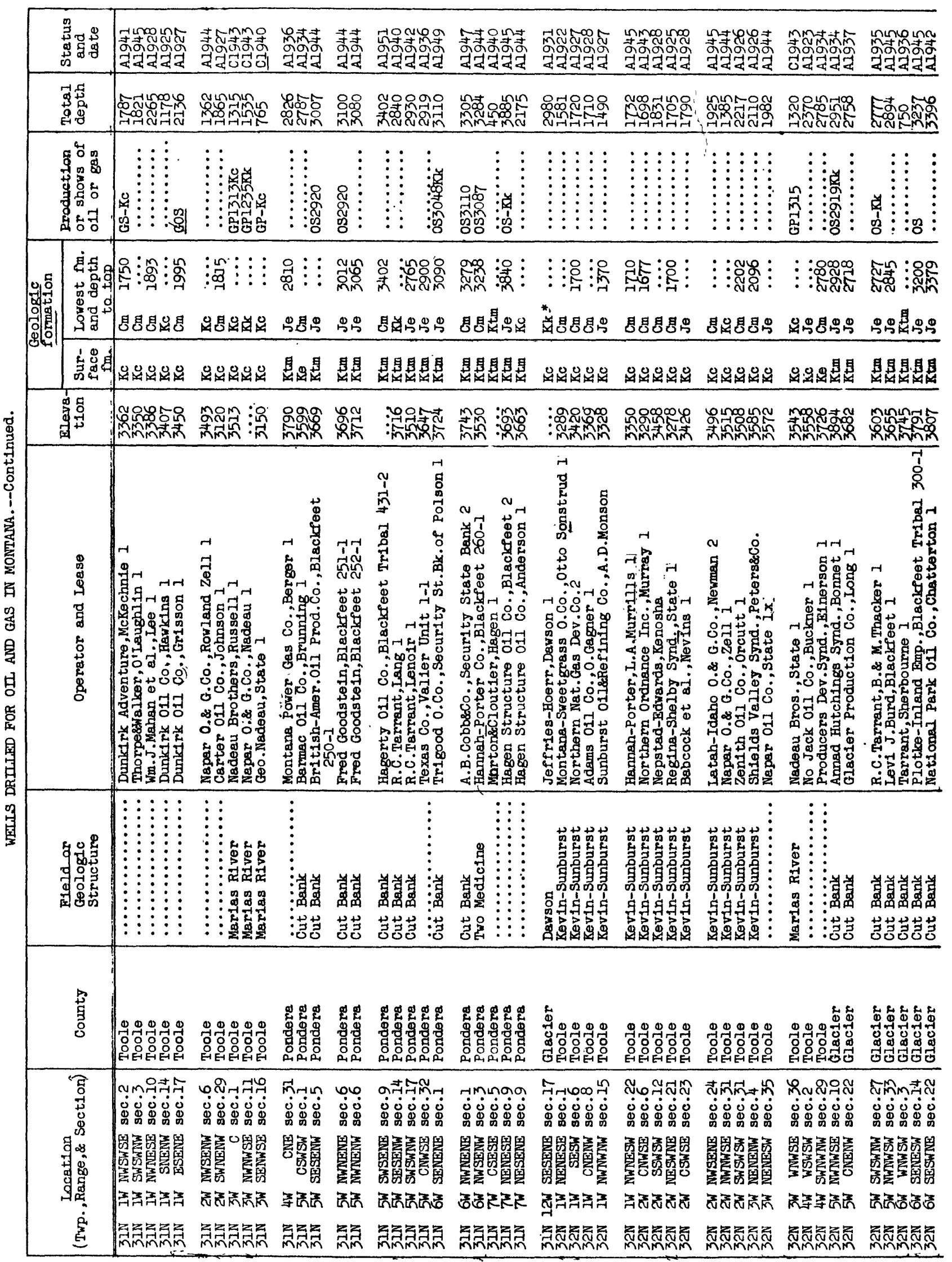




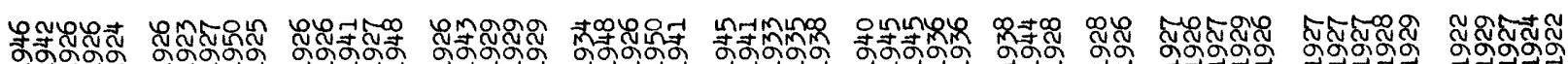

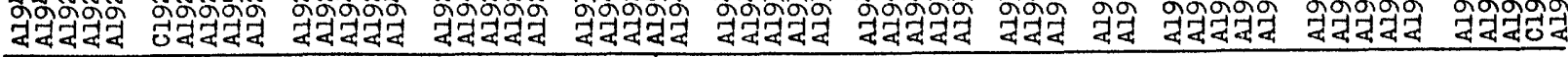

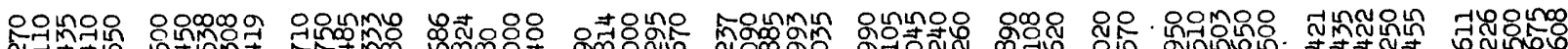
ผ

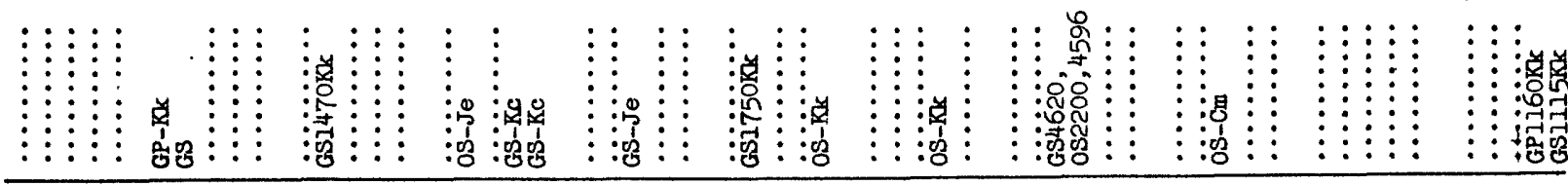

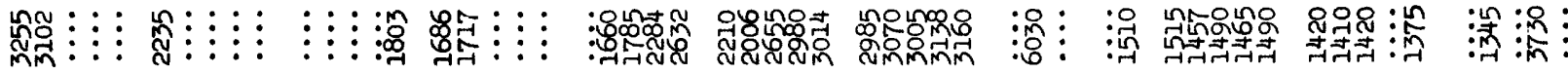

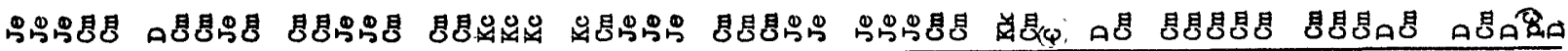

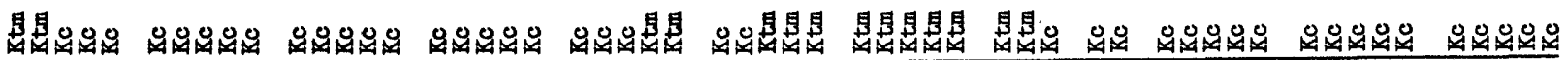

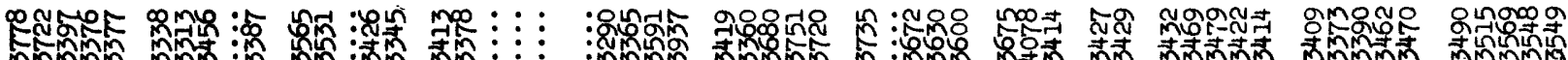

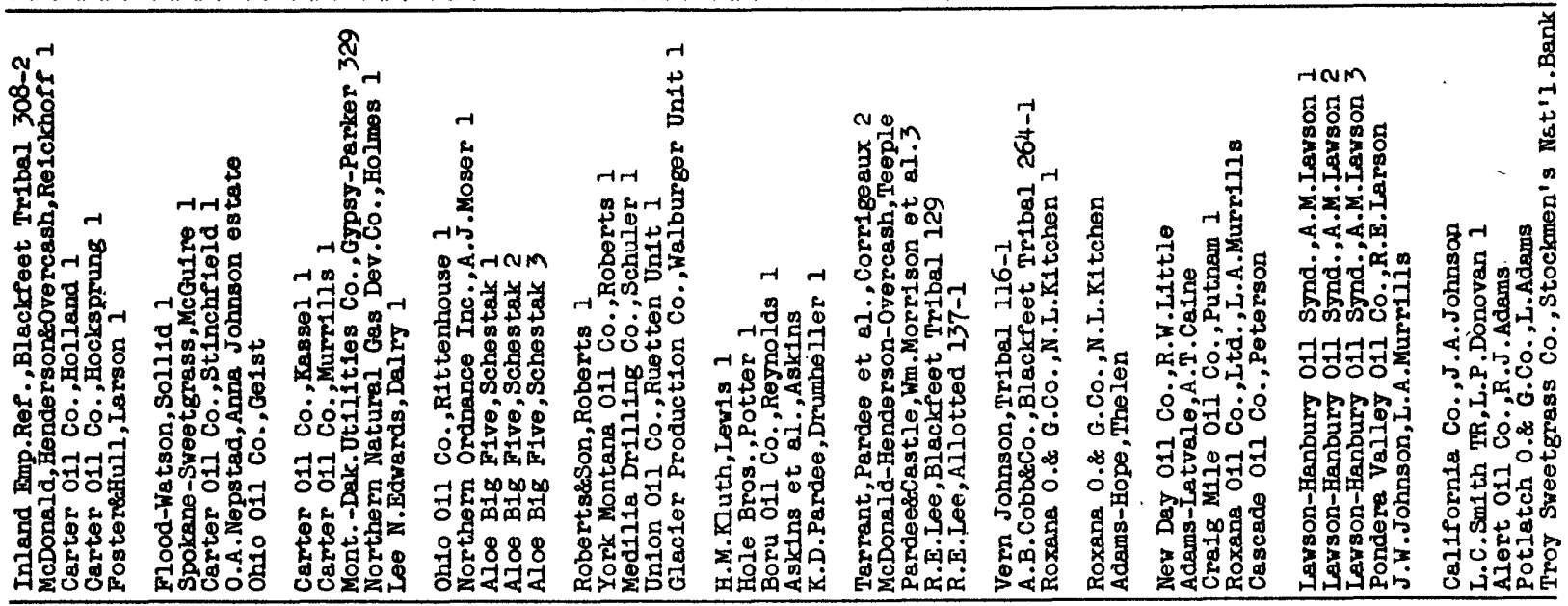

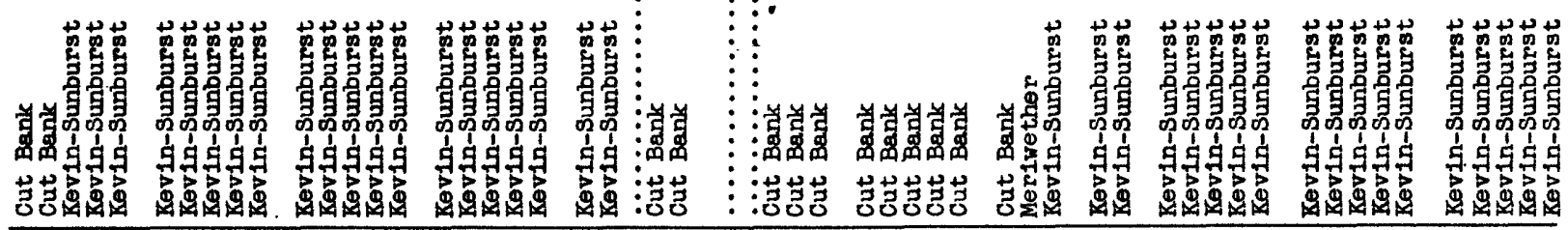

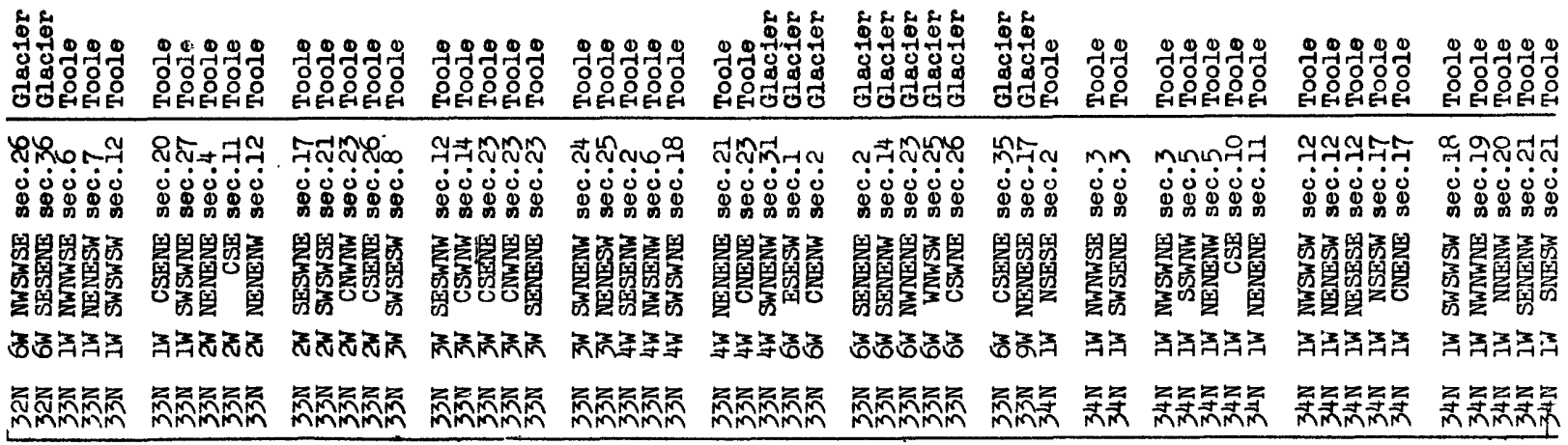




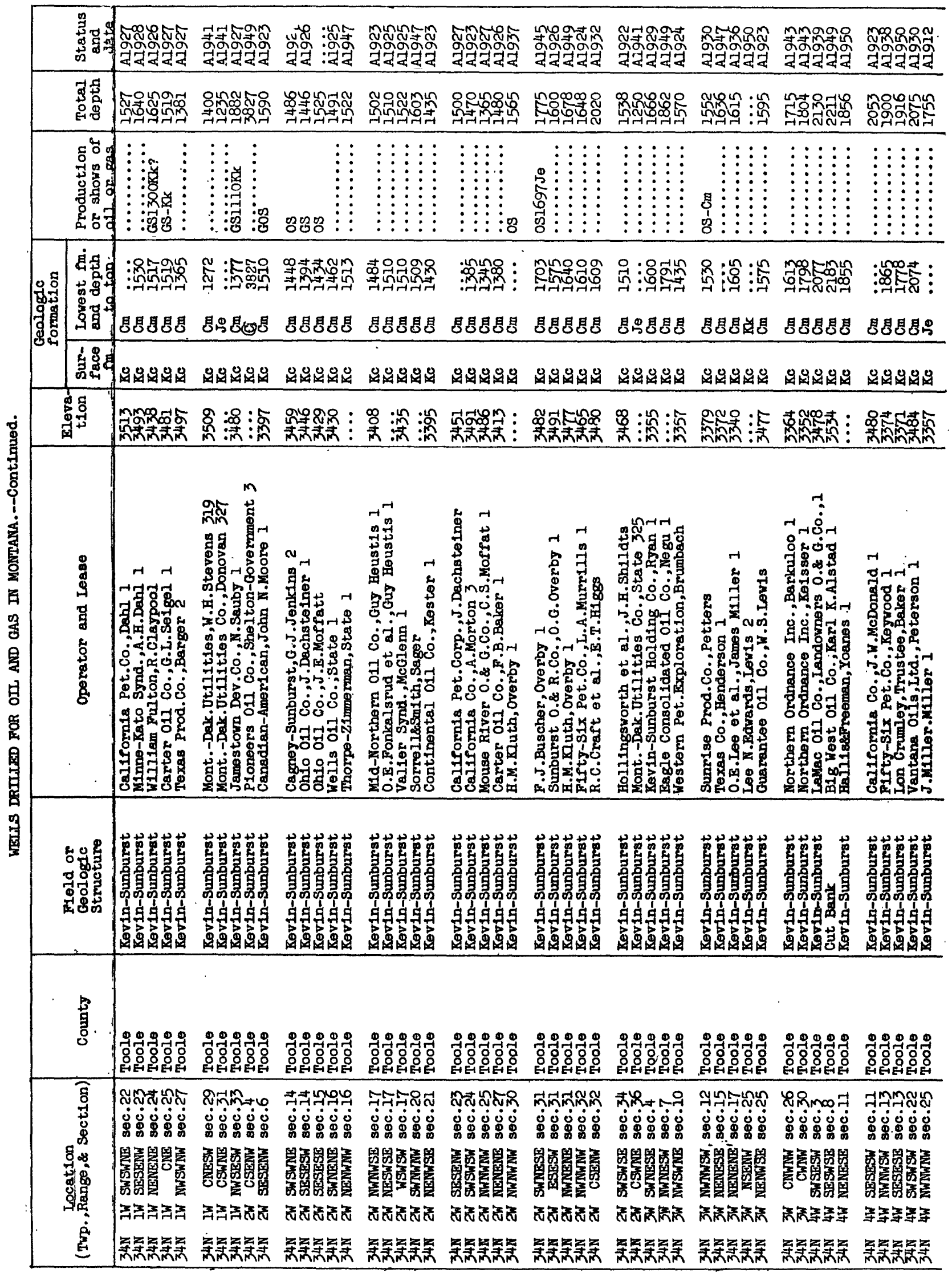




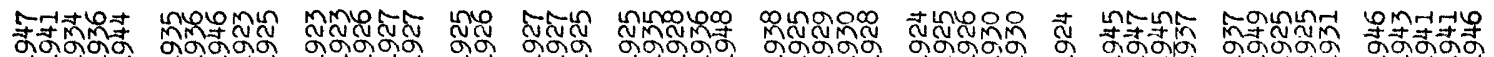

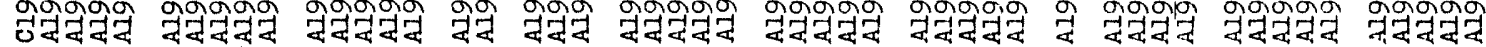

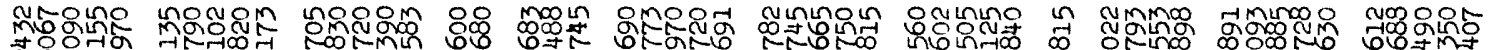

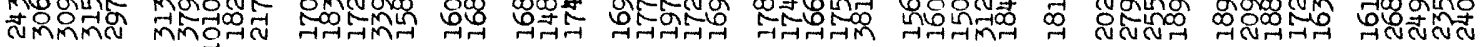

.

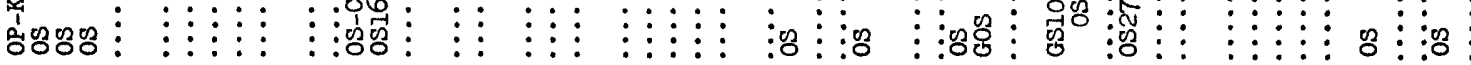

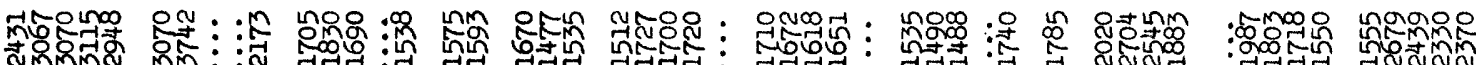

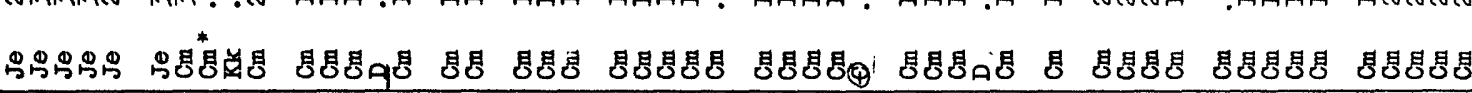

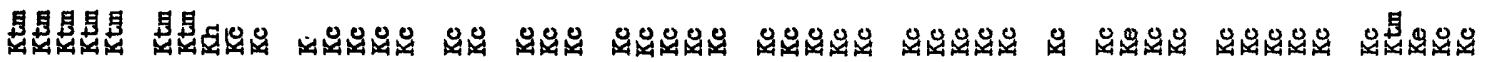

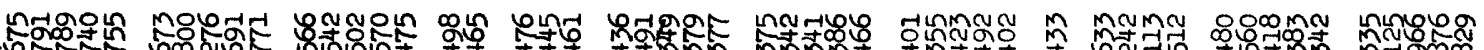
mininin min

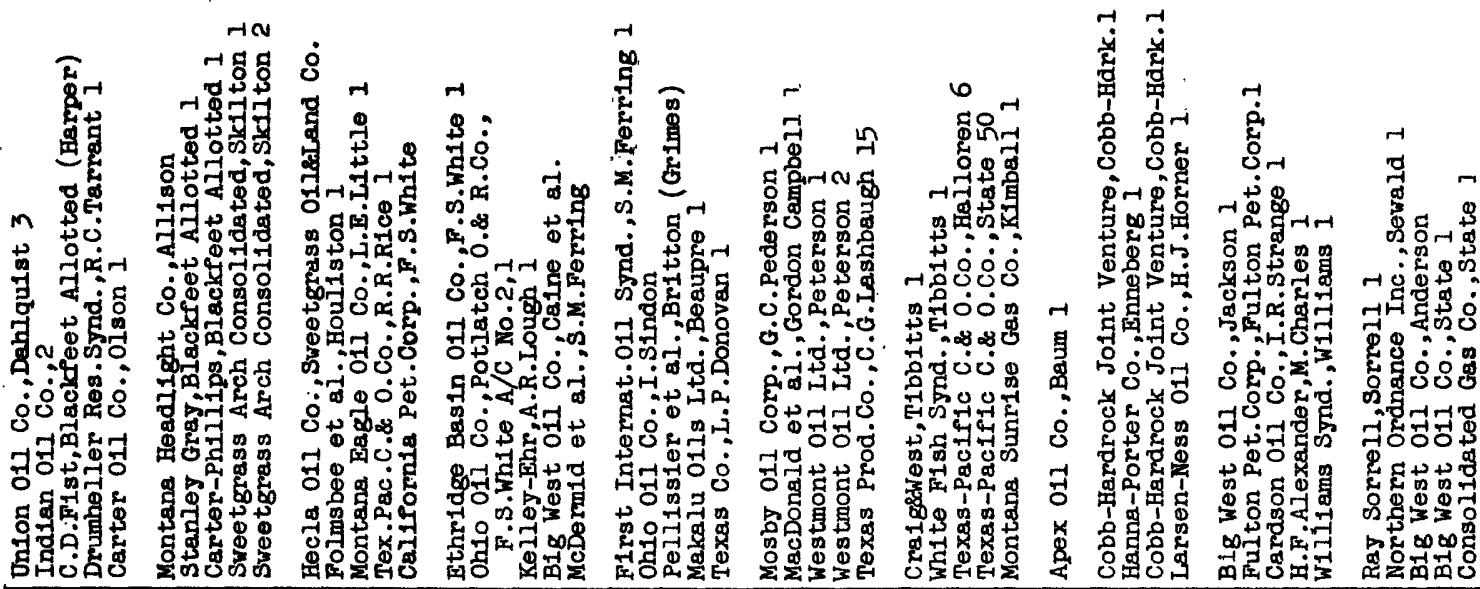

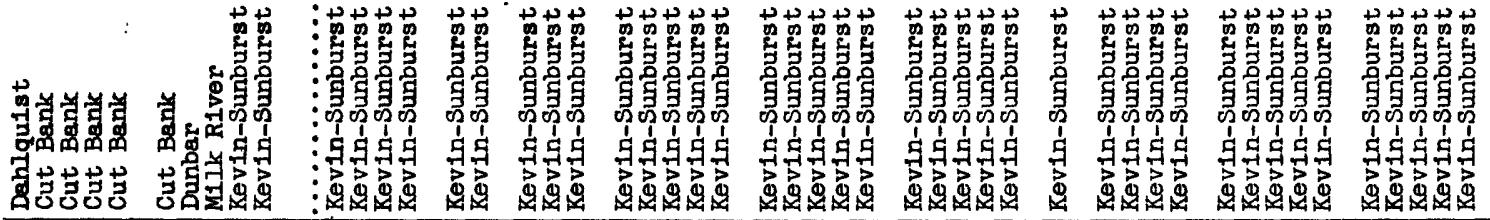

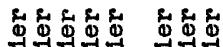

-1

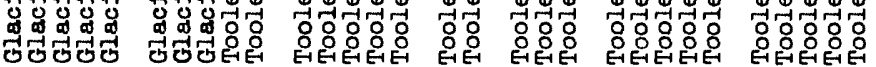

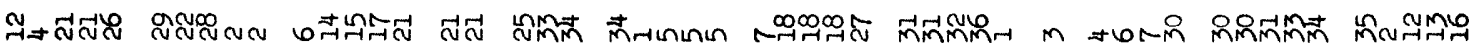

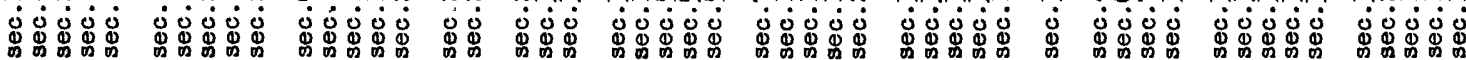

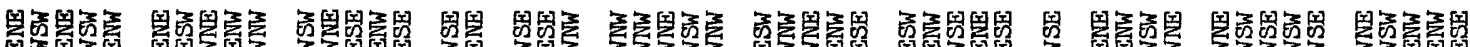

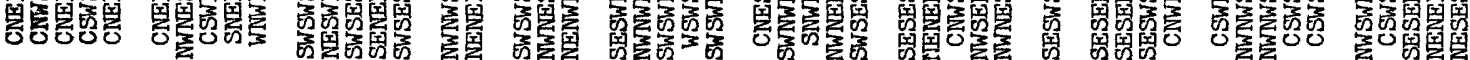

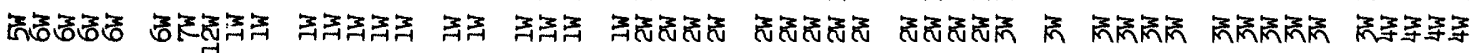

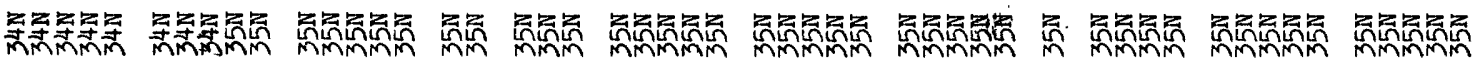




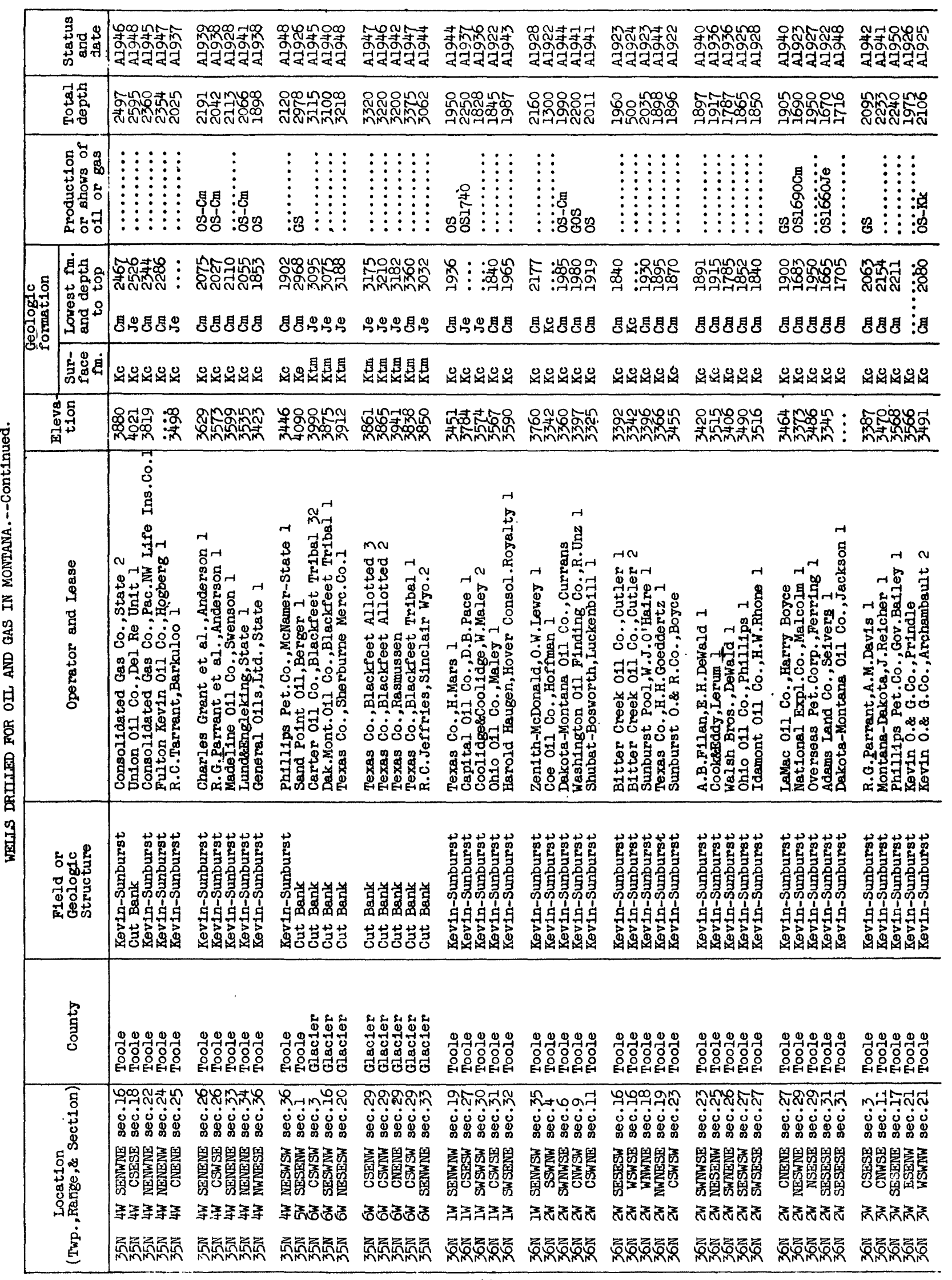




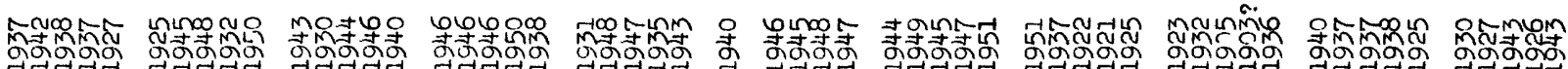

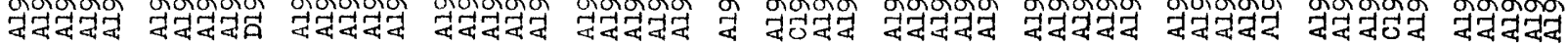

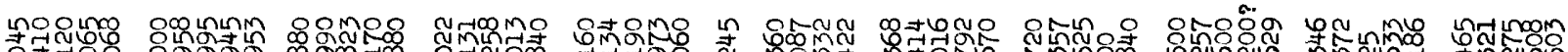

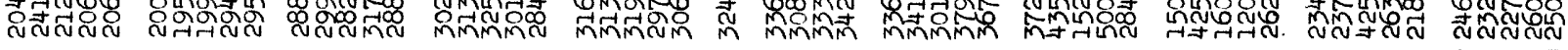

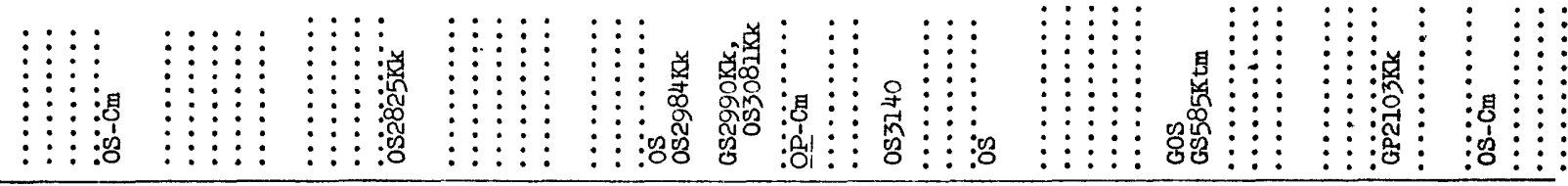

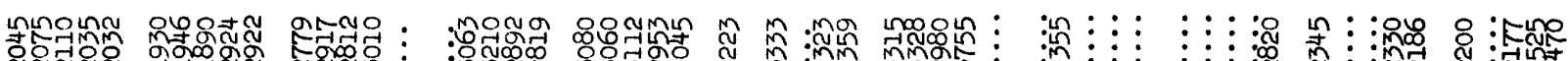

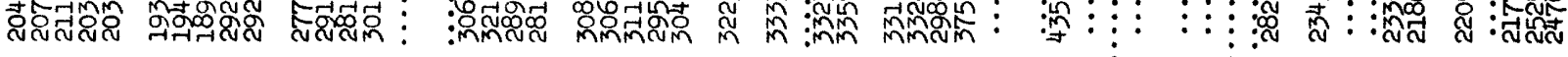

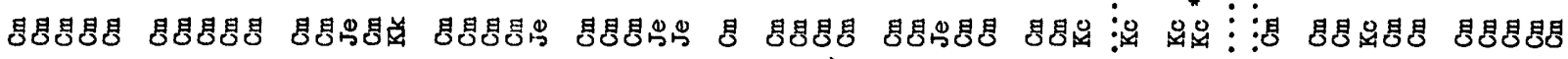

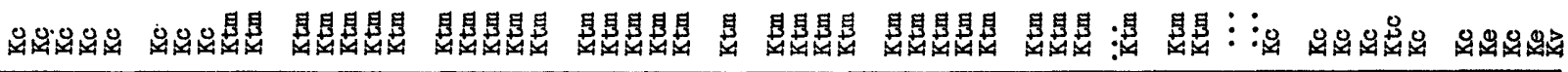

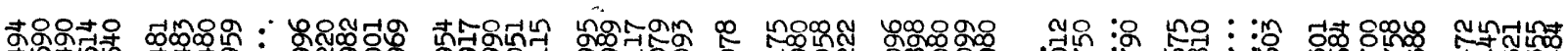

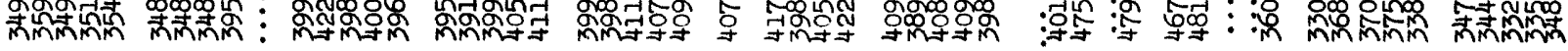

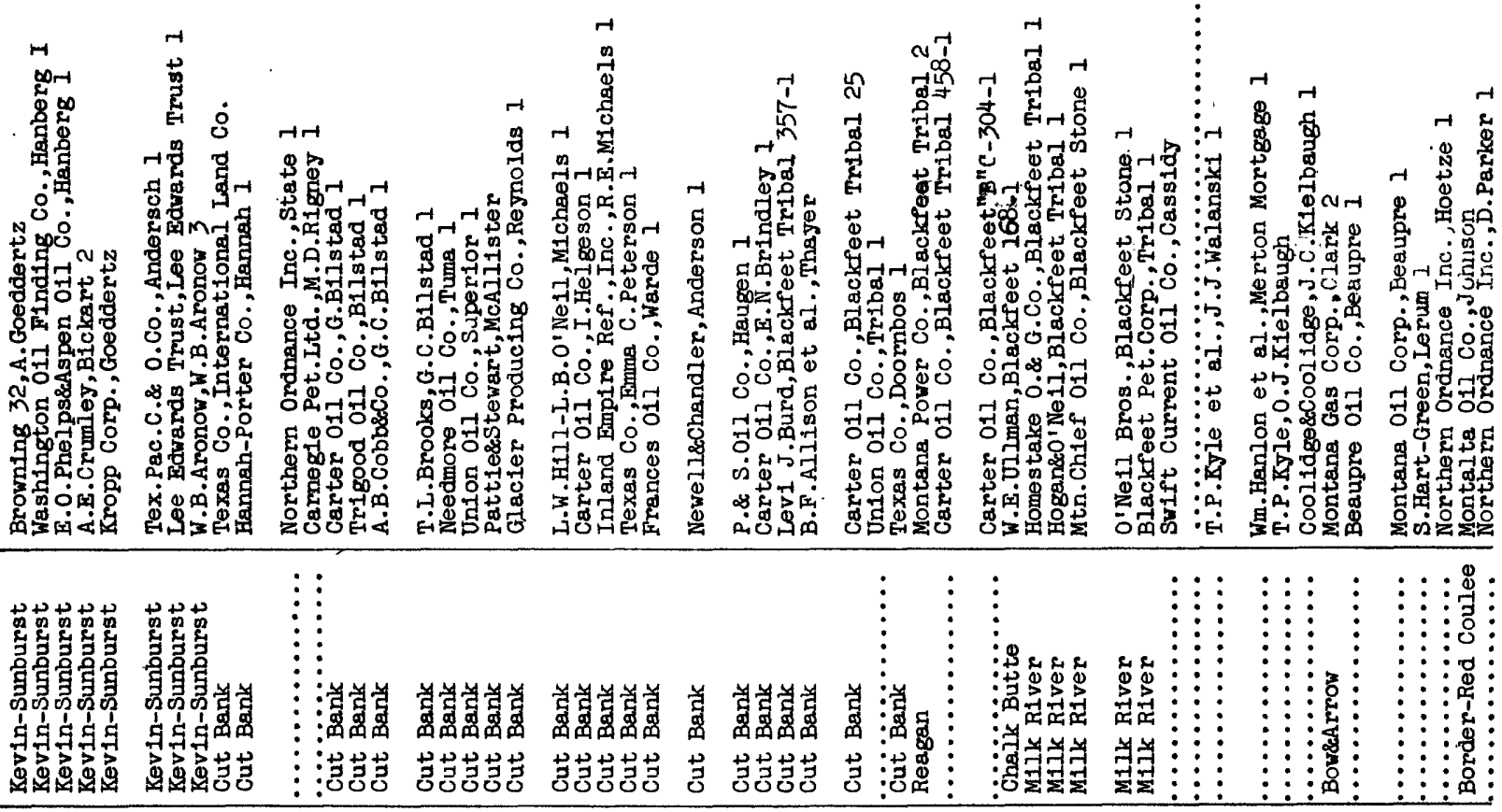

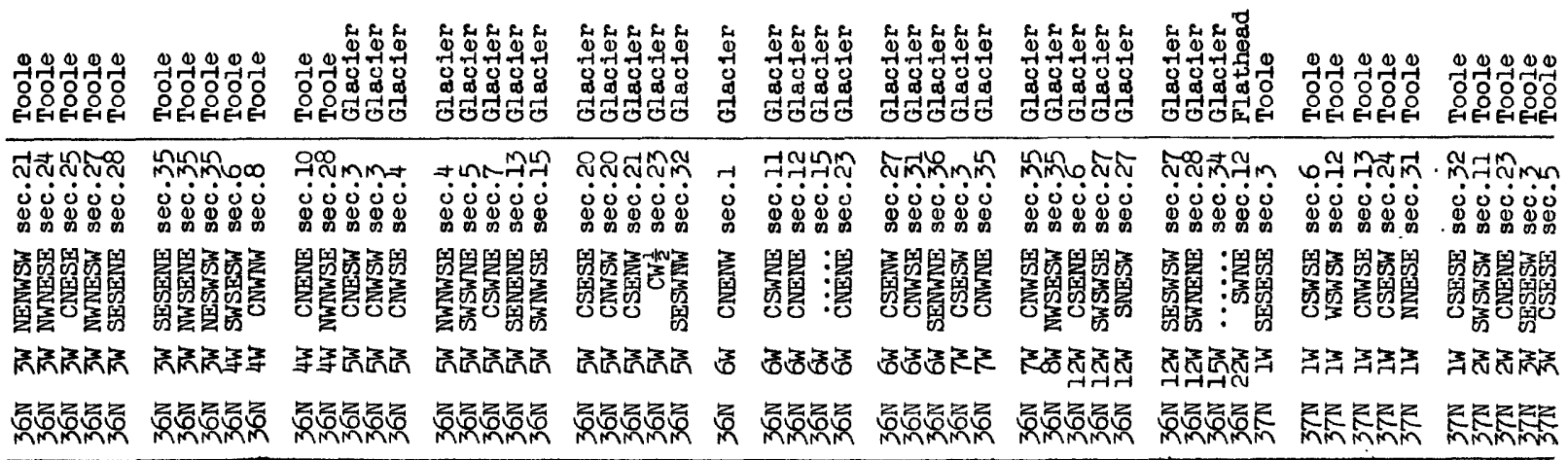




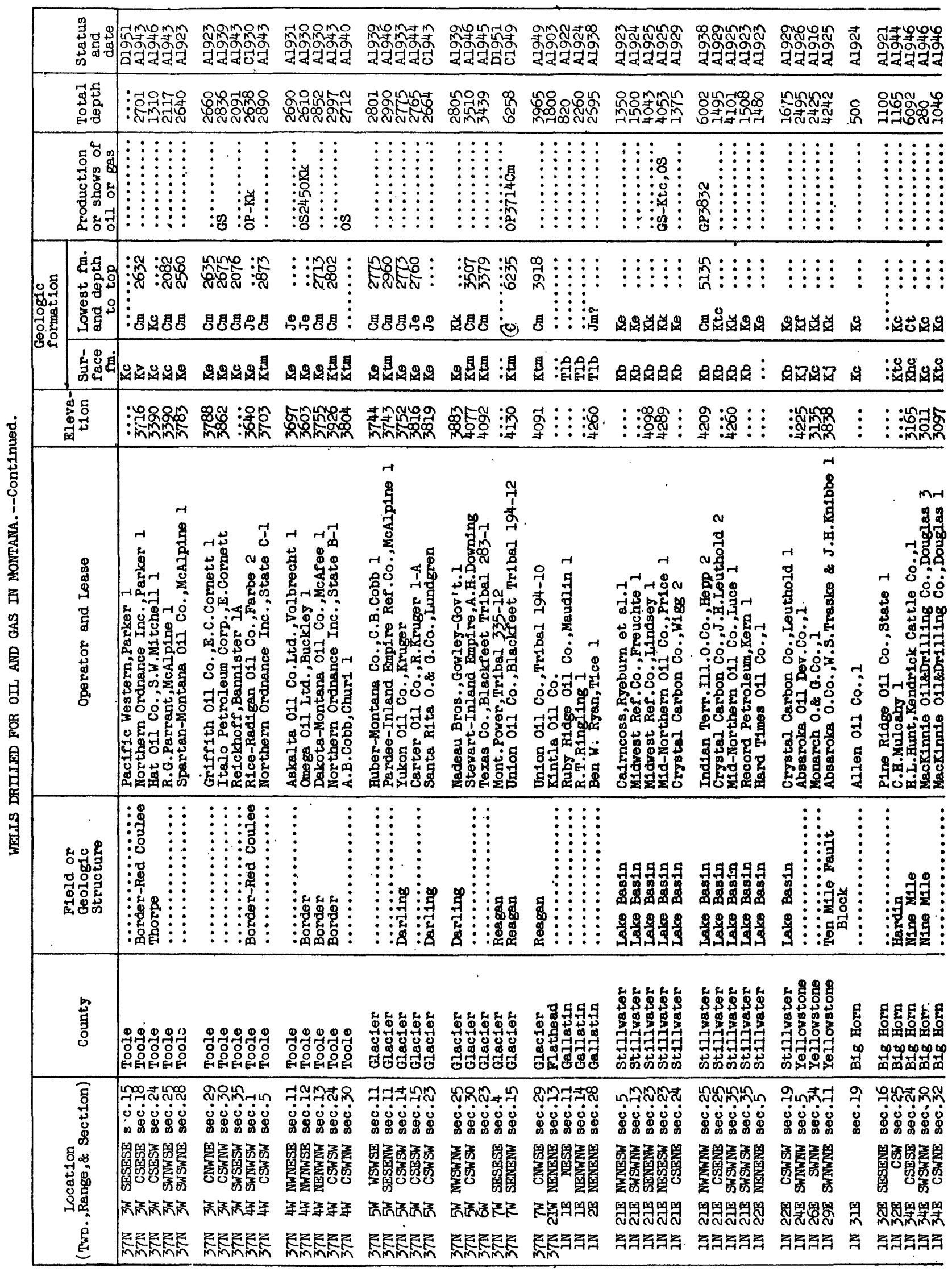




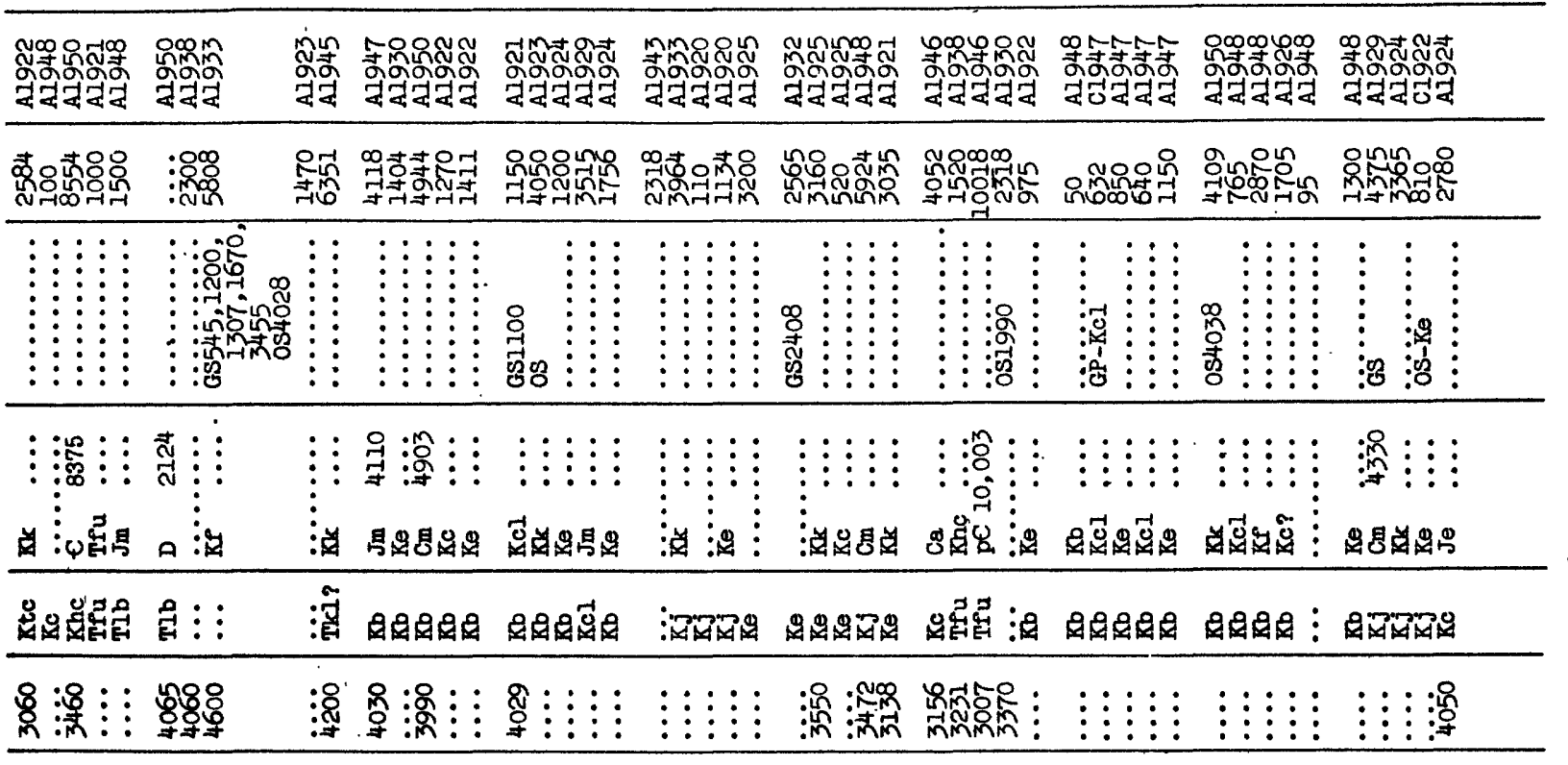

\begin{tabular}{|c|c|c|c|c|c|c|c|c|c|c|}
\hline 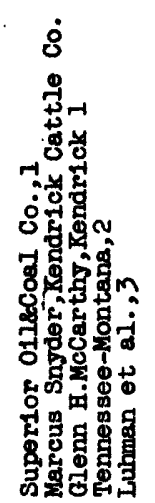 & 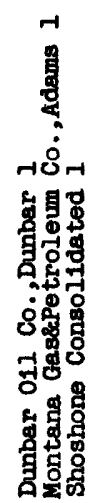 & 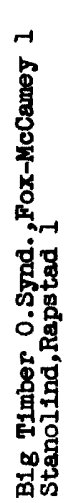 & 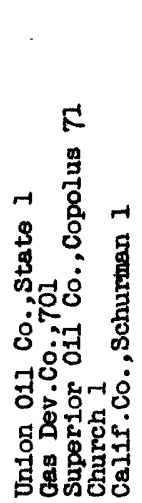 & 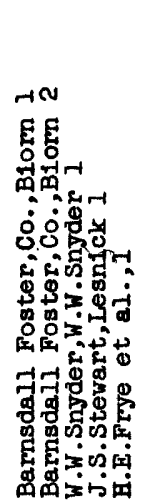 & 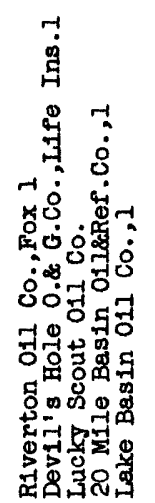 & $\begin{array}{r}1-1 \\
\end{array}$ & 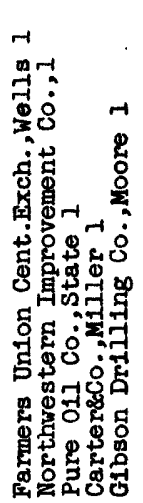 & 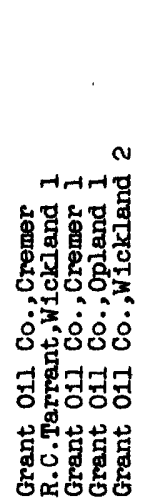 & 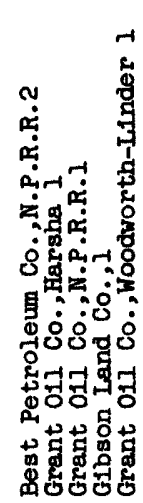 & 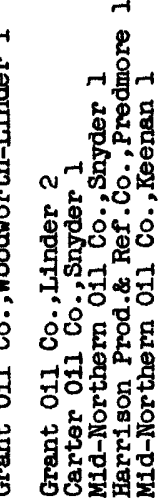 \\
\hline
\end{tabular}

\begin{tabular}{|c|c|c|c|c|c|c|c|c|c|c|}
\hline$\vdots$ & $\begin{array}{c}\vdots \\
\vdots \\
\vdots \\
\vdots \\
\vdots \\
\vdots \\
\vdots \\
\vdots \\
\vdots \\
\vdots \\
\vdots \\
\vdots \\
\vdots \\
\vdots \\
\vdots\end{array}$ & 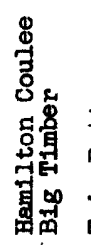 & 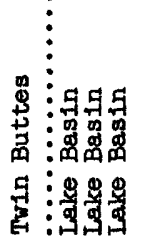 & 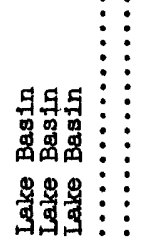 & $\begin{array}{c}\vdots \\
\vdots \\
\vdots \\
\vdots \\
\vdots \\
\vdots \\
\vdots \\
\vdots \\
\vdots \\
\vdots \\
\vdots \\
\vdots \\
\vdots \\
\vdots \\
\vdots\end{array}$ & 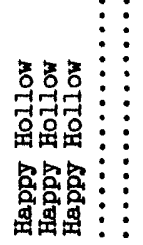 & 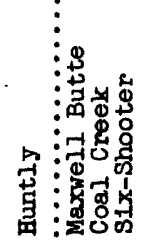 & 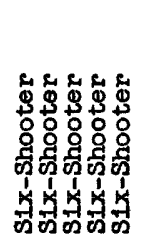 & 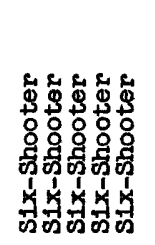 & 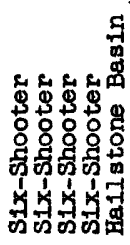 \\
\hline
\end{tabular}

\begin{tabular}{|c|c|c|c|c|c|c|c|c|c|c|}
\hline 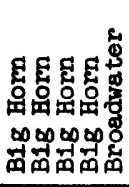 & 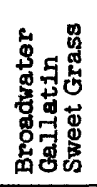 & 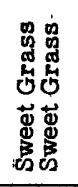 & 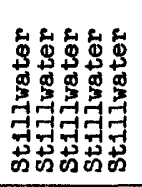 & 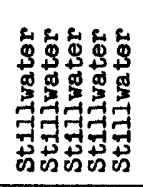 & 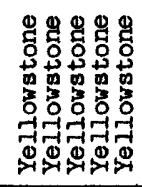 & 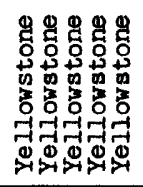 & 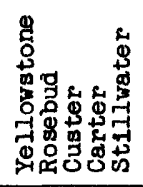 & 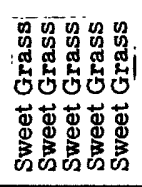 & 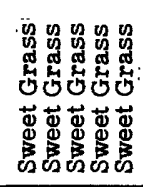 & $\begin{array}{l}0 \\
0 \\
5 \\
5 \\
5\end{array}$ \\
\hline 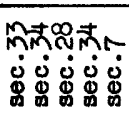 & 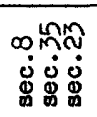 & 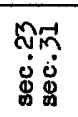 & 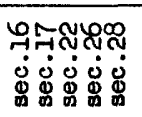 & 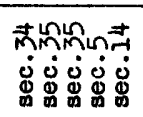 & 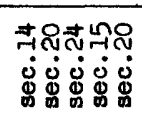 & 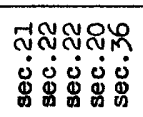 & 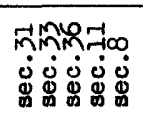 & 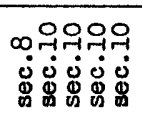 & 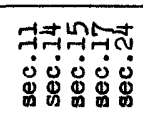 & 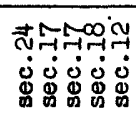 \\
\hline 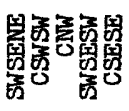 & 国鼠 & 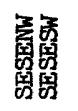 & 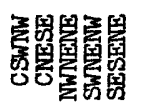 & 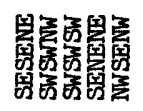 & 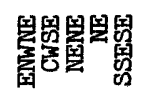 & 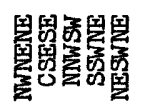 & 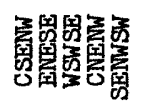 & 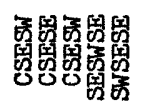 & 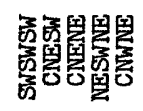 & 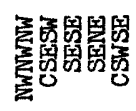 \\
\hline 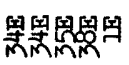 & 国国睤 & 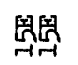 & 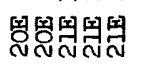 & 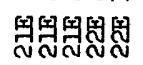 & 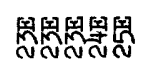 & 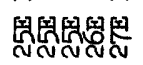 & 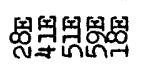 & 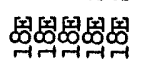 & 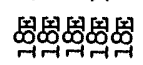 & 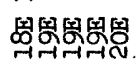 \\
\hline 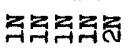 & สำส & ลืส & สెสำส & ไูสสสสี & 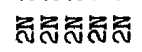 & ไสสสสส & ไูงสำ & 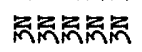 & 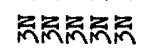 & 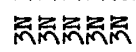 \\
\hline
\end{tabular}




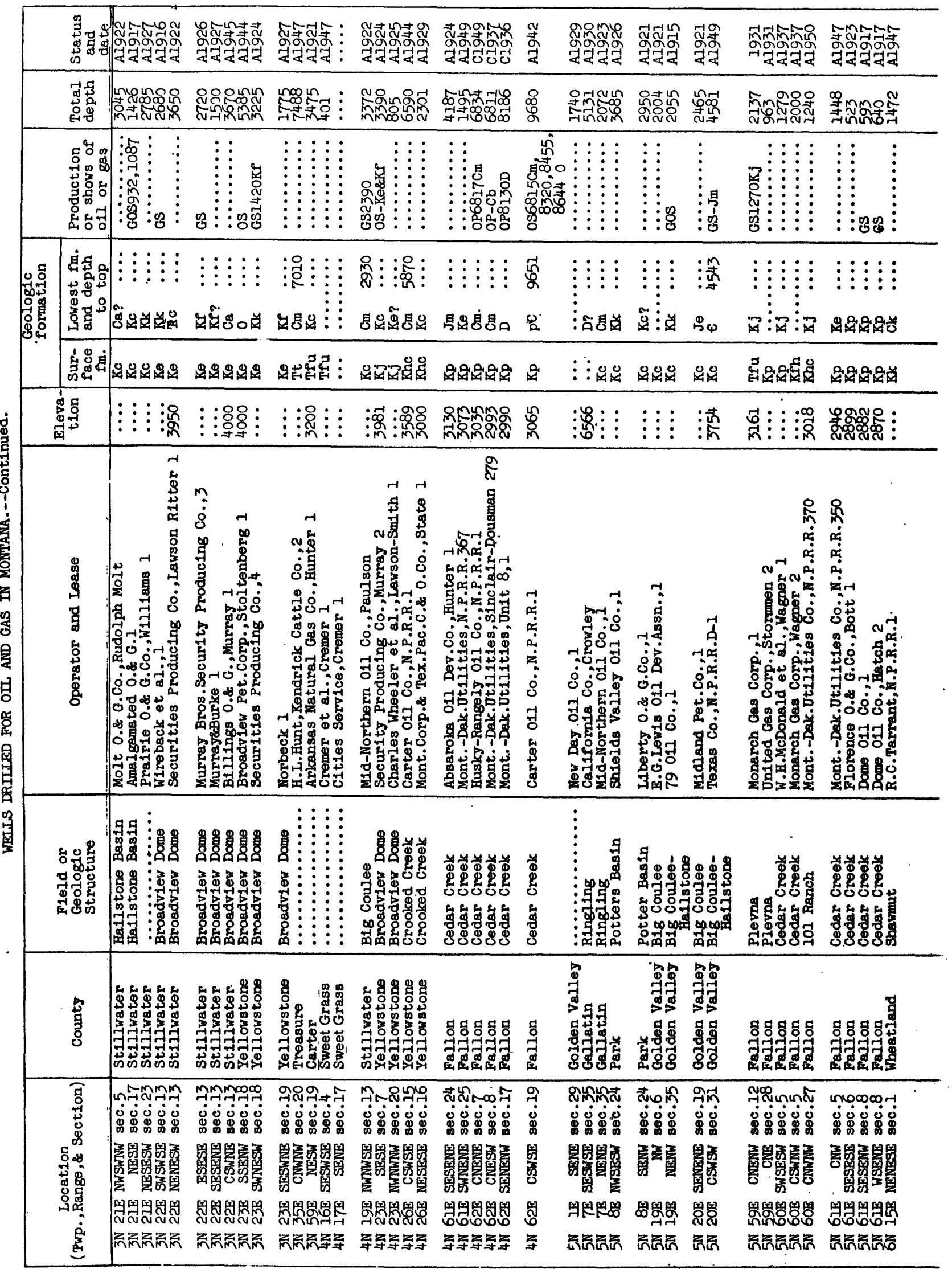




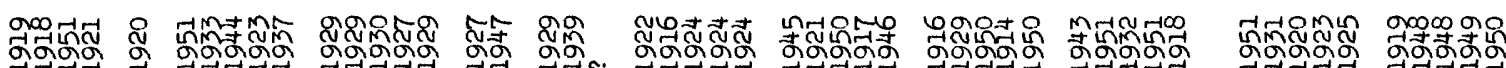

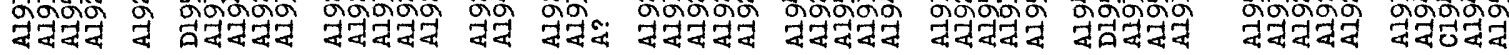

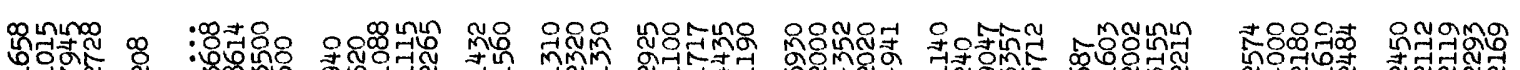

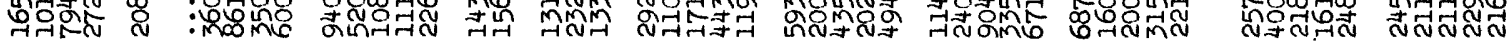

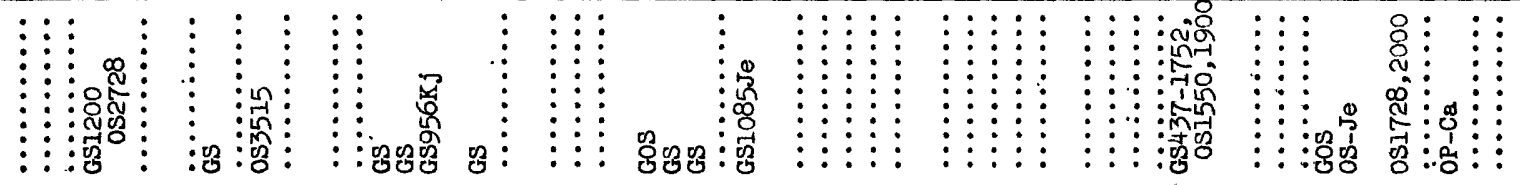

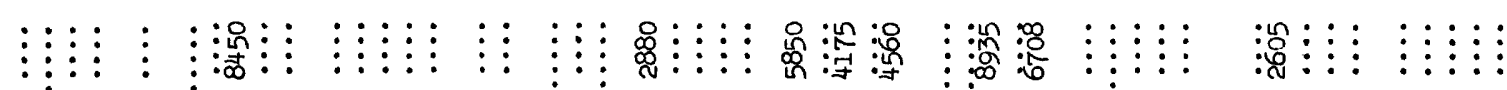

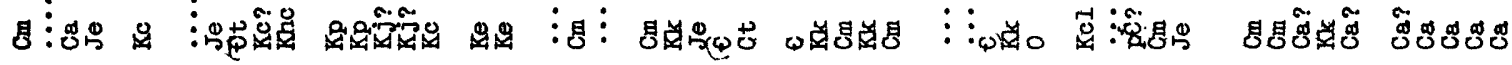

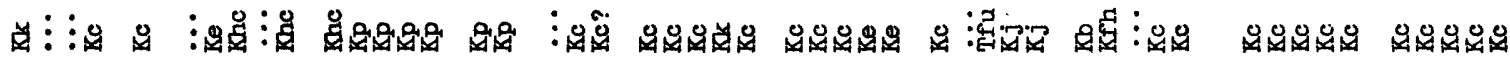
多:

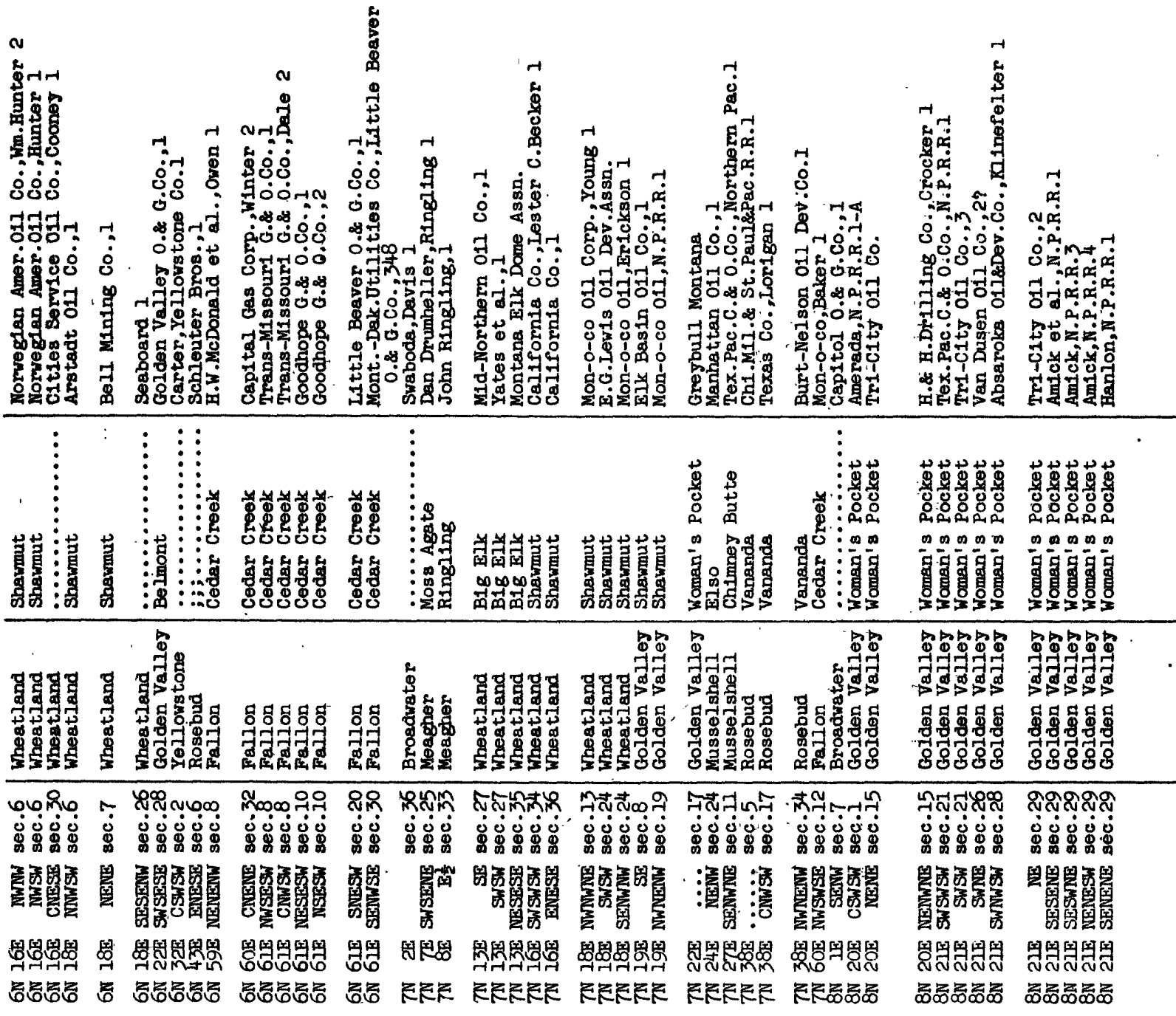




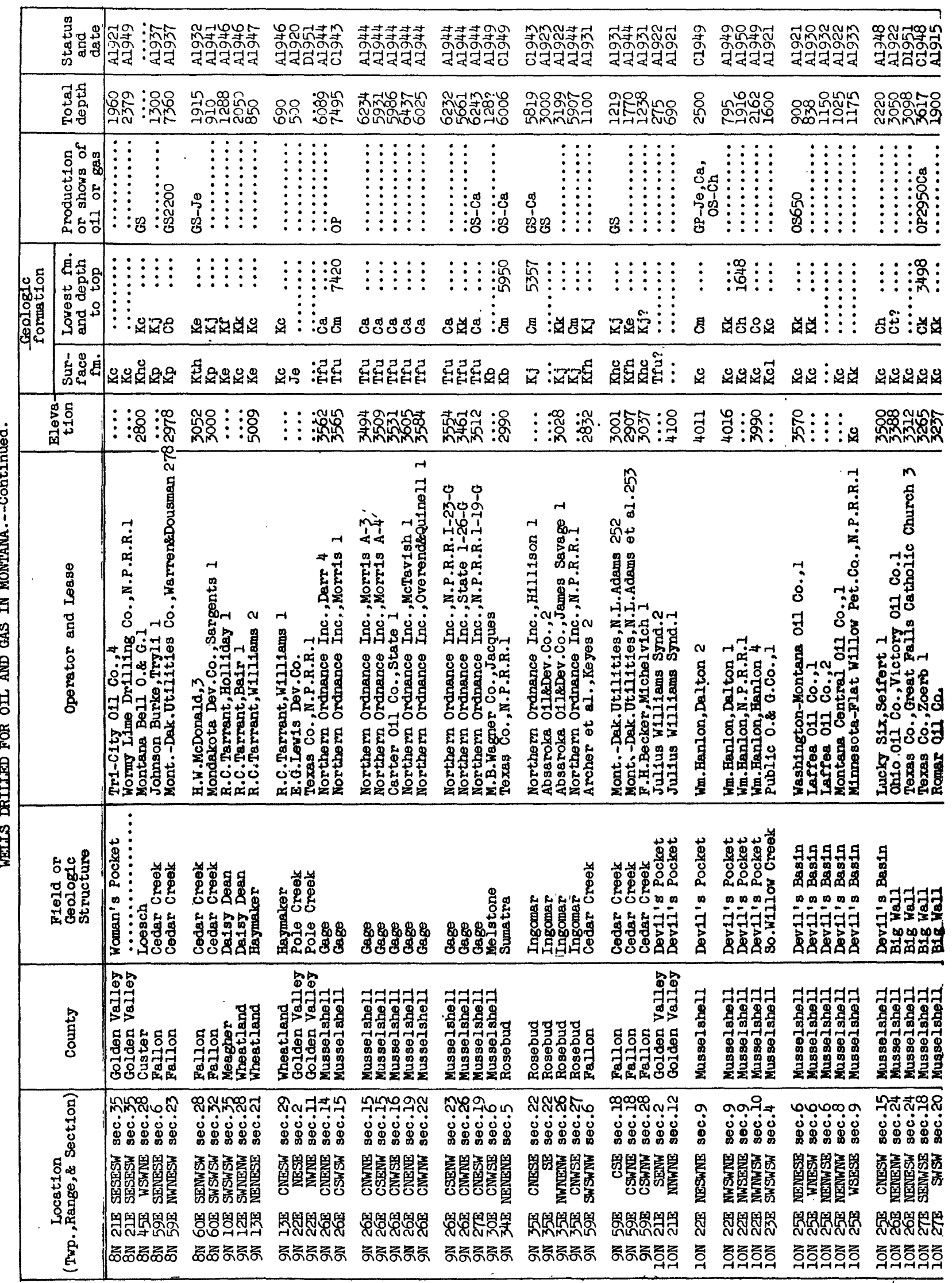




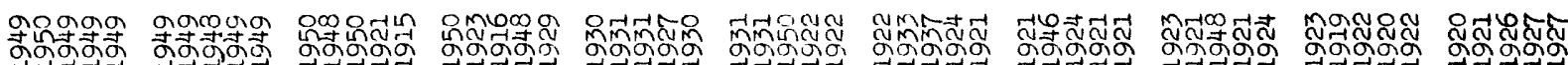

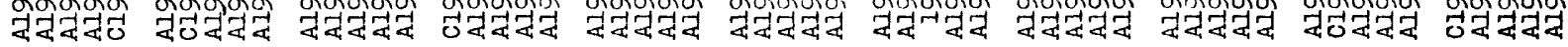

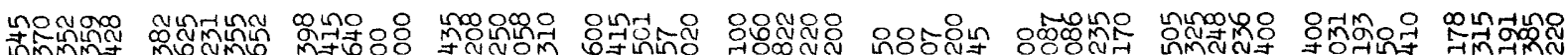

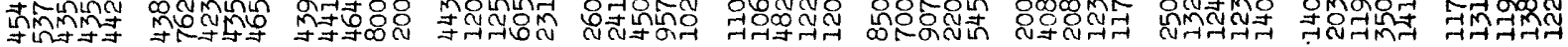

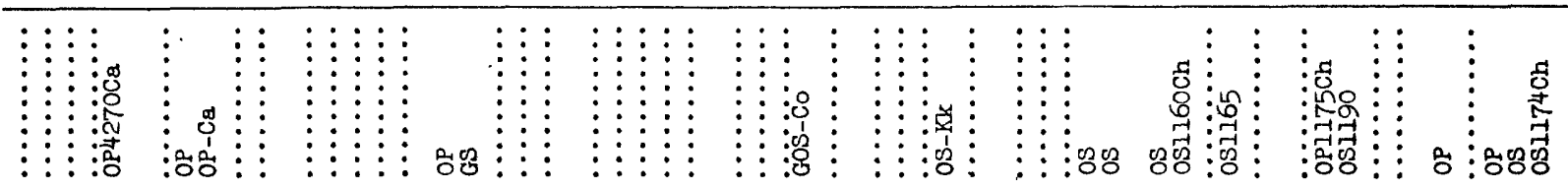

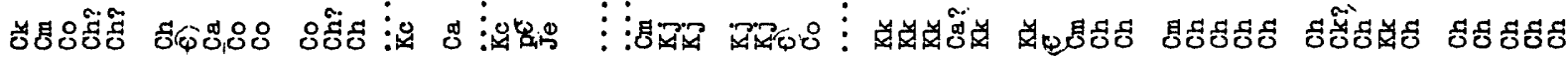

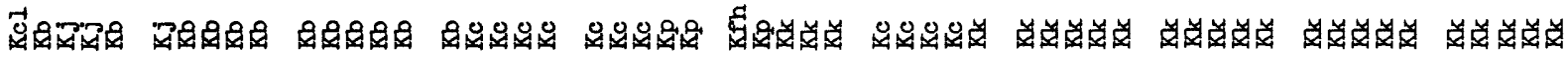

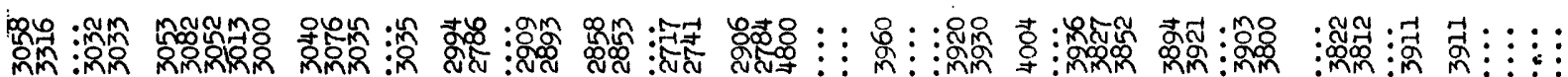

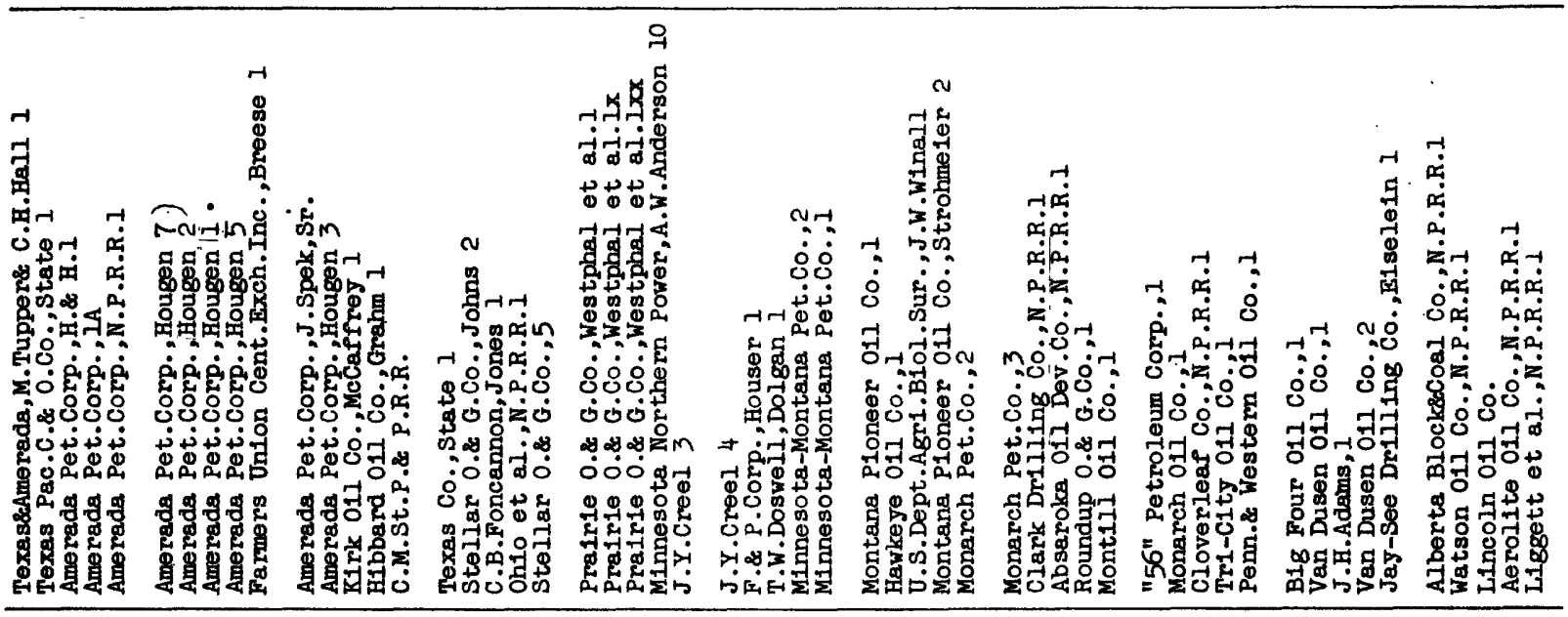

\section{$\vdots:$

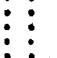 \\ 然}

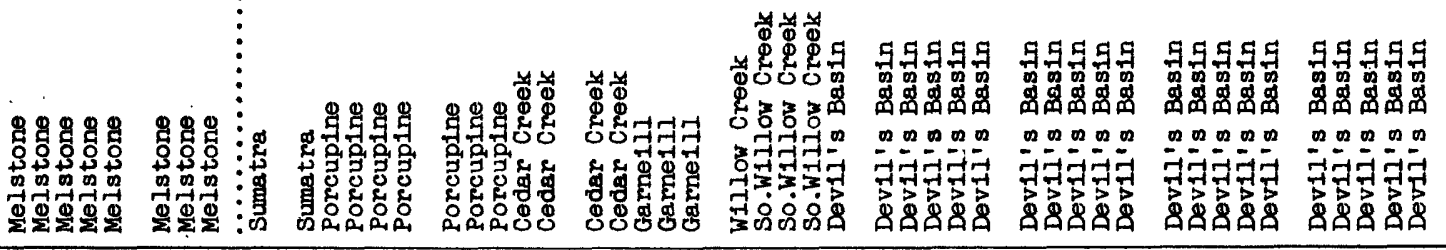

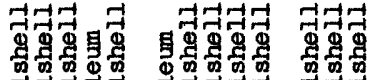

플

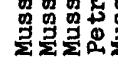

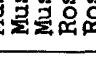

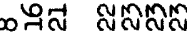

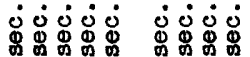

它四国

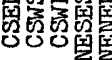

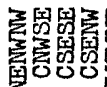

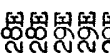

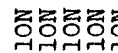

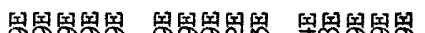

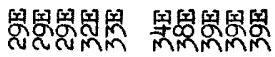

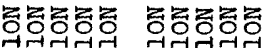

\section{7ng}

sy

蜜触

동동혀ㄴㅕㅕ

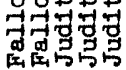

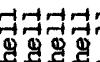

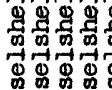

o

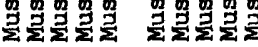

주워नㄱ

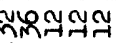

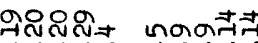

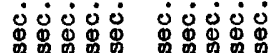

J

瓷瓷

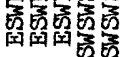

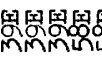

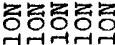

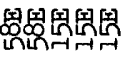

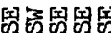

㼭会会

客荥学

\section{国国国完}

空惯管

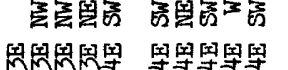

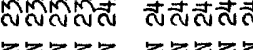

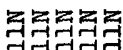

न겅거웡

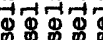

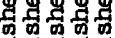

का 


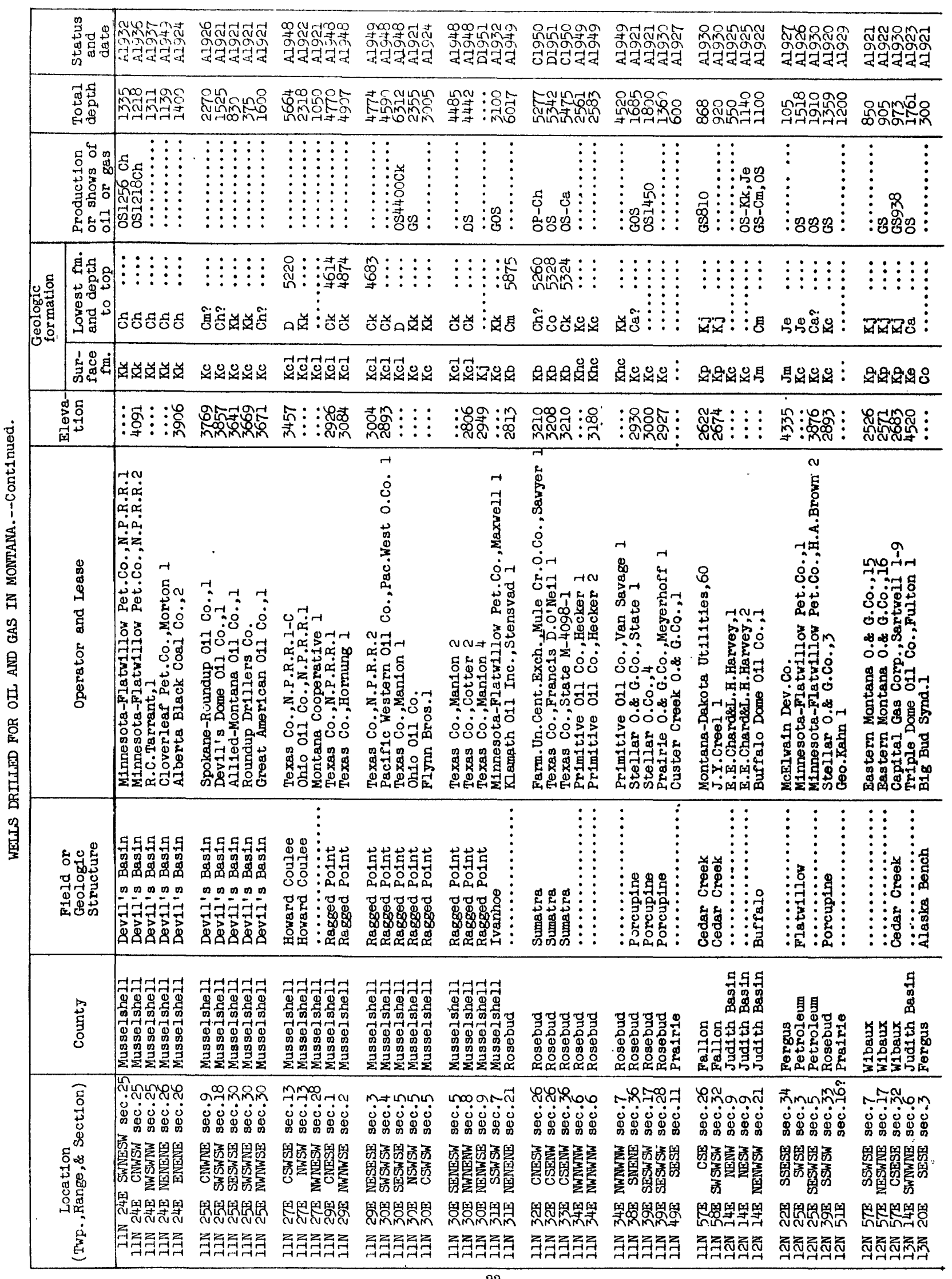




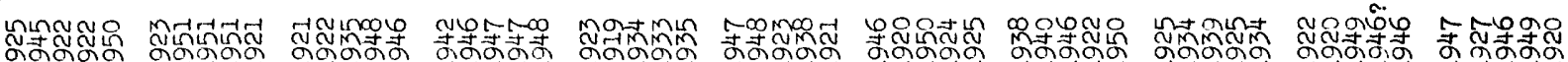

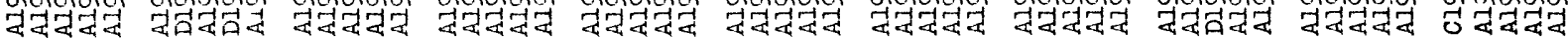

นnمo요

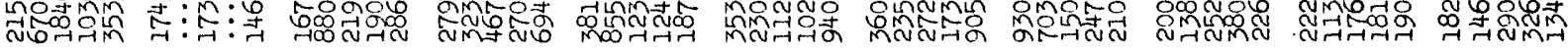

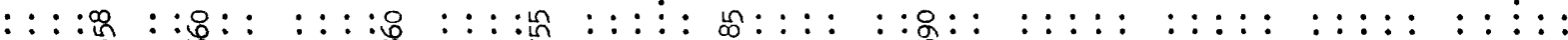

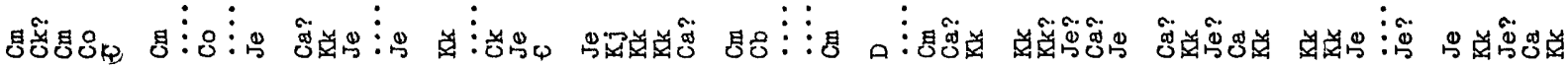

영ㄷㅇㅇ

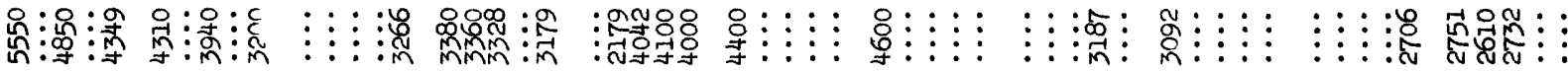

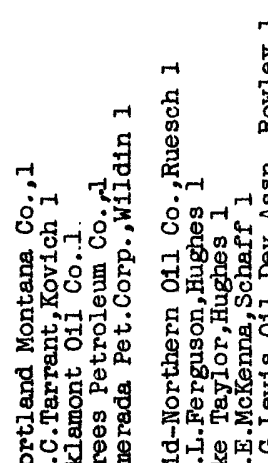

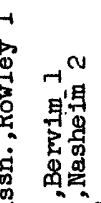

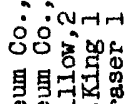

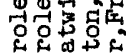

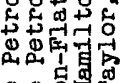

\& 8 品窟

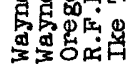

(a)

造

4

4 नुम

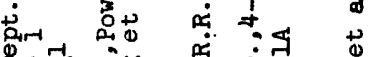

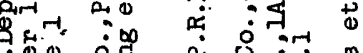

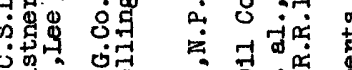

मीं

तथम्:

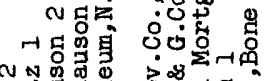

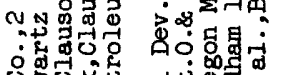

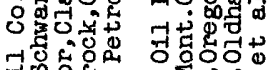

万人

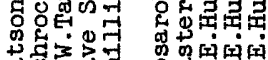

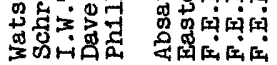

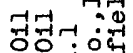

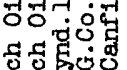

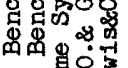

औै

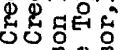

×x

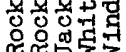

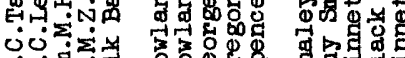

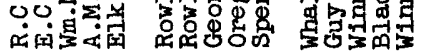

$\$ \$ \$ \$$

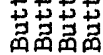

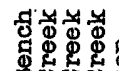

In:

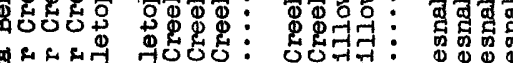

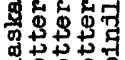

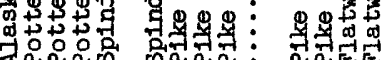

o on o o

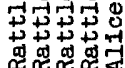

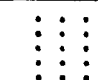

괌 $: \vdots::::: \$$

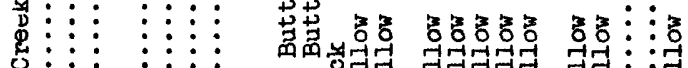

: : : : : 4 व

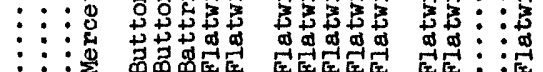

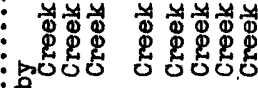

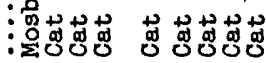

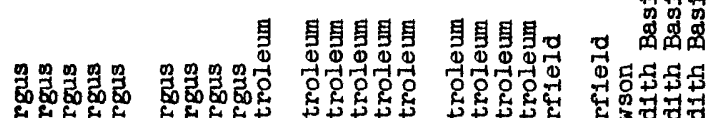

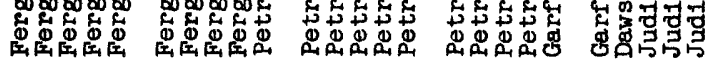

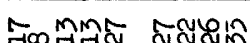

نंنं: $\dot{0} \dot{0} \dot{0} \dot{0}$

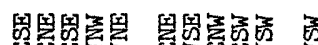

国界会

国瓷闵

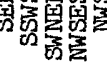

in 8

งกับูง

ํํํำत

O: 000

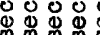

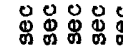

国舅国

鼠窟界鼠

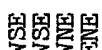

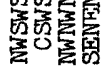

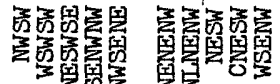

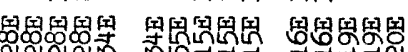

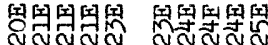

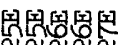

药流

mingmin

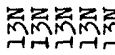

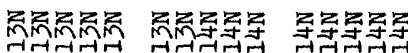

뵈되되되젇

貝县

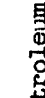

目目目目

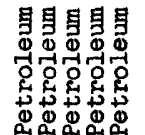

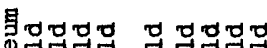
(1)

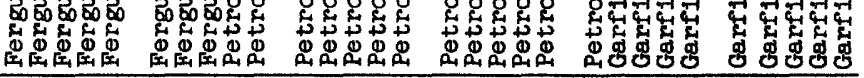
(1) 


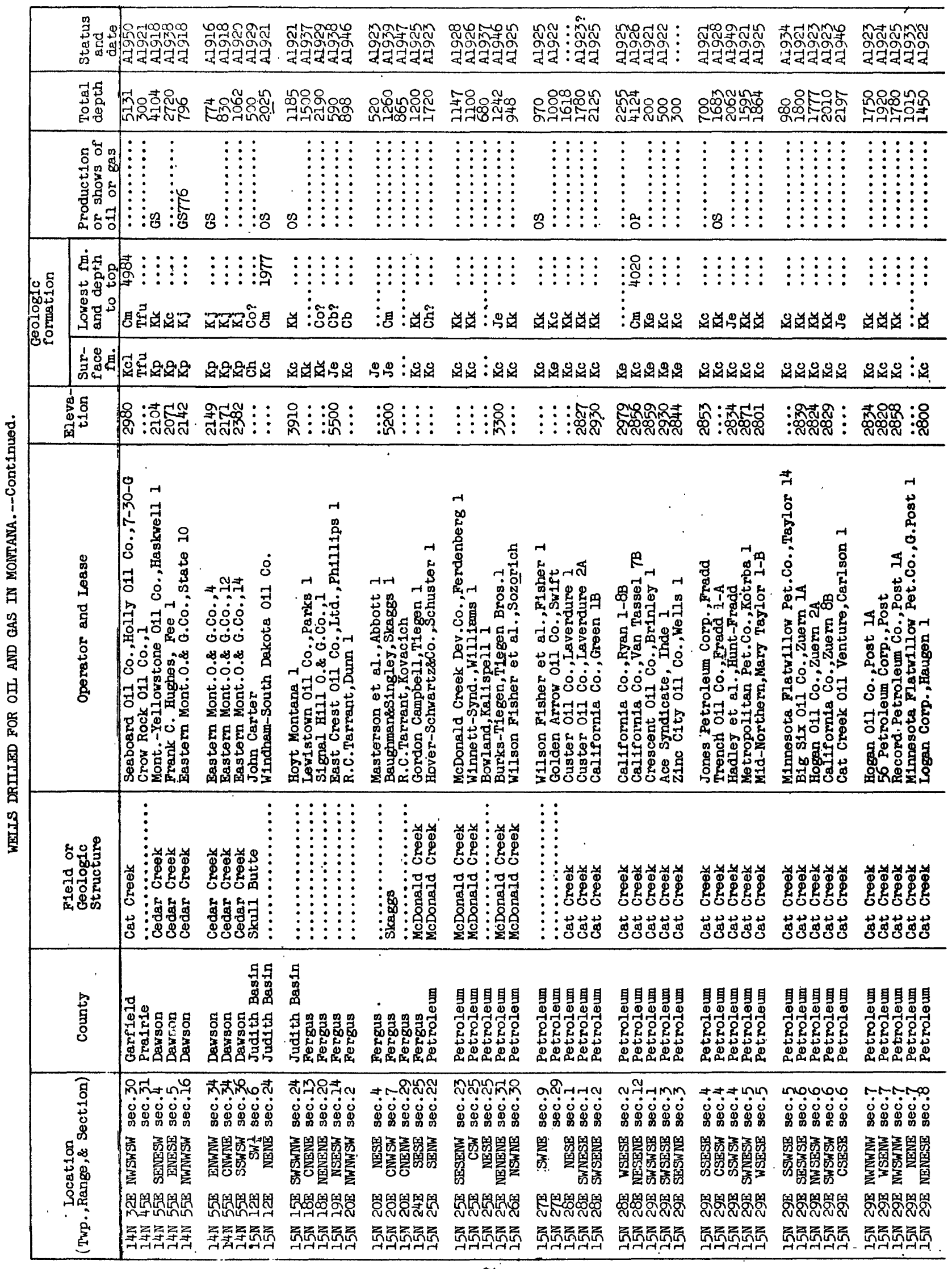




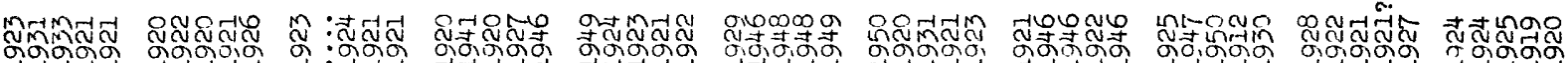

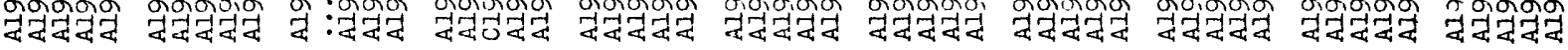

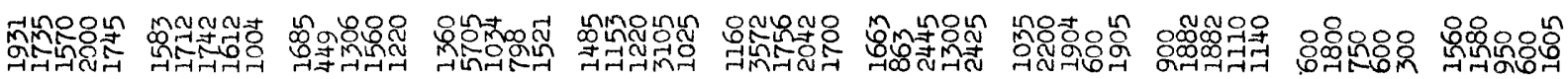

$:::::: \quad:: \quad::: \vdots: \vdots$

ø

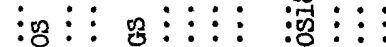

a

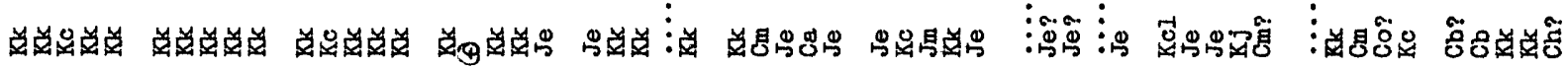

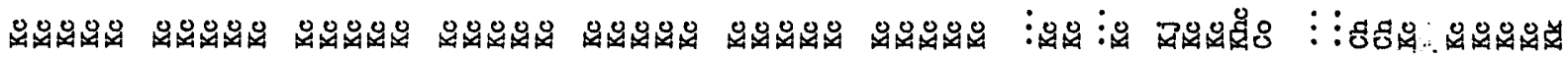

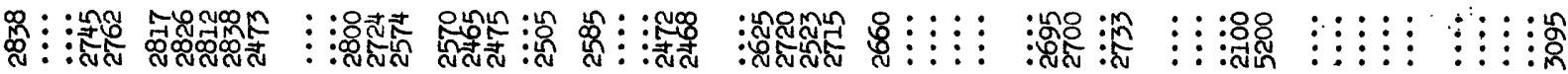

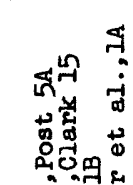

ㄷํㅇ영

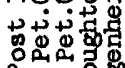

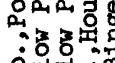

\&नت

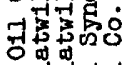

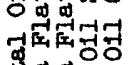

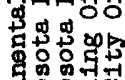

牙卷它

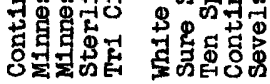

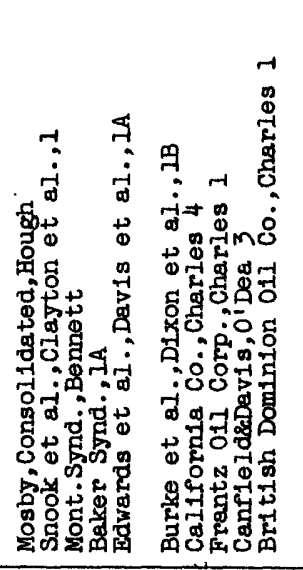

\begin{abstract}
(1)
\end{abstract}

(1)

(1)




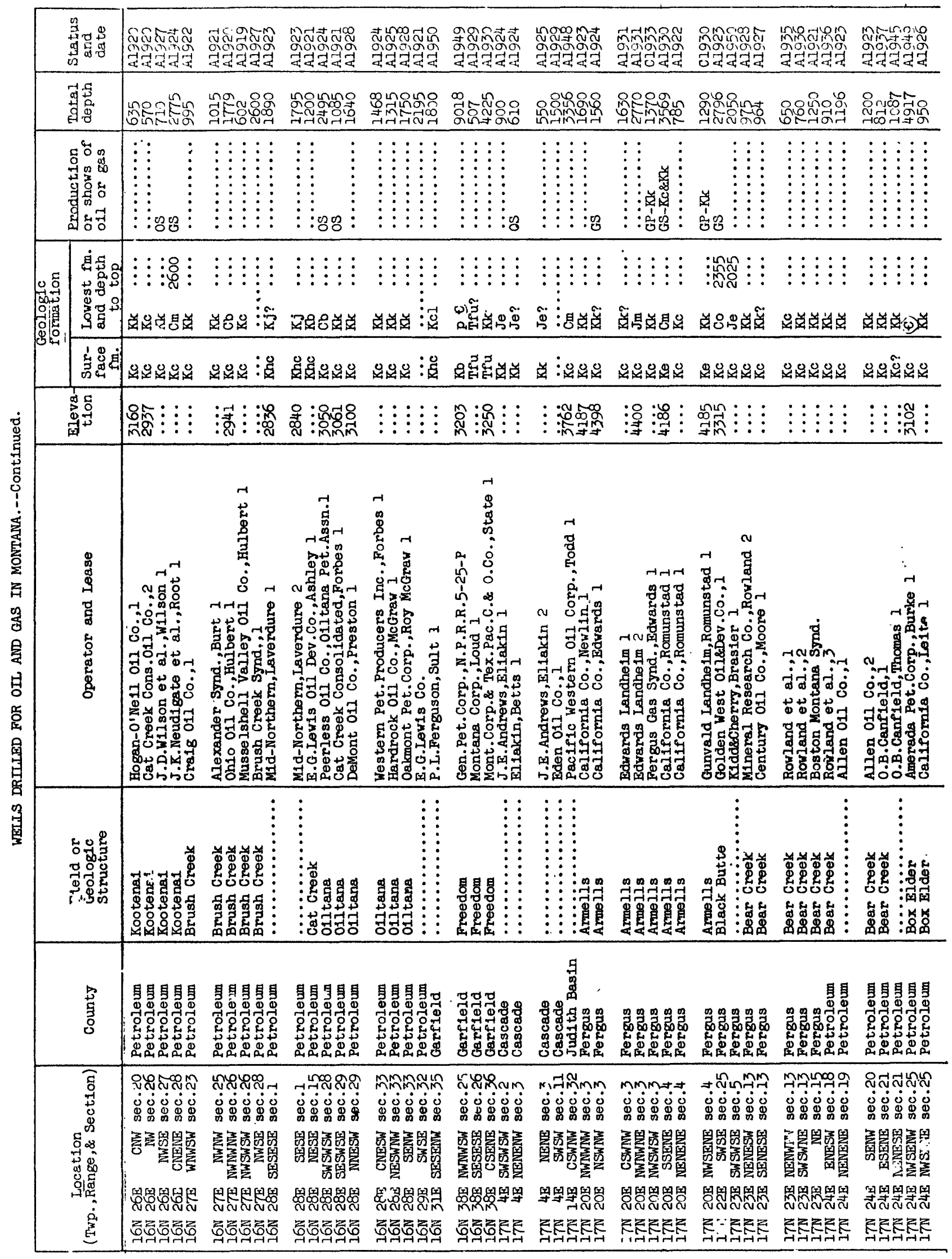




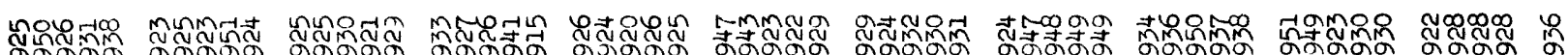

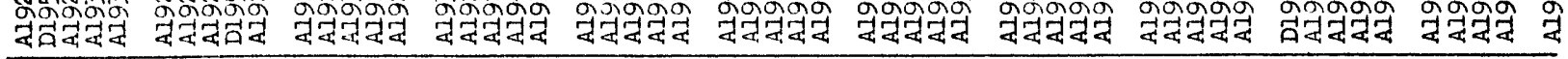

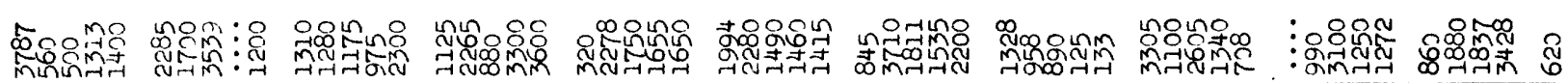

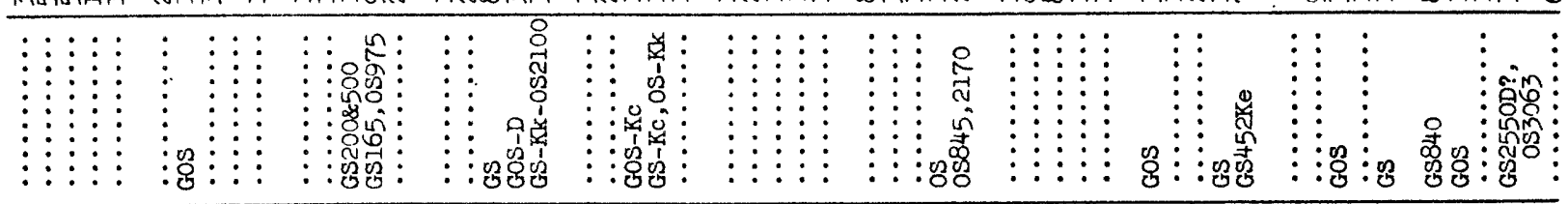

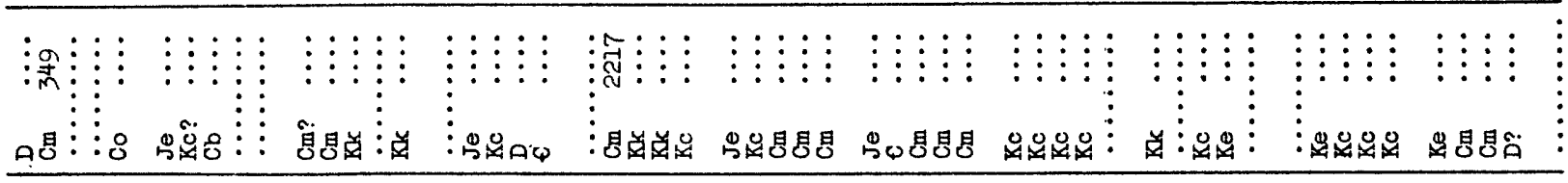

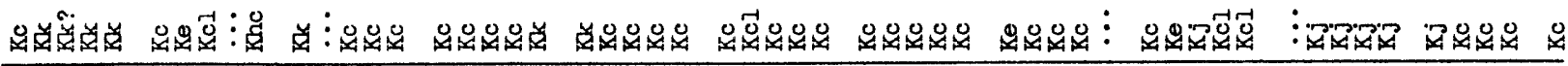

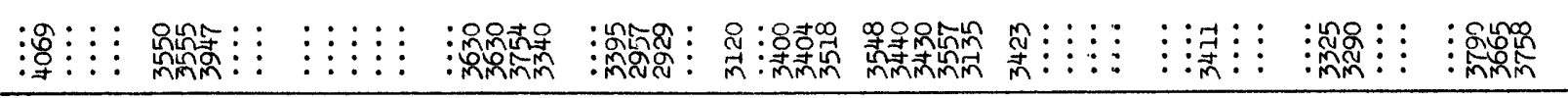

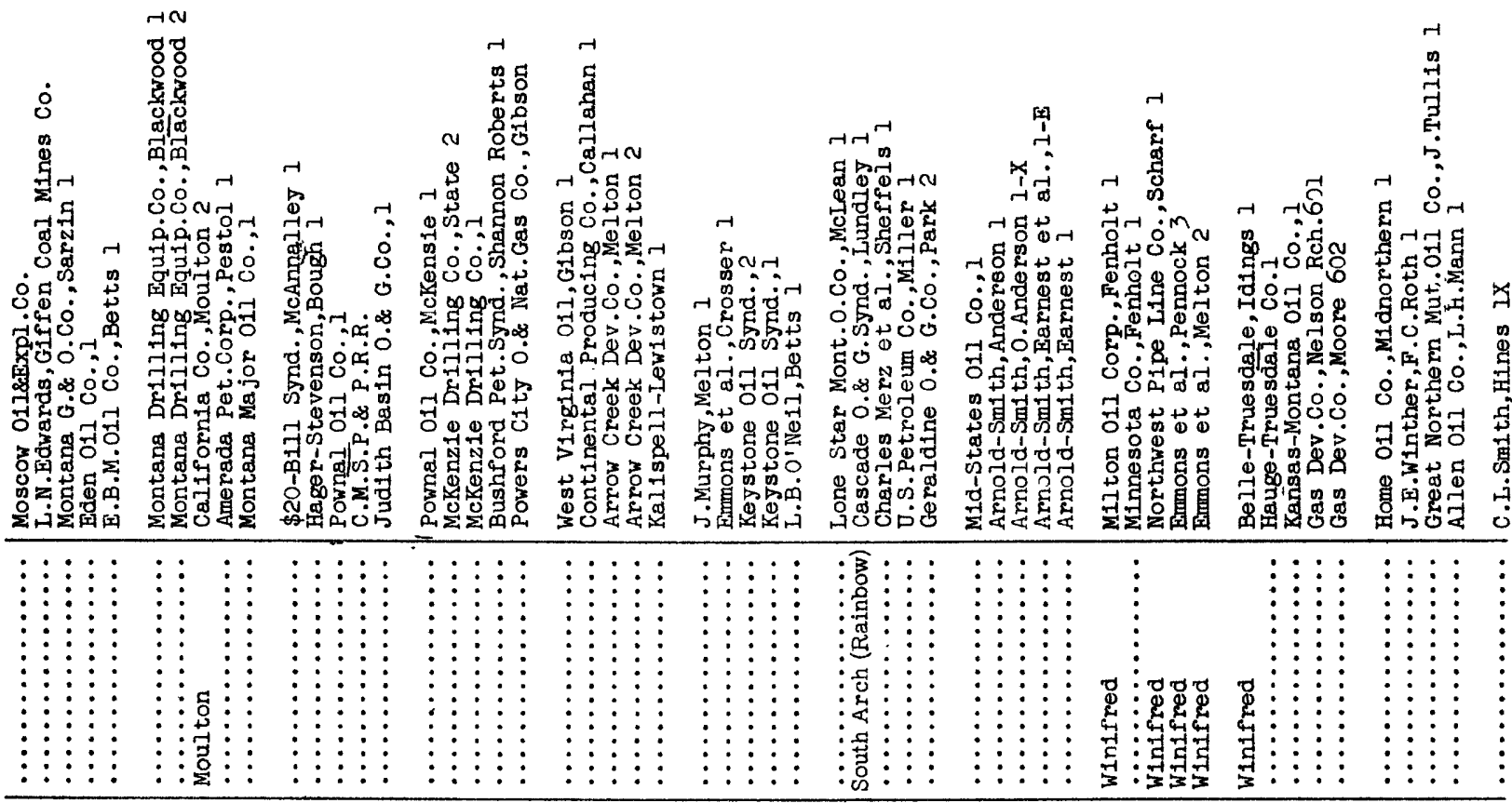

\begin{tabular}{|c|c|c|c|c|c|c|c|c|c|c|}
\hline 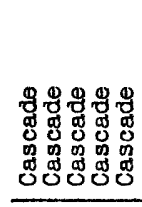 & 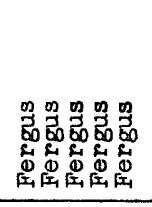 & 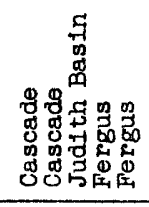 & 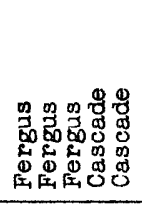 & 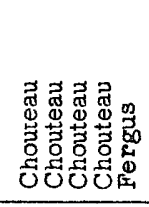 & 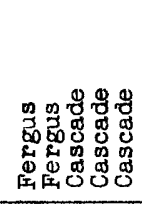 & 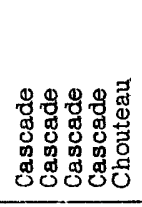 & 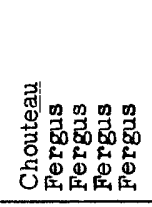 & 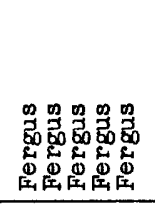 & 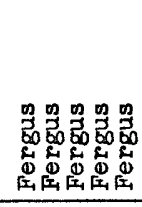 & 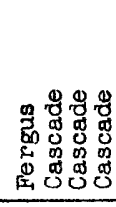 \\
\hline 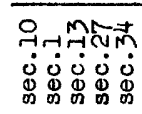 & 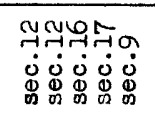 & 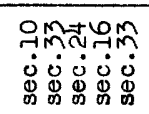 & & 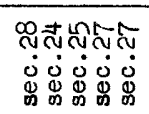 & & 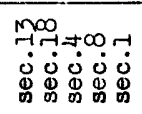 & & & & \\
\hline 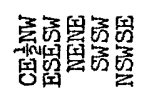 & 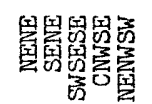 & 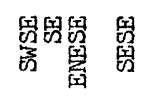 & 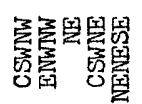 & 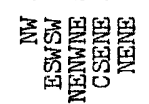 & 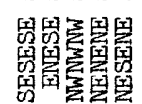 & 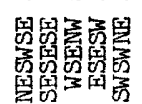 & 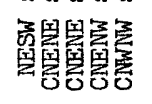 & 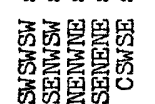 & 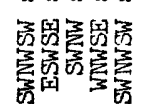 & 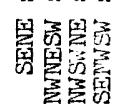 \\
\hline 国舁等舁舁 & 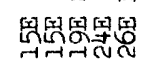 & 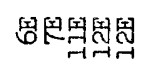 & 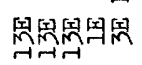 & 国国鱼国国 & 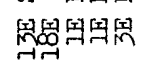 & 国国學菣国 & 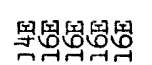 & 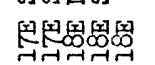 & 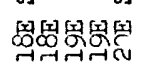 & 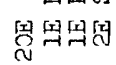 \\
\hline క్యేర్య & 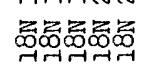 & 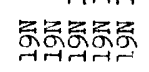 & 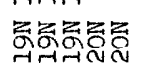 & ํํํํํํํํํำ & 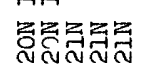 & 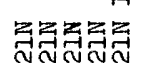 & สู่สี่ส & สื่สูสสุส & สูงสำส & สำสำ \\
\hline
\end{tabular}




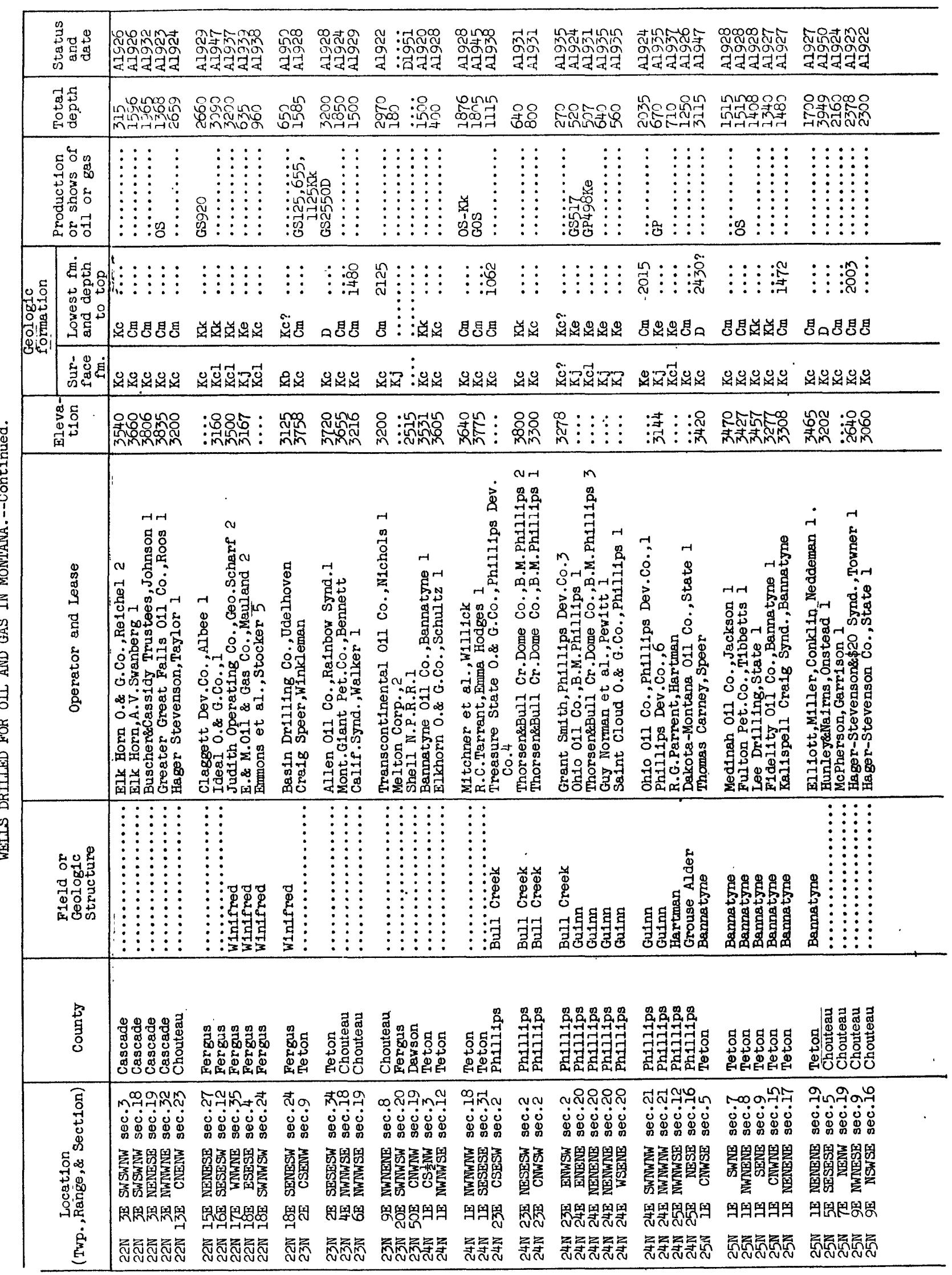




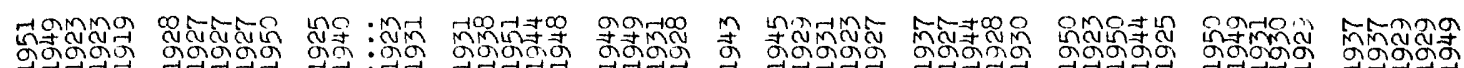

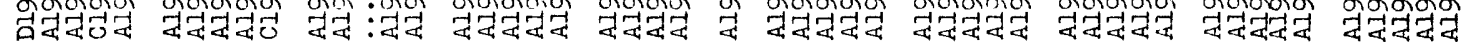

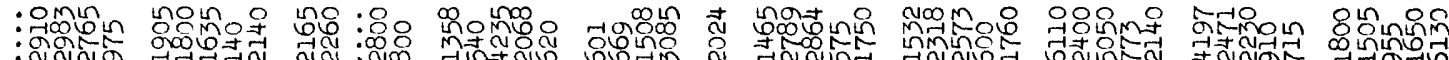

: WNen minta तN :

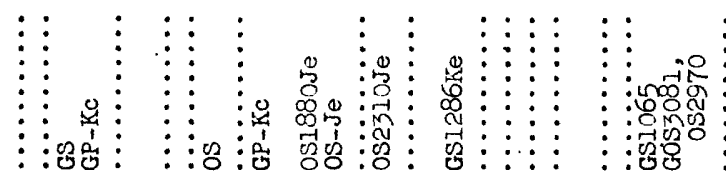

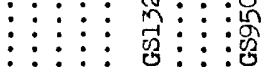

$\vdots::$ :

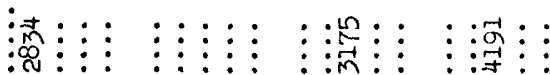

秝递

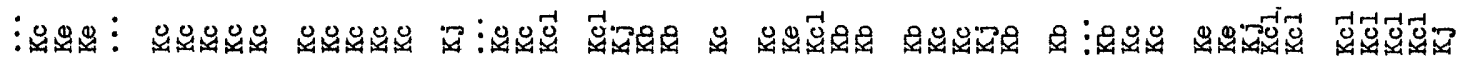

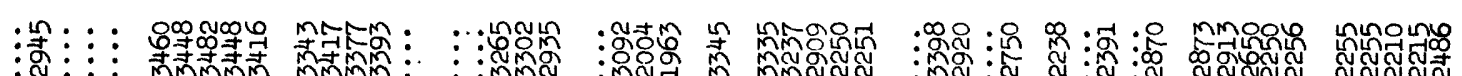

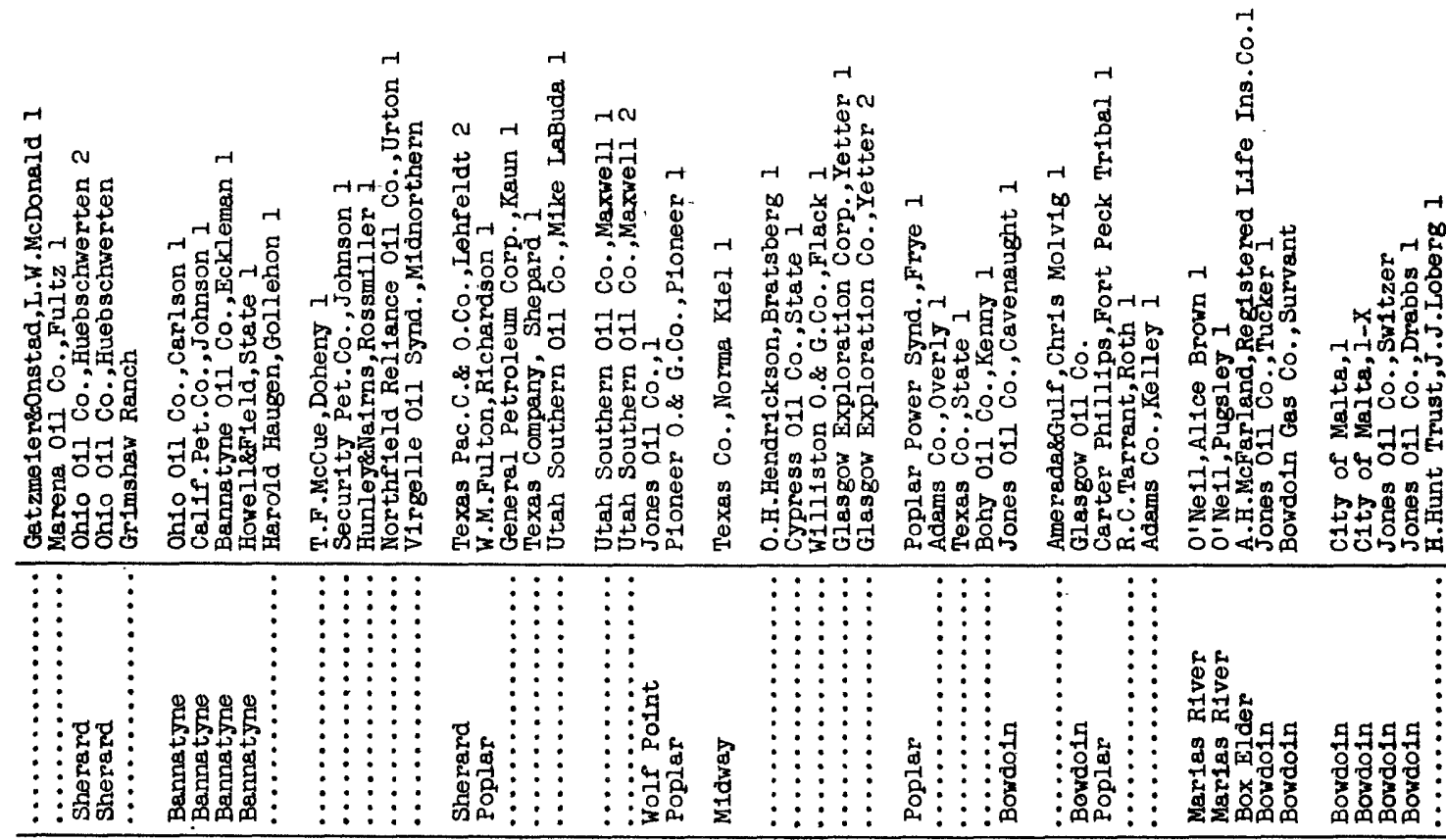

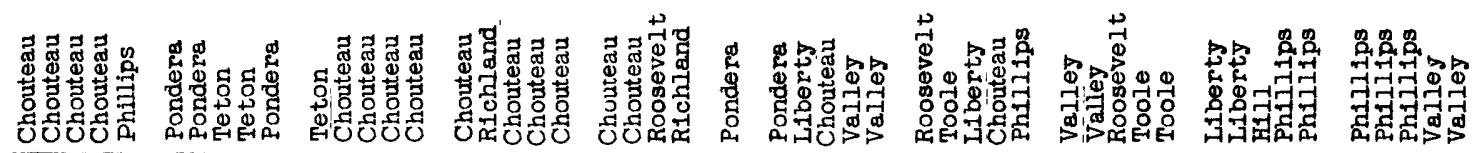

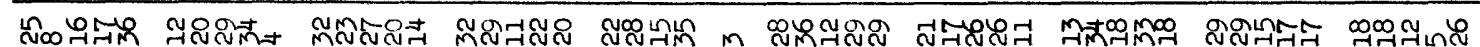

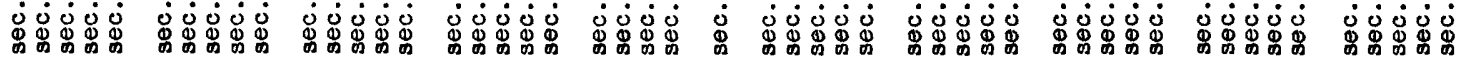

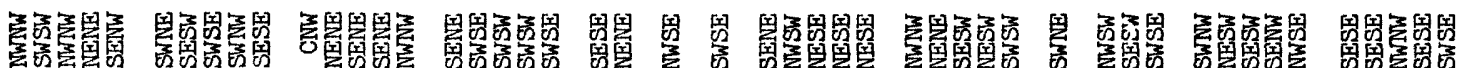

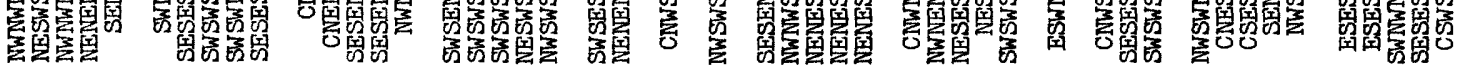

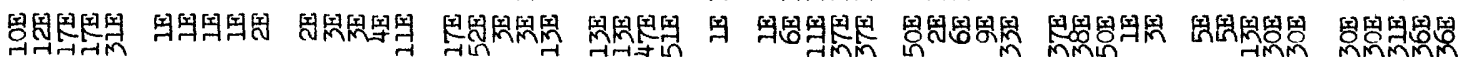

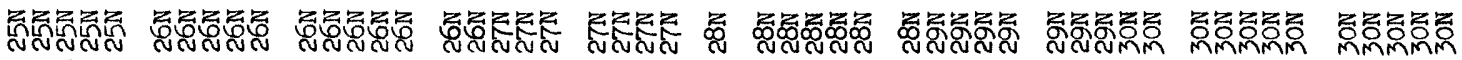




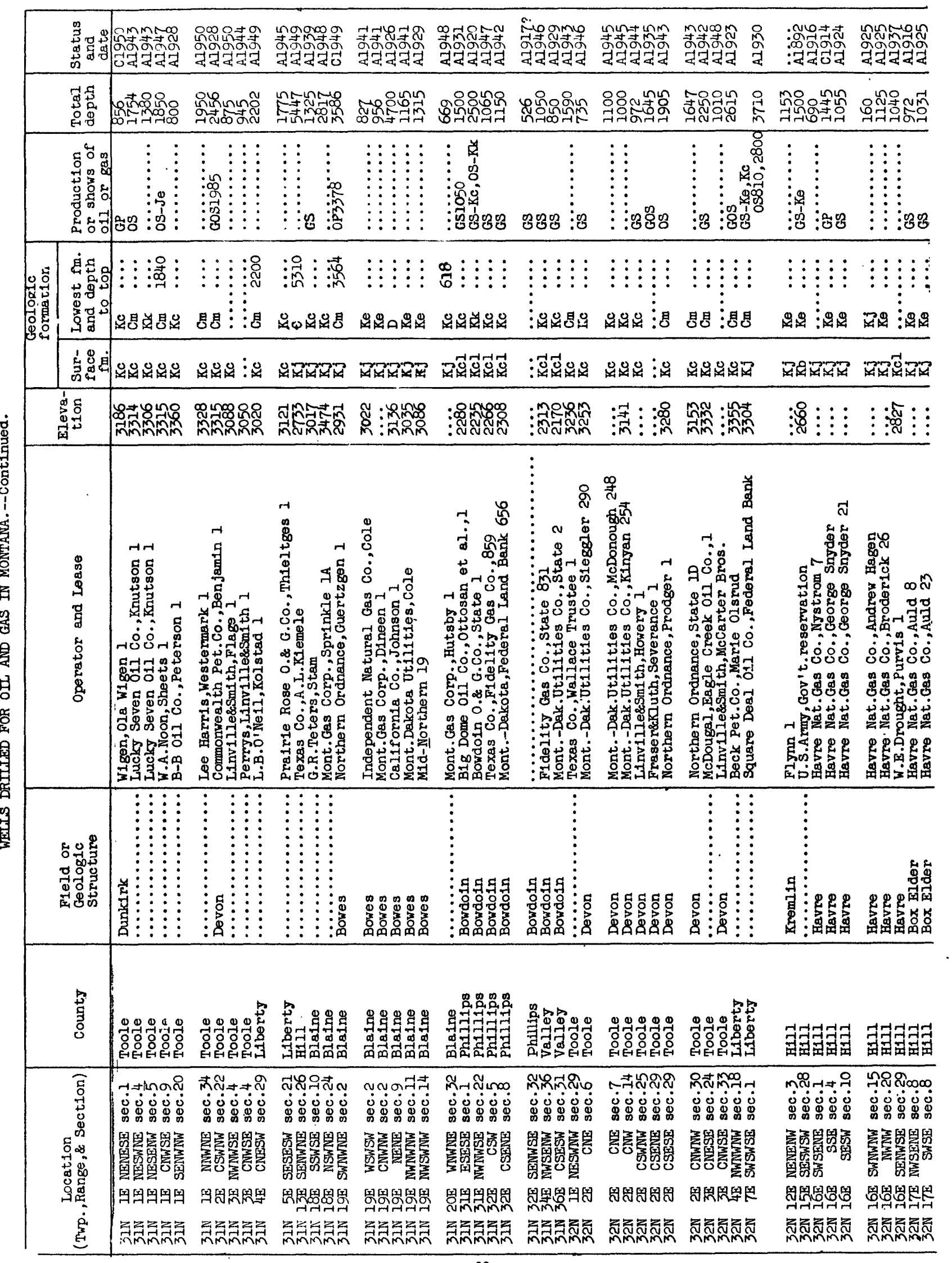




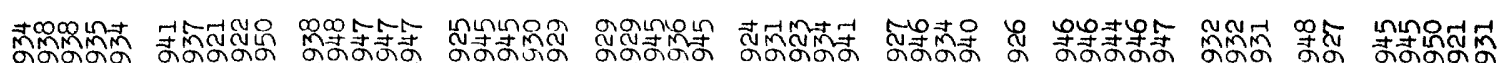

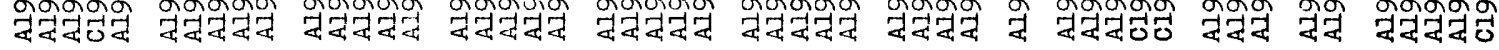

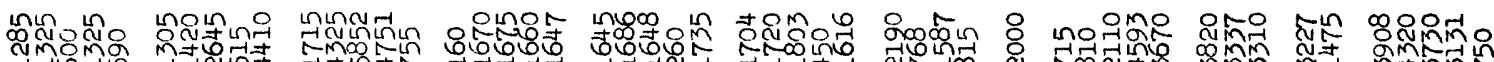

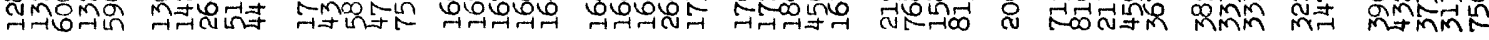

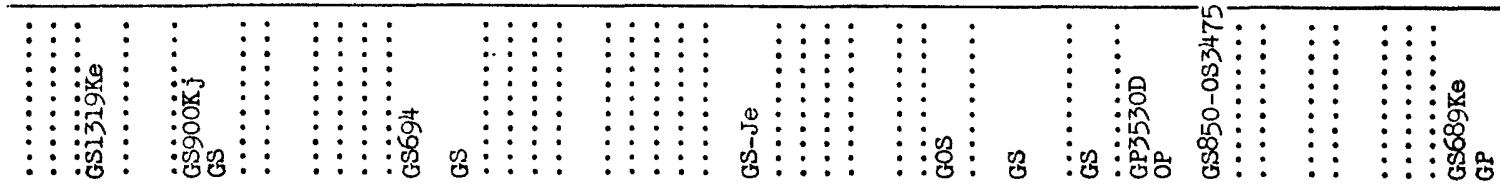

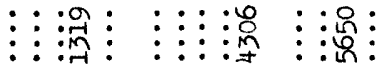

و舟氙

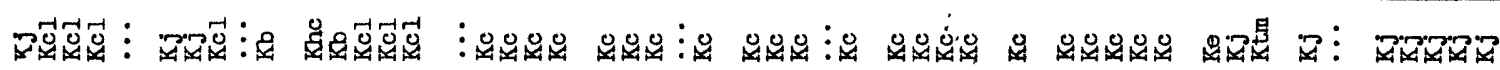

궁유 :

\begin{tabular}{|c|c|c|c|c|c|c|c|c|c|c|}
\hline 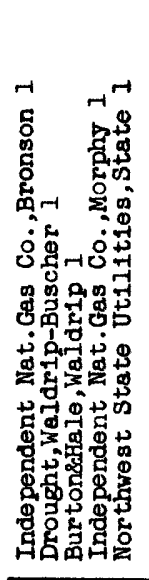 & 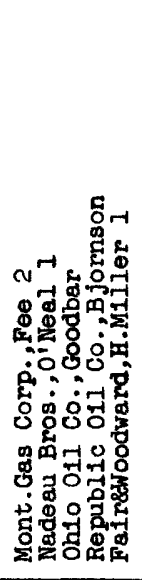 & 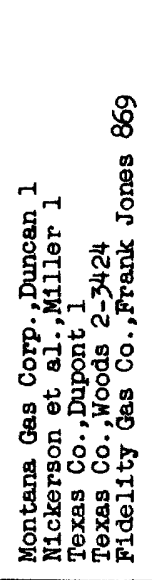 & 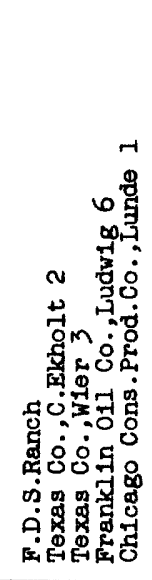 & 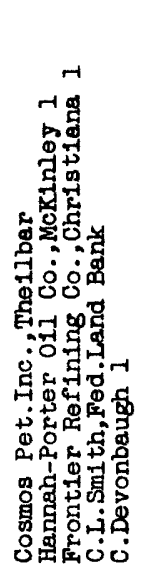 & 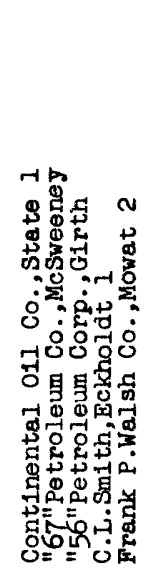 & 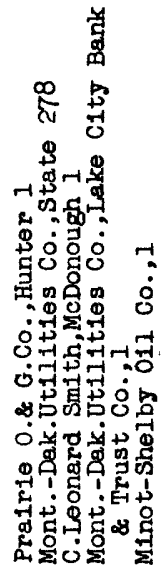 & 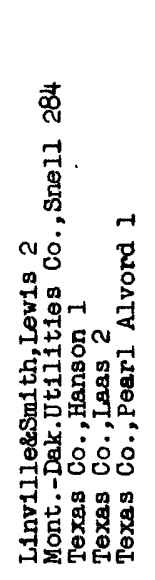 & 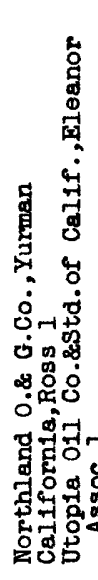 & 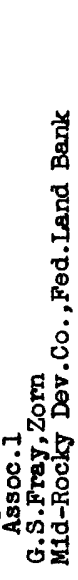 & 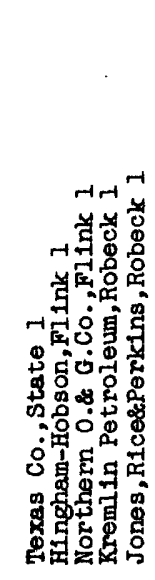 \\
\hline 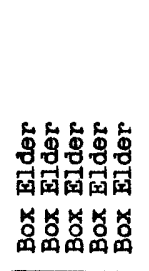 & 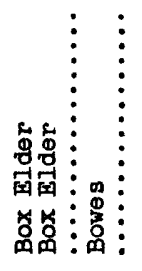 & $\begin{array}{l}\vdots \\
\vdots \\
\vdots \\
\vdots \\
\vdots:\end{array}$ & & & $\begin{array}{c}\vdots \\
\vdots \vdots \\
\vdots \\
\vdots \\
\vdots \\
\vdots\end{array}$ & 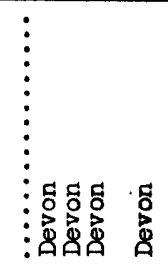 & 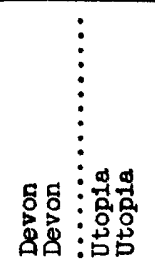 & 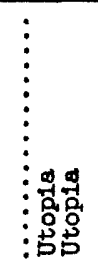 & 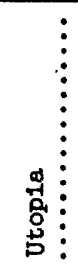 & $\begin{array}{c}: \\
\vdots \\
\vdots \\
\vdots \\
\vdots \\
\vdots\end{array}$ \\
\hline
\end{tabular}

\begin{tabular}{|c|c|c|c|c|c|c|c|c|c|c|c|}
\hline 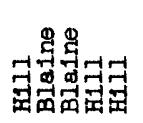 & 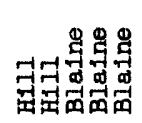 & 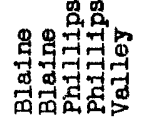 & 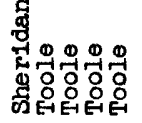 & 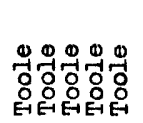 & 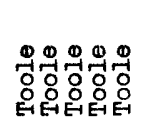 & 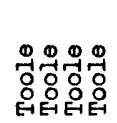 & : & 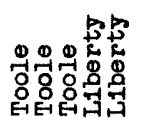 & 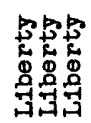 & 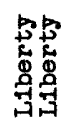 & 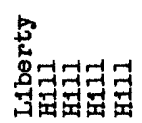 \\
\hline 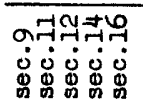 & 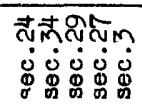 & 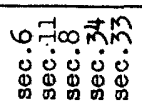 & 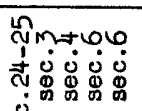 & 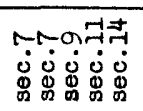 & 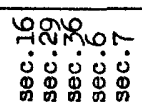 & 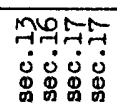 & 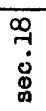 & 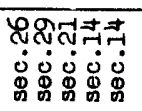 & 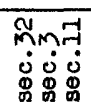 & 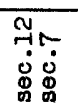 & 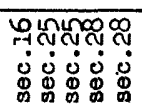 \\
\hline 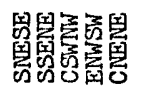 & 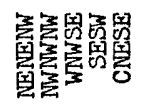 & 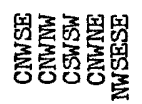 & 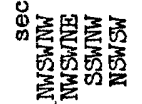 & 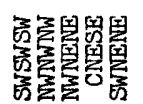 & 鼠鼠翼 & 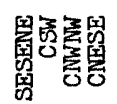 & 国 & 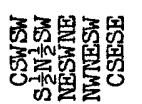 & 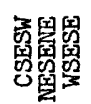 & 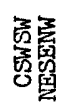 & 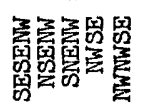 \\
\hline 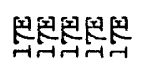 & 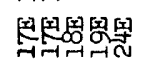 & 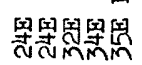 & 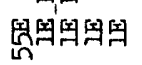 & 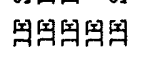 & 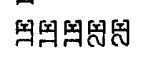 & 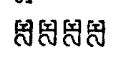 & 因 & 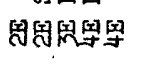 & 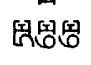 & ⿶ㅓㅇㄹㅣ & 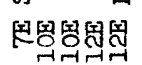 \\
\hline 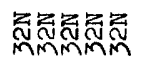 & 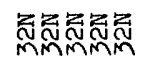 & 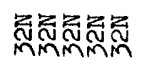 & 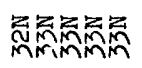 & 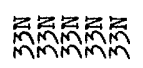 & 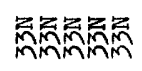 & 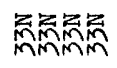 & 昰 & 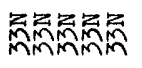 & 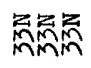 & 确 & 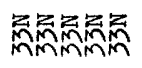 \\
\hline
\end{tabular}




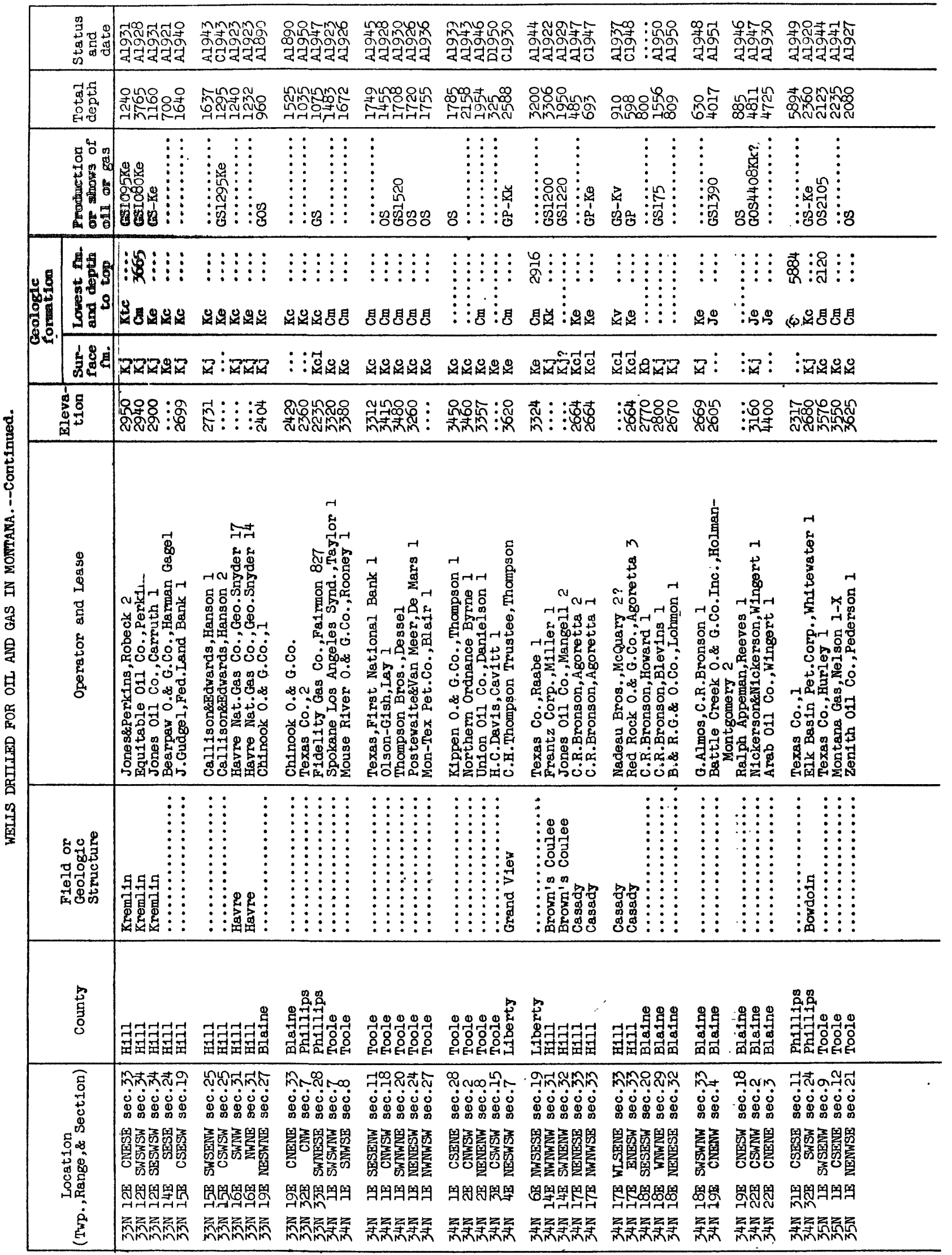




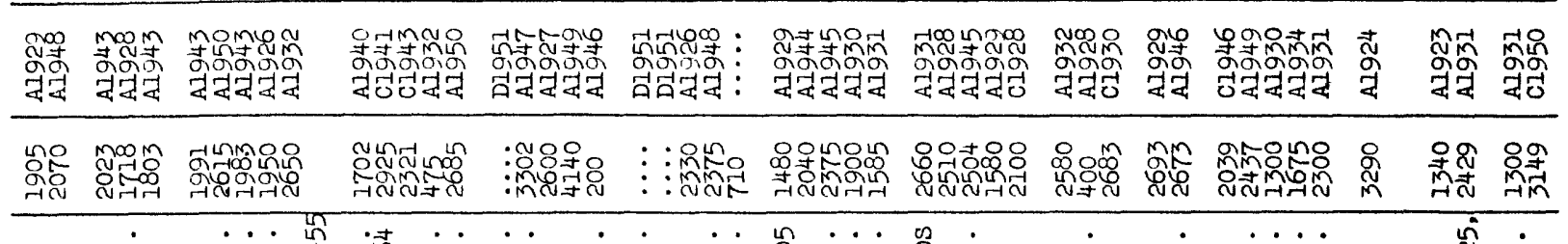

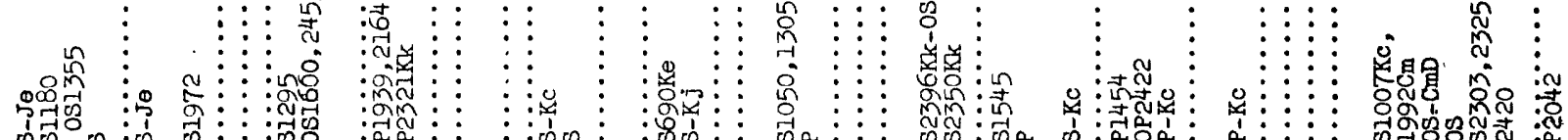

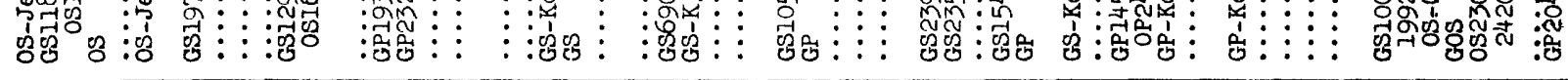

蓣

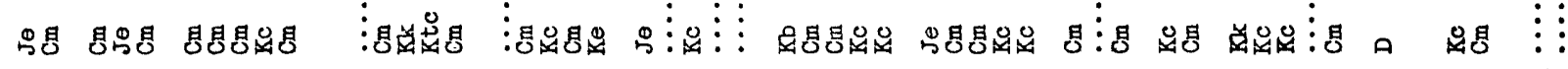

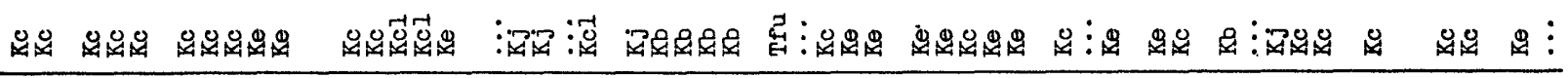

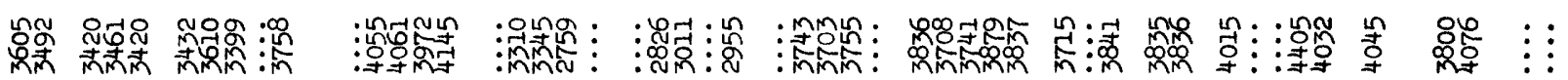

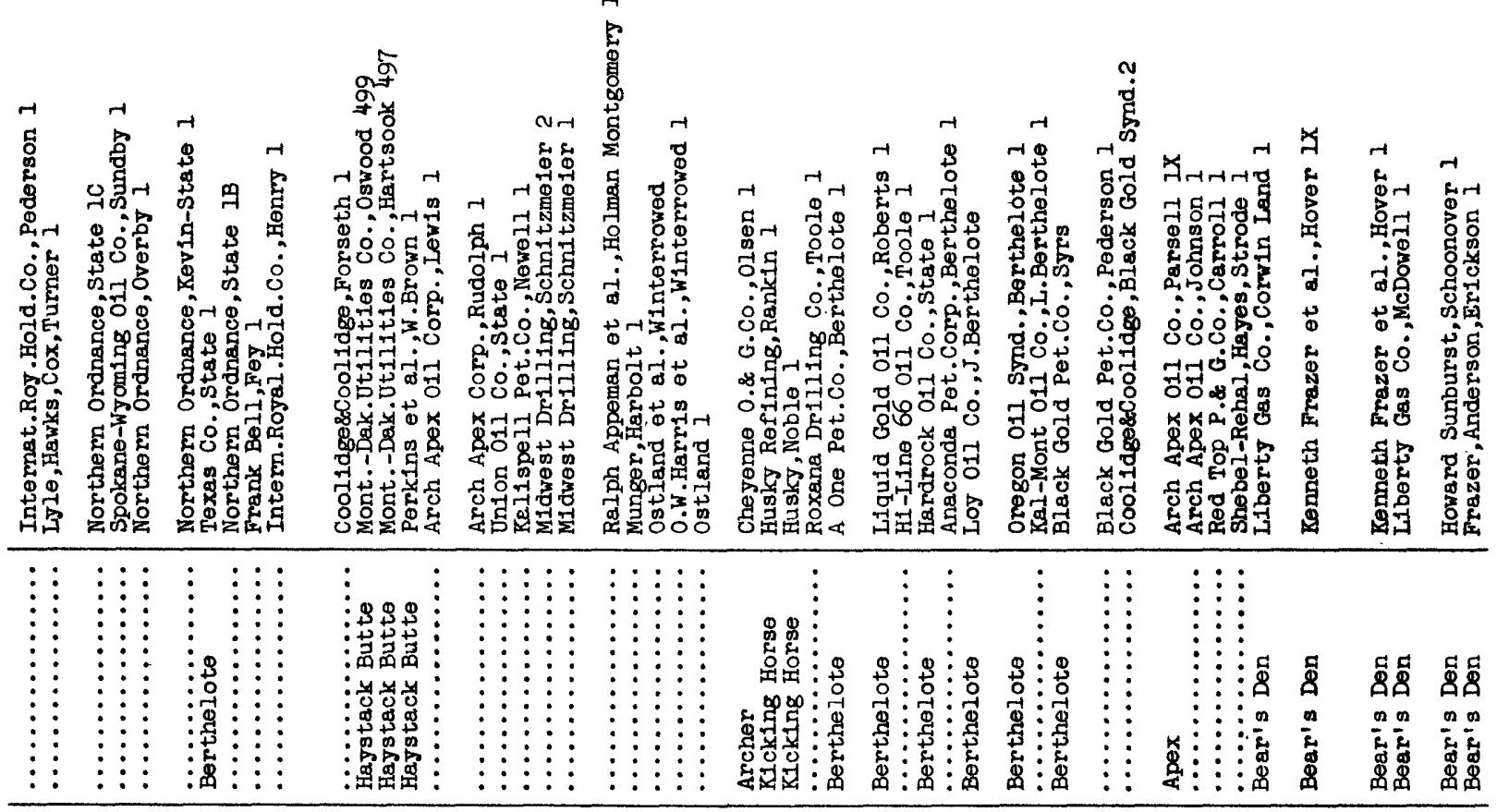

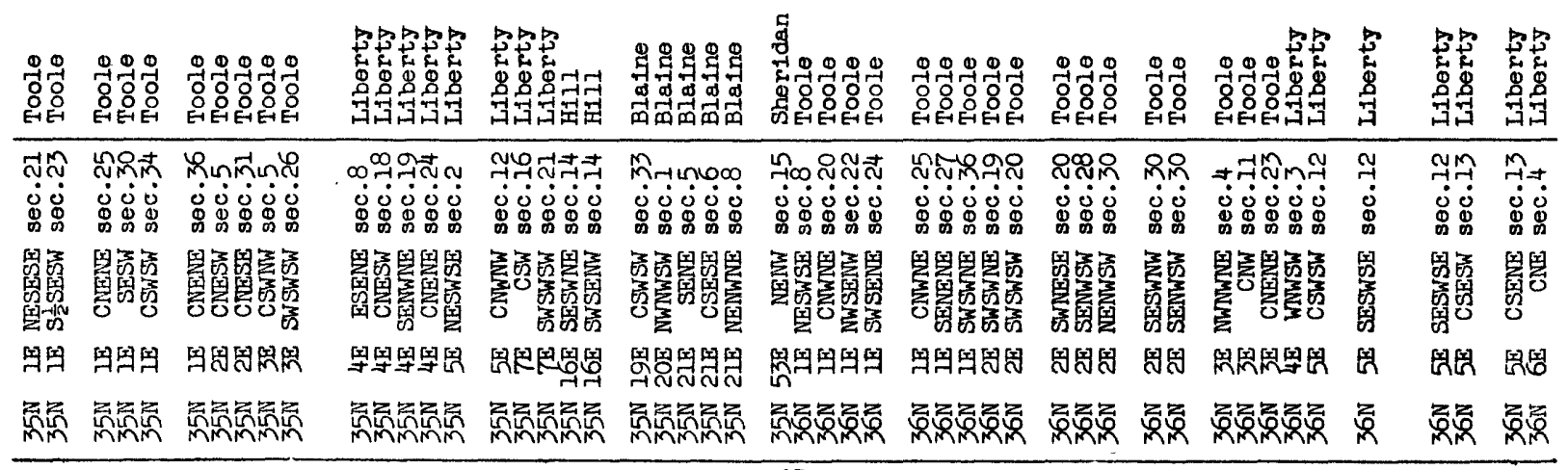




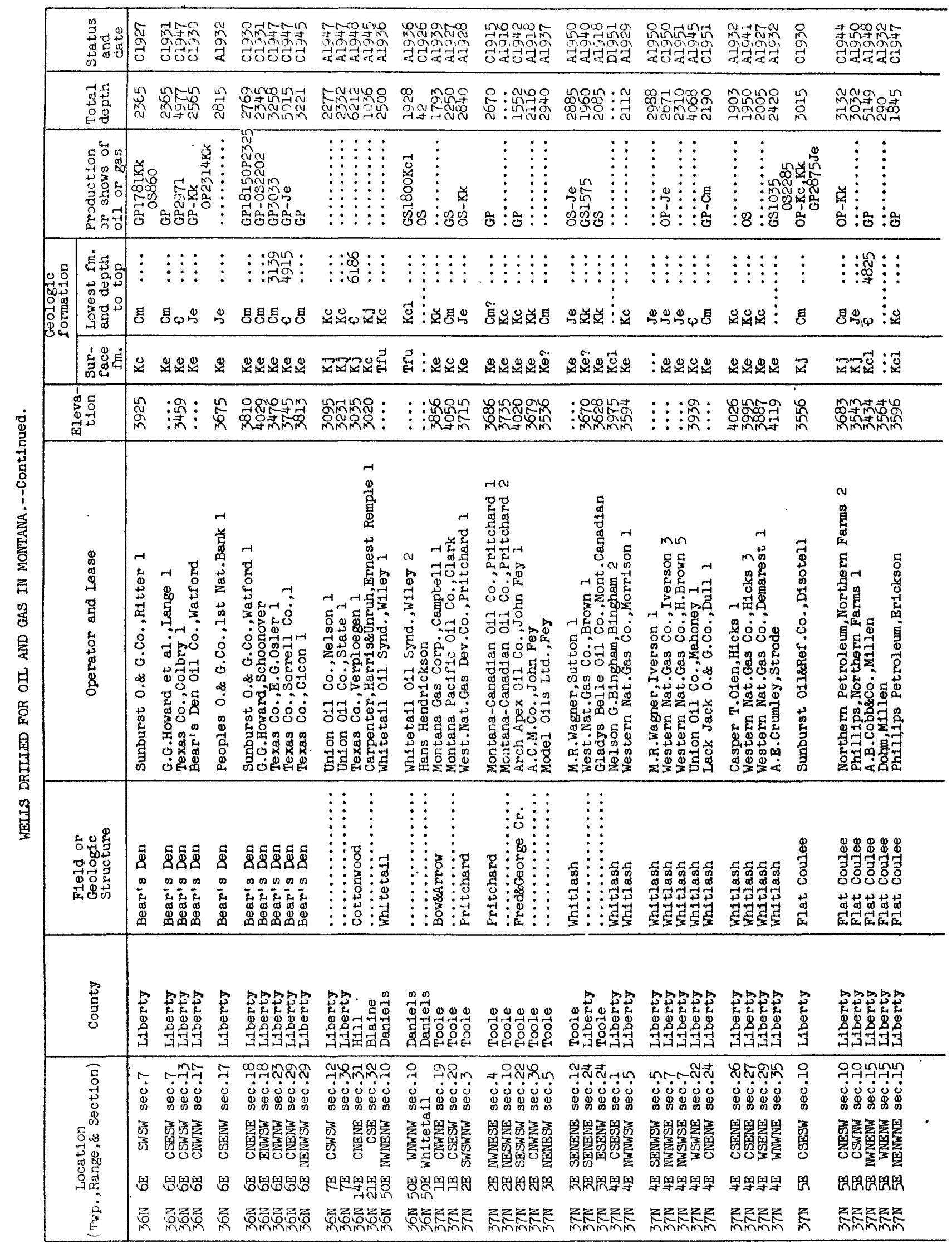




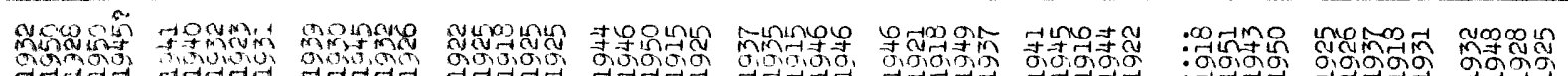

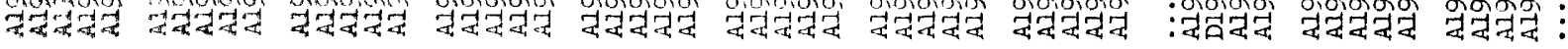

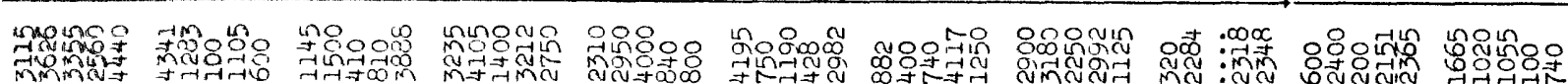

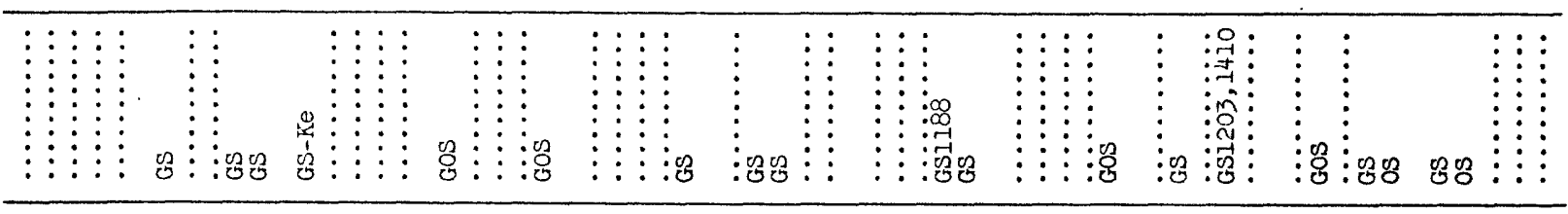

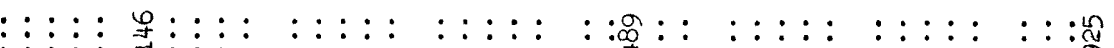

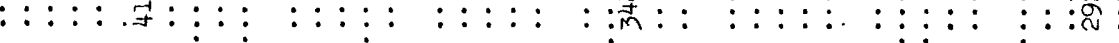

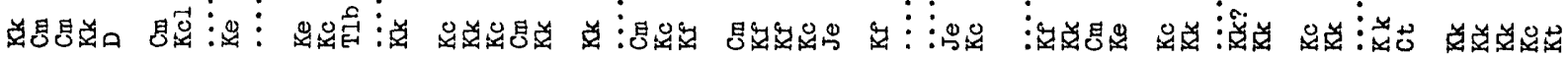

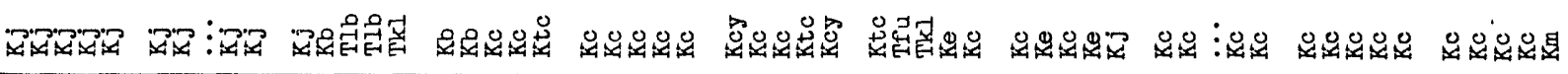

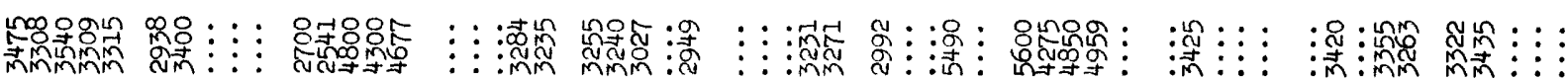

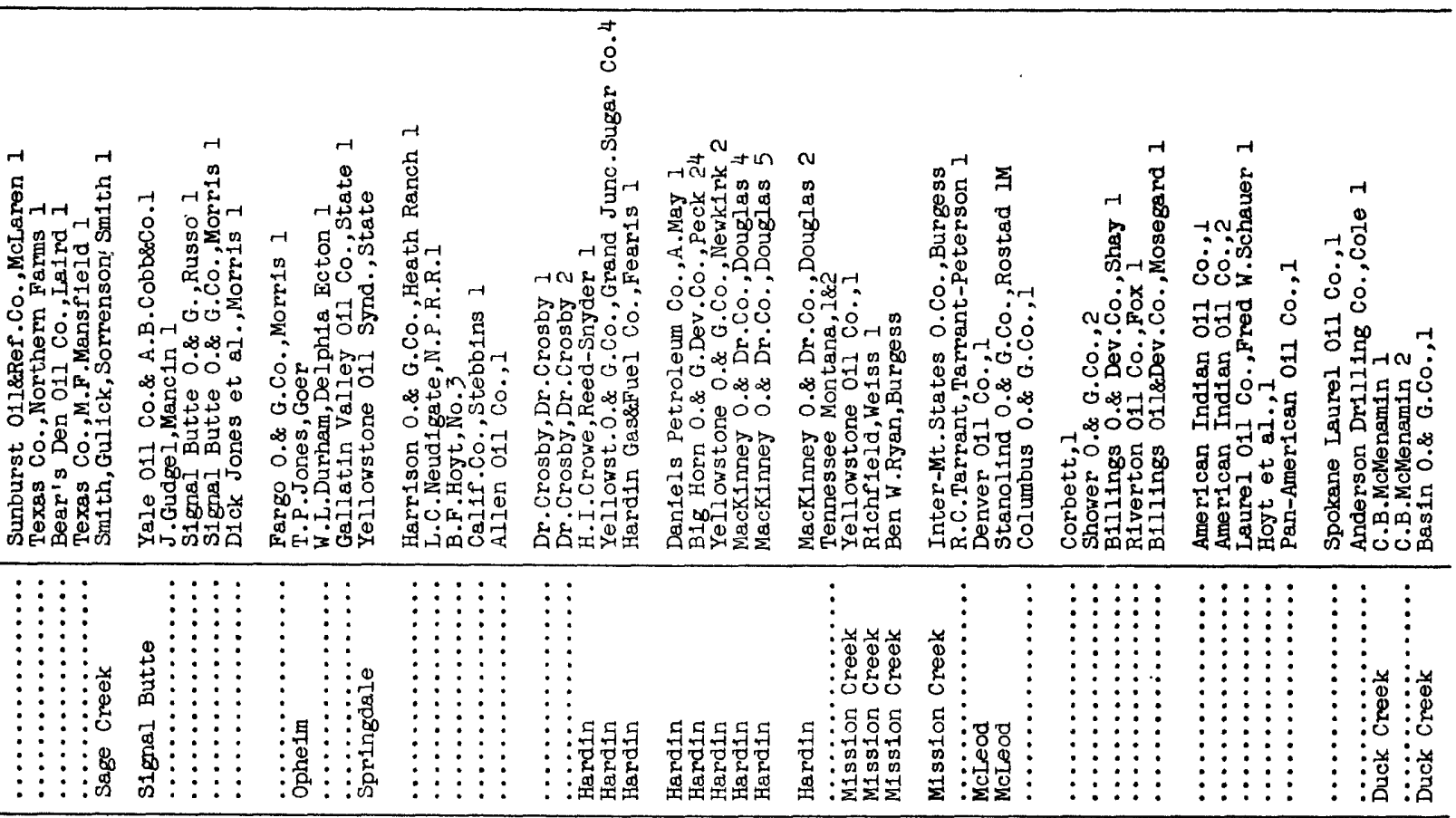

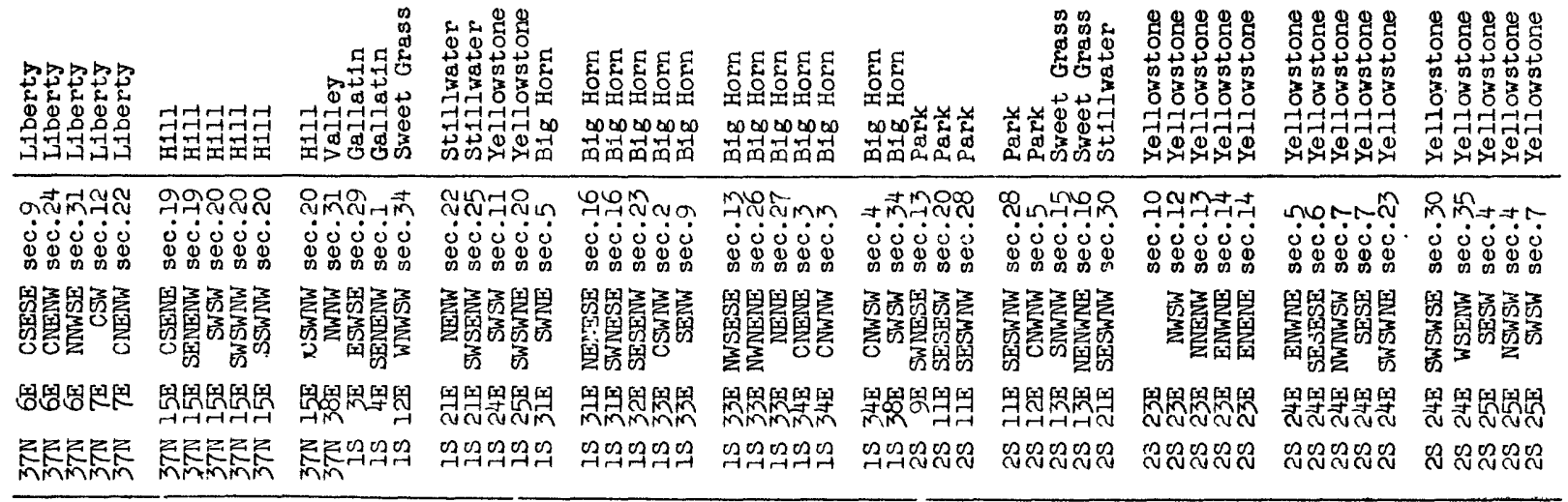




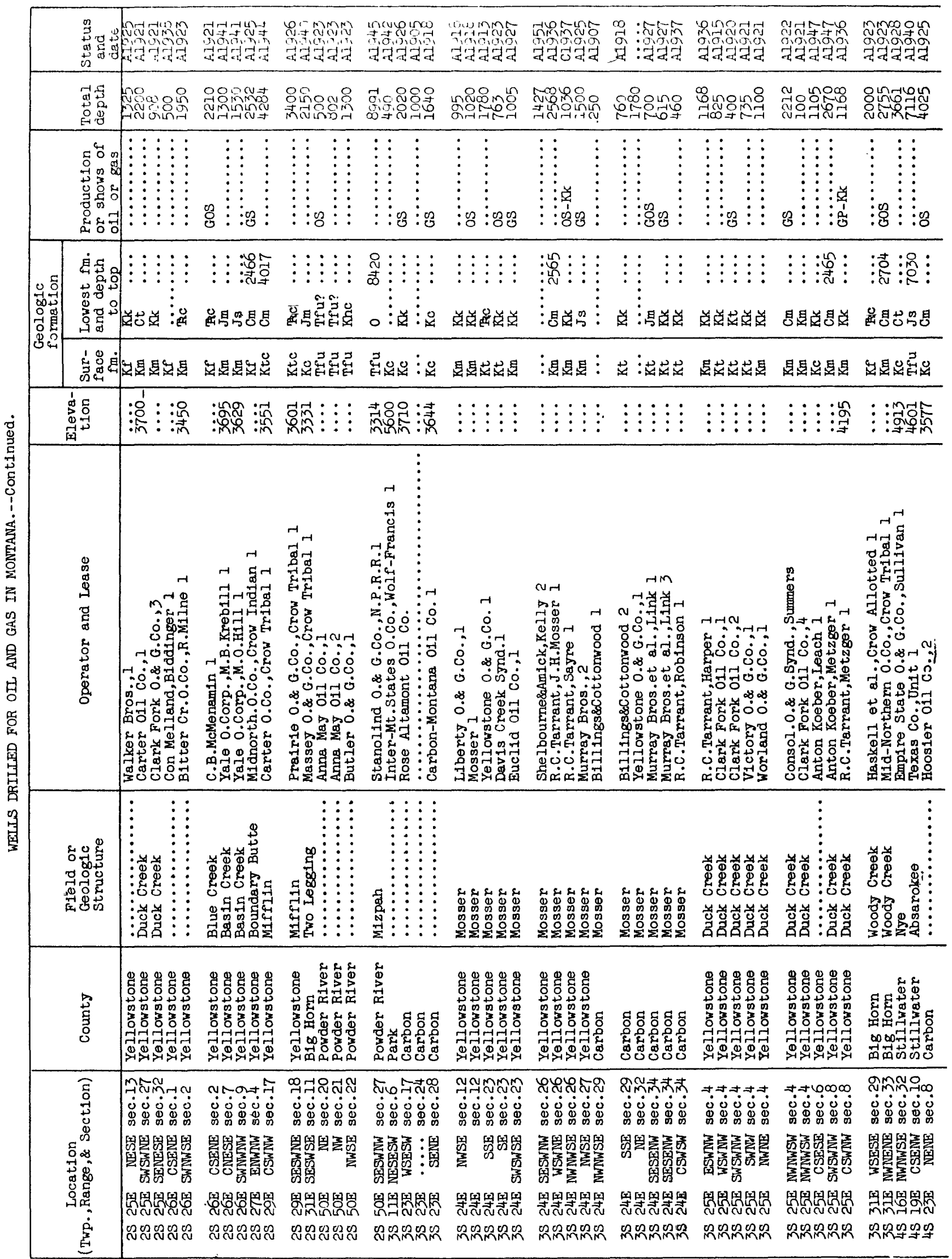




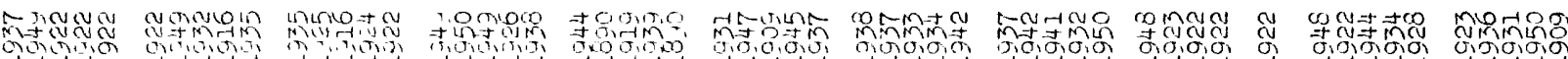

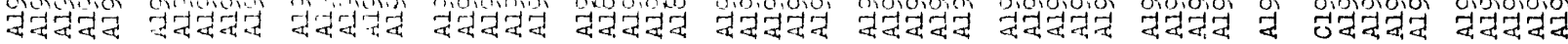

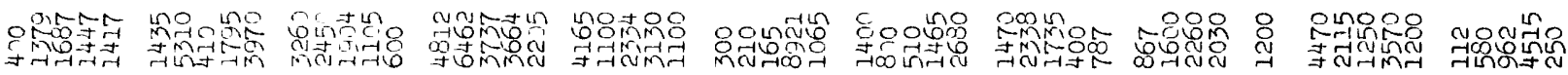
$::$

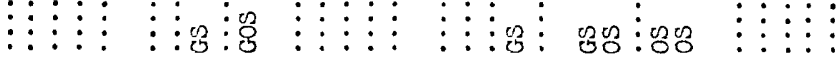

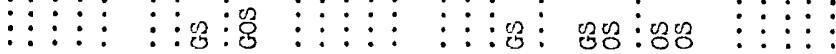

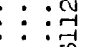

: ::8

号:

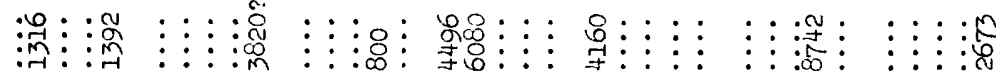

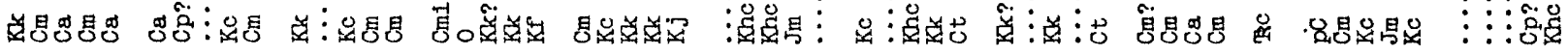

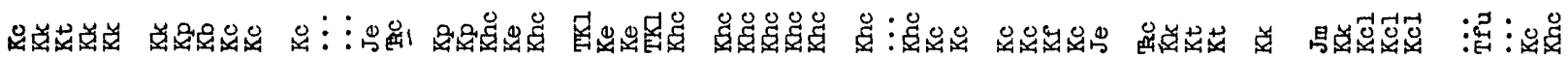

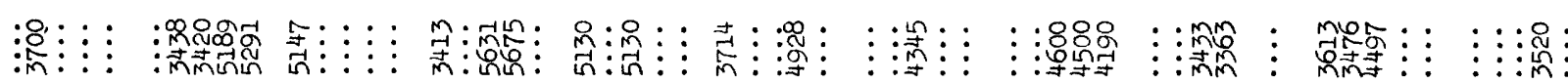

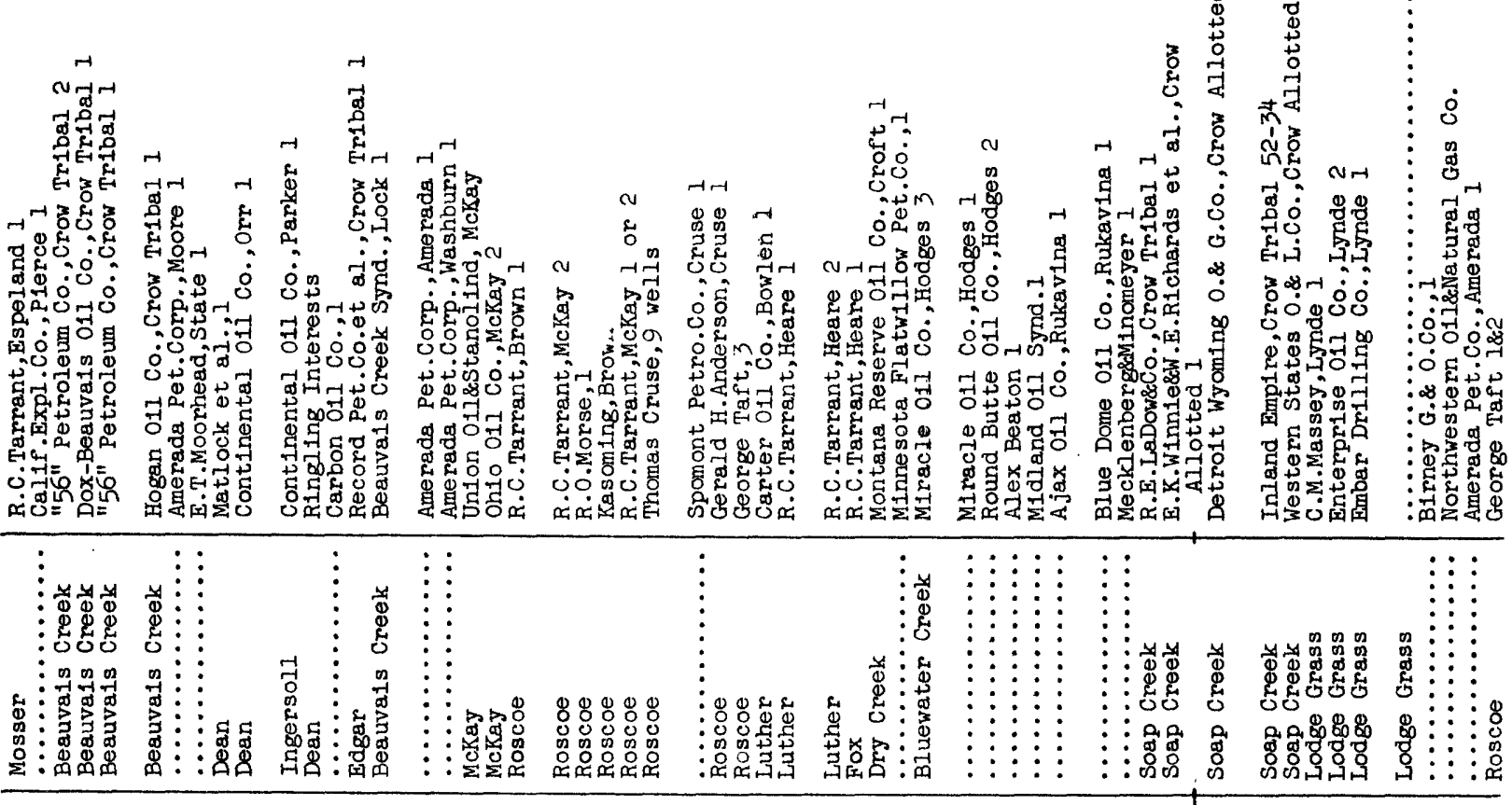

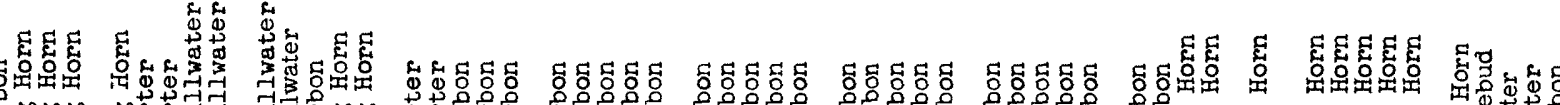

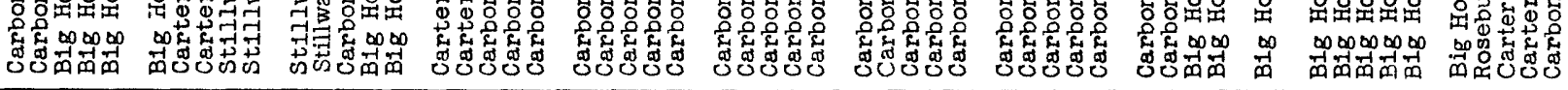

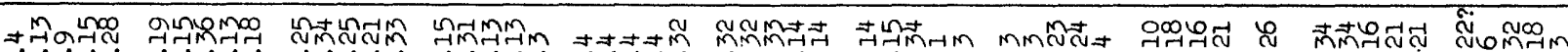

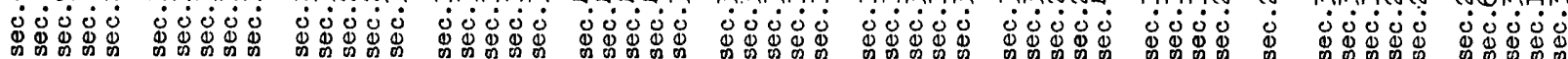

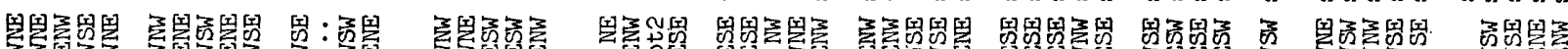

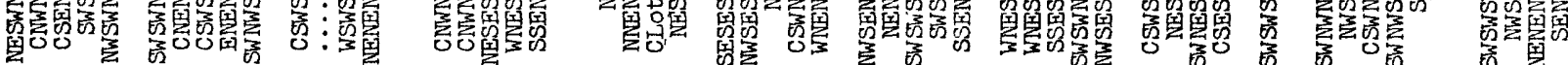

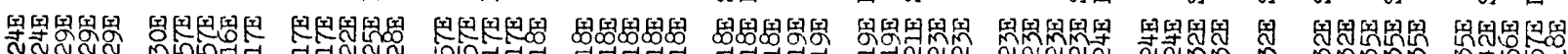

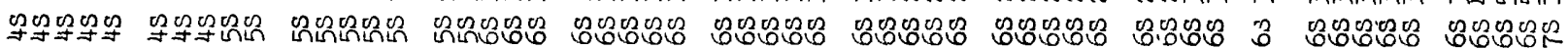




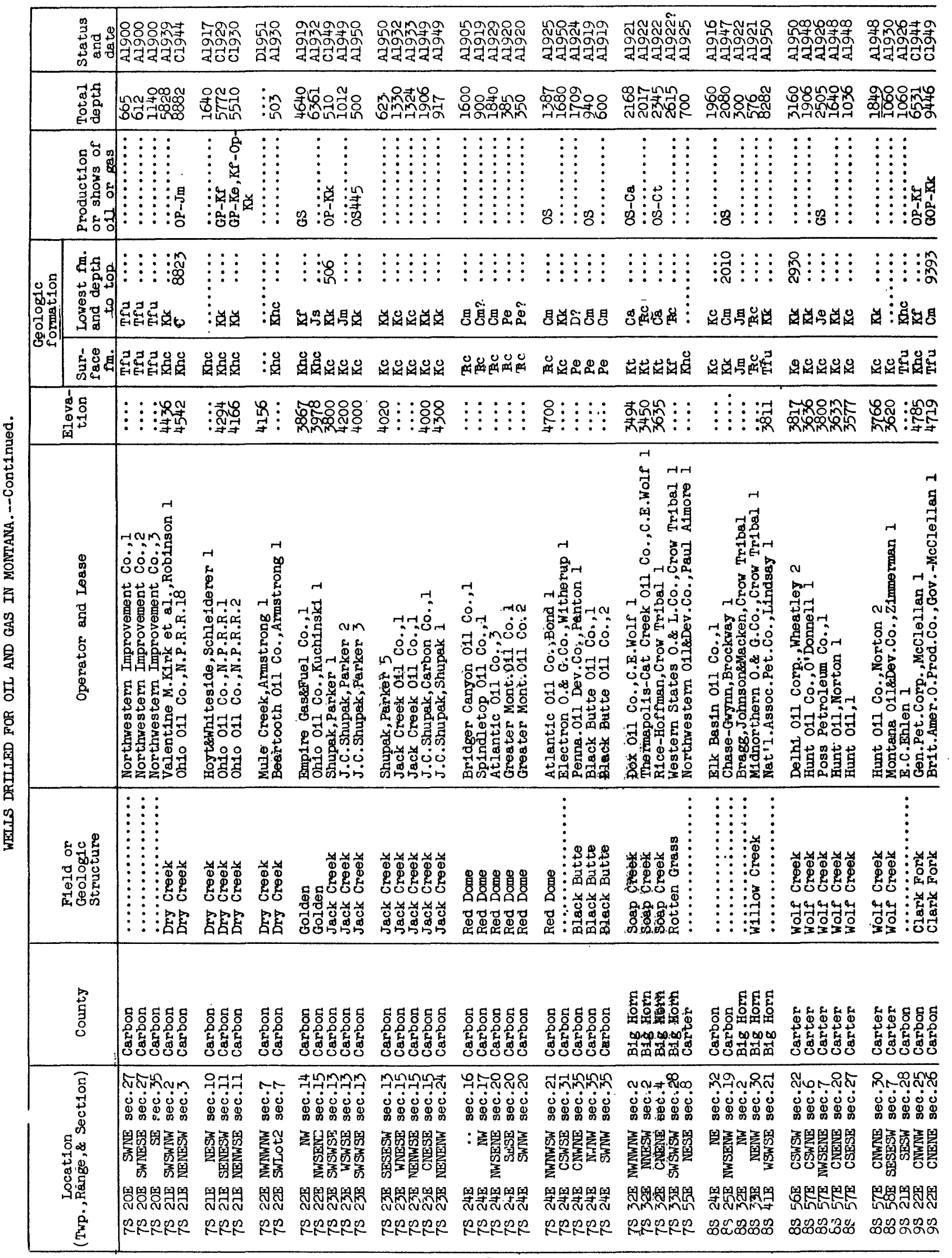




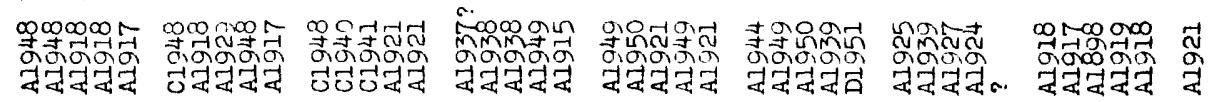

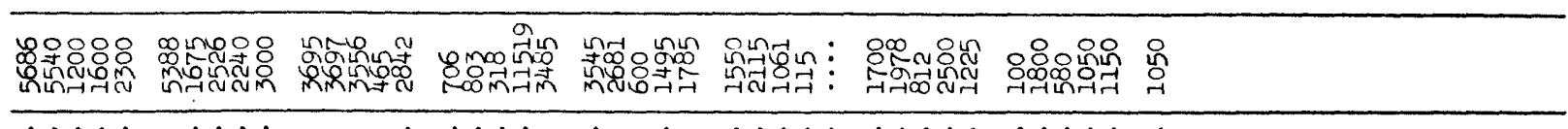

$\vdots: \vdots:$

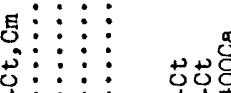

$\vdots: \vdots: \vdots$ :

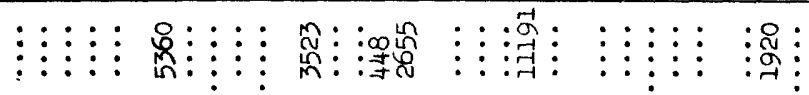

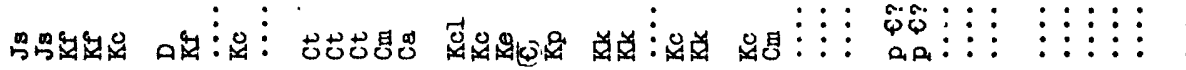

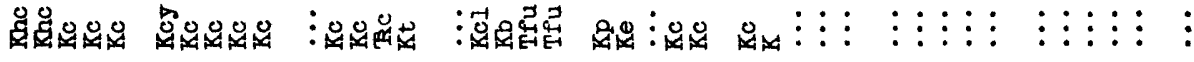

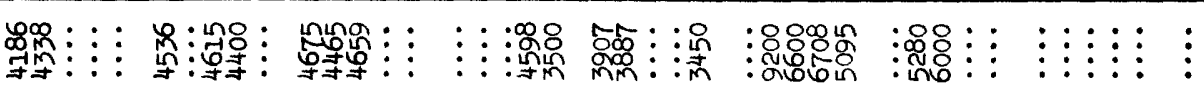

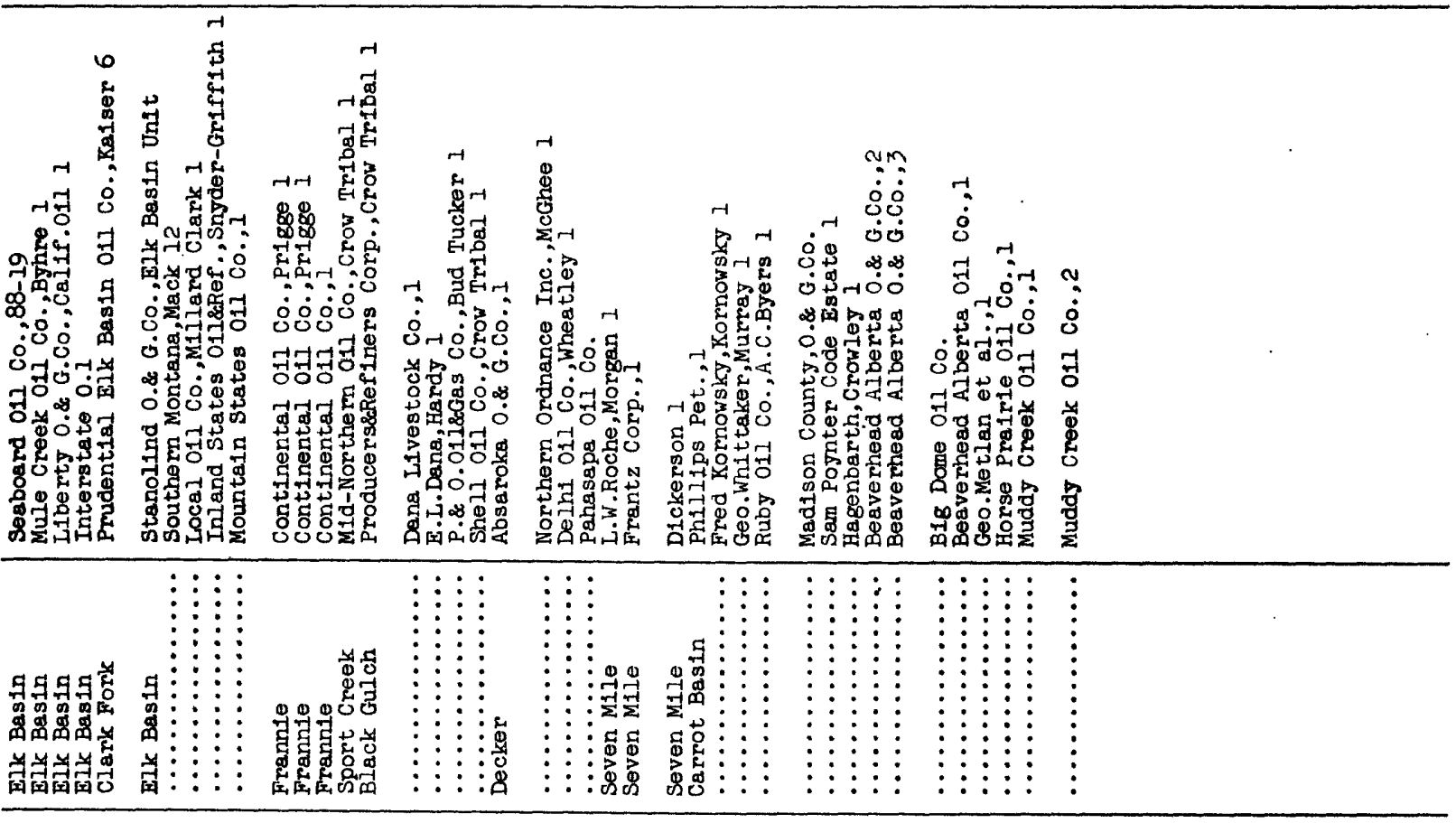

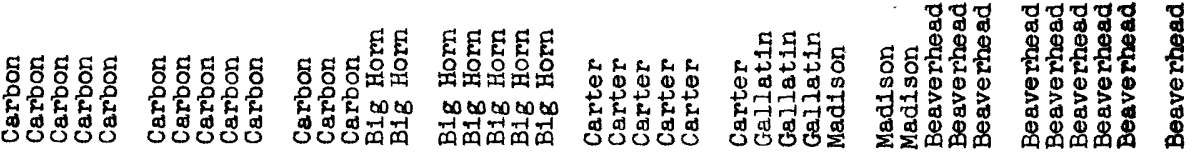

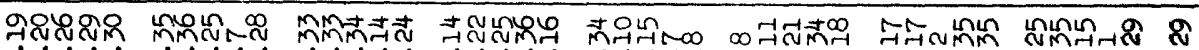

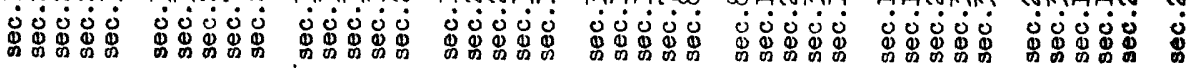

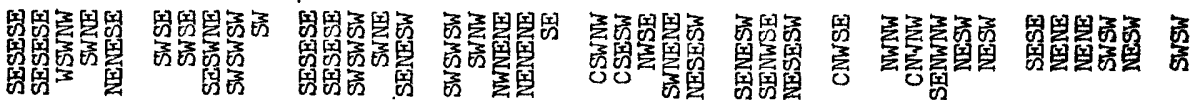

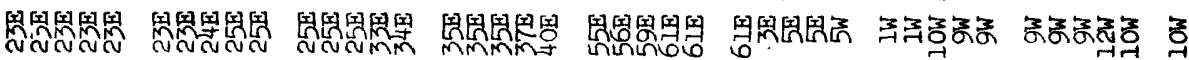

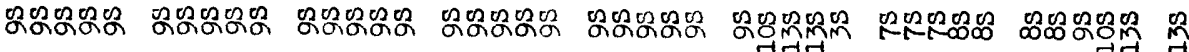

